Old Dominion University

ODU Digital Commons

Winter 2009

\title{
A Meta-Analysis of Supplemental Educational Services (SES) Provider Effects on Student Achievement
}

Shanan L. Chappell

Old Dominion University

Follow this and additional works at: https://digitalcommons.odu.edu/teachinglearning_etds

Part of the Curriculum and Instruction Commons, Educational Assessment, Evaluation, and Research Commons, and the Education Policy Commons

\section{Recommended Citation}

Chappell, Shanan L.. "A Meta-Analysis of Supplemental Educational Services (SES) Provider Effects on Student Achievement" (2009). Doctor of Philosophy (PhD), Dissertation, Teaching \& Learning, Old Dominion University, DOI: 10.25777/85x1-hz26

https://digitalcommons.odu.edu/teachinglearning_etds/17

This Dissertation is brought to you for free and open access by the Teaching \& Learning at ODU Digital Commons. It has been accepted for inclusion in Teaching \& Learning Theses \& Dissertations by an authorized administrator of ODU Digital Commons. For more information, please contact digitalcommons@odu.edu. 


\author{
A META-ANALYSIS OF \\ SUPPLEMENTAL EDUCATIONAL SERVICES (SES) \\ PROVIDER EFFECTS ON STUDENT ACHIEVEMENT \\ by \\ Shanan L. Chappell \\ B.A. May 1991, Virginia Wesleyan College \\ M.Ed. December 2002, Regent University \\ A Dissertation \\ Submitted to the Faculty of Old Dominion University \\ In Partial Fulfillment of the Requirements for the Degree of \\ DOCTOR OF PHILOSOPHY \\ CURRICULUM AND INSTRUCTION \\ OLD DOMINION UNIVERSITY \\ DECEMBER 2009
}

Approved by:

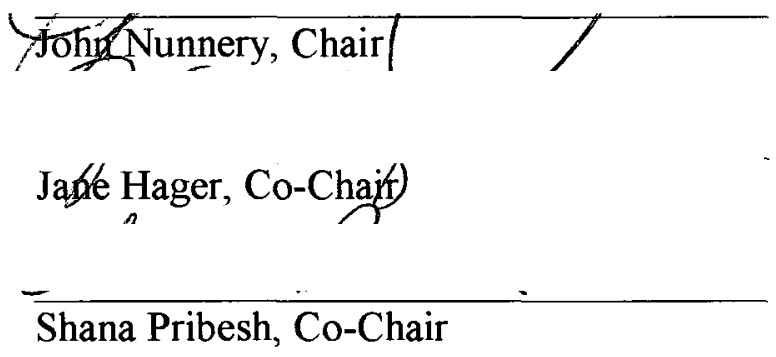




\title{
ABSTRACT \\ A META-ANALYSIS OF SUPPLEMENTAL EDUCATIONAL SERVICES (SES) PROVIDER EFFECTS ON STUDENT ACHIEVEMENT
}

\author{
Shanan L. Chappell \\ Old Dominion University, 2009 \\ Committee Chair: Dr. John Nunnery
}

The 2001 renewal of the United States' Title I program, which provides federal funds to schools with large populations of low-income students, instituted the Supplemental Educational Services (SES) program in which schools in their third year of failing to make Adequate Yearly Progress (AYP) are required to offer after-school tutoring in core subjects to low-income students, provided by public or private tutoring agencies. States are responsible for implementing, overseeing, and evaluating the SES programs; currently, several states and large local school districts have performed evaluations, with many more in the process of publishing results from statewide SES studies. Although state and district-level provider evaluations have measured SES provider effects on student achievement, there has been no comprehensive synthesis of overall program effects across states, and there is little information that relates provider characteristics to variation in student achievement outcomes. The proposed study will synthesize provider effects reported in the extant body of SES provider evaluations to generate an estimate of the overall effectiveness of the SES policy in terms of improving student achievement, and will seek to identify provider characteristics that are associated with variation in student achievement effects using a fixed effects model.

$$
\begin{array}{ll}
\text { Dissertation Committee Co-Chairs: } & \text { Dr. Jane Hager } \\
& \text { Dr. Shana Pribesh }
\end{array}
$$


Copyright (C), 2009, by Shanan L. Chappell, All Rights Reserved. 
This dissertation is dedicated to Sarah, Beth, and Shaelynn the promise of the future! 


\section{ACKNOWLEDGMENTS}

I would like to thank the members of my dissertation committee, John Nunnery, Jane Hager, and Shana Pribesh, for their direction and assistance in this project. Without their guidance, this dissertation would not have been completed. I also would like to thank other Curriculum and Instruction faculty, including Linda Bol, Daniel Dickerson, and Sue McKinney for their support and advice throughout my program. My classmates and colleagues in the ECI program have also provided invaluable assistance by offering opinions, constructive criticism, and optimism.

To my family, I owe unending gratitude for all they've done for me the past three years. My mom, who has provided everything from babysitting to emotional encouragement, has helped me maintain my composure and accomplish my goals. I only wish my dad could be here to share this with us. My daughters, Sarah and Beth, have especially sacrificed and this accomplishment is as much theirs as it is mine. And my husband Jerry, who was really just a new friend when all this began, has definitively been my most dedicated supporter and enthusiast, applauding when things went well, encouraging when times were tough, providing all the girls and I could ever want or need, and there to share every moment. He provided hope and inspiration and I never could have realized my dream without him. 
TABLE OF CONTENTS

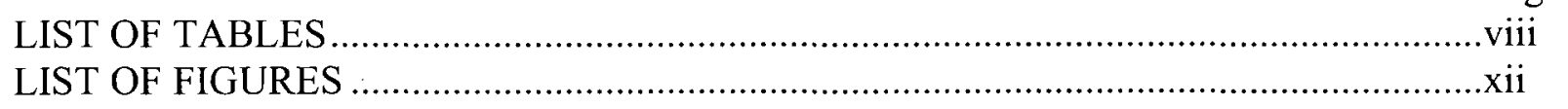

Chapter

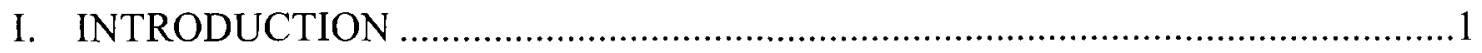

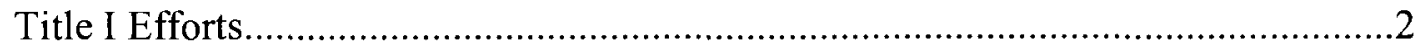

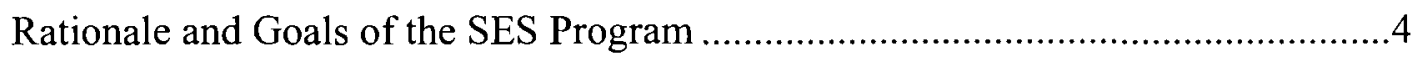

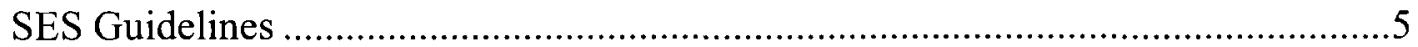

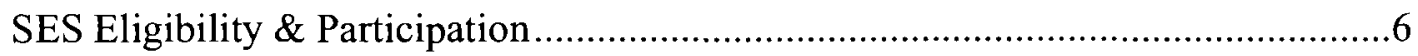

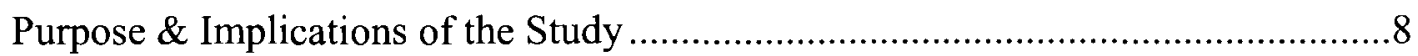

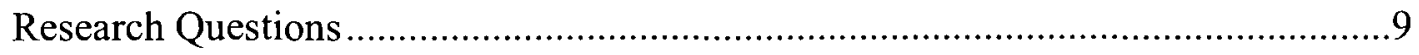

Definition of Terms

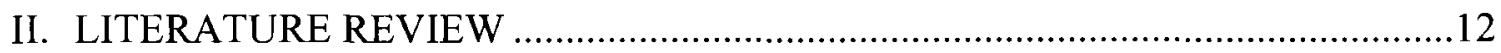

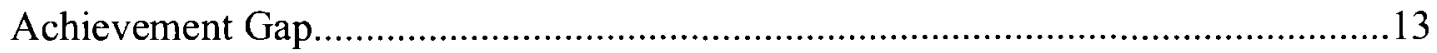

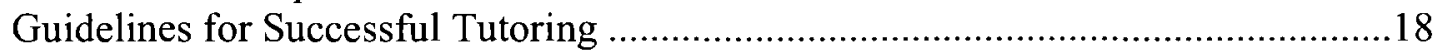

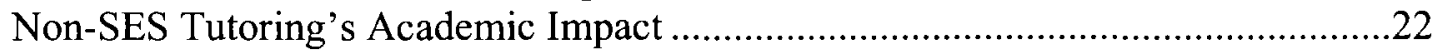

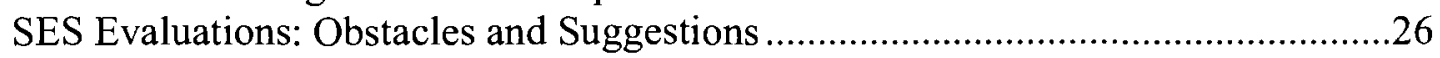

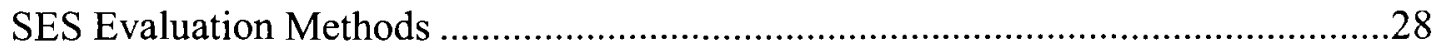

Matched Samples Comparison ……………………....................................29

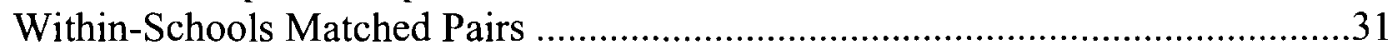

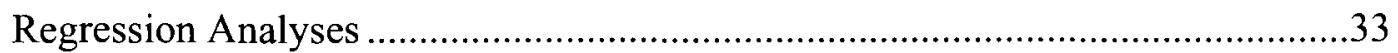

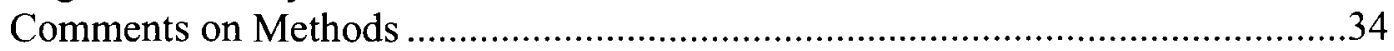

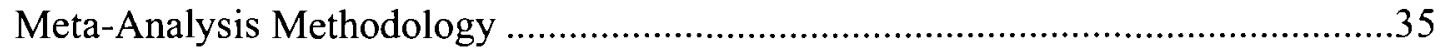

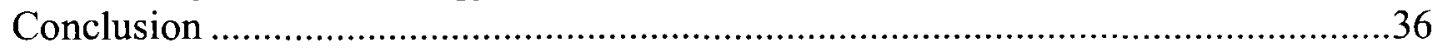

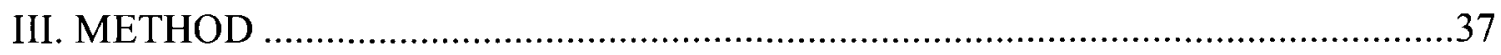

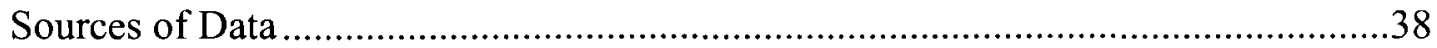

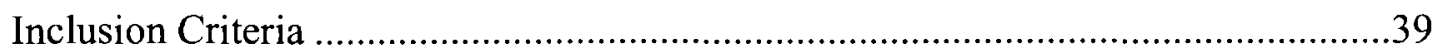

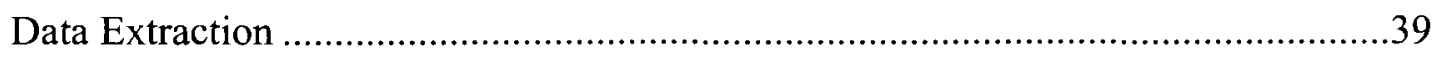

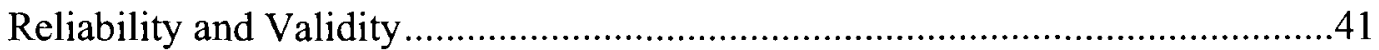

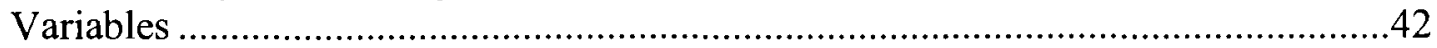

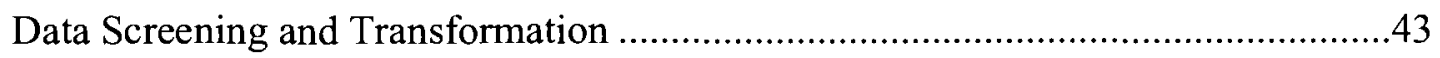

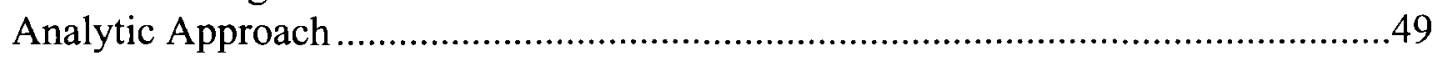

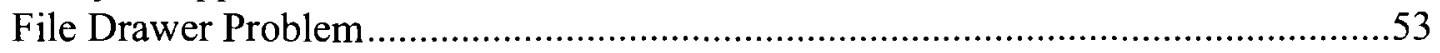

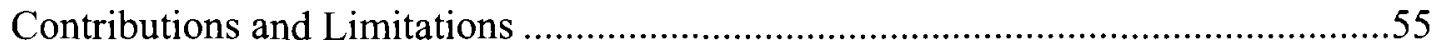


IV. RESULTS 57

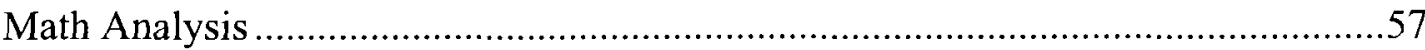

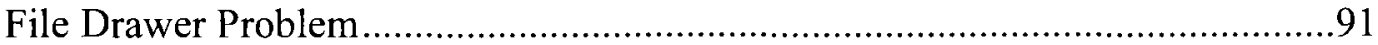

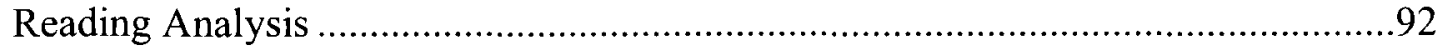

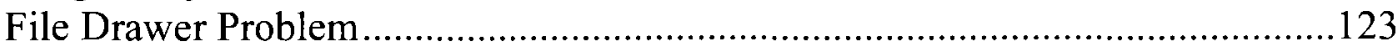

V. DISCUSSION, RECOMMENDATIONS, AND CONCLUSION ……………........124

Research Question One: What are the mean provider effect size estimates in mathematics and reading?......................................................................... 124

Research Question Two: How do provider effects vary as a function of provider characteristics for the mathematics and reading analyses?.................................126

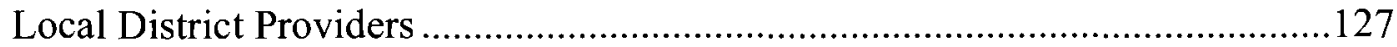

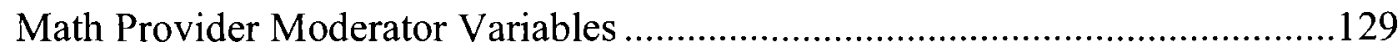

Reading Provider Moderator Variables .................................................... 133

Research Question Three: How do provider effects vary as a function of the methodology used to estimate them? ....................................................... 136

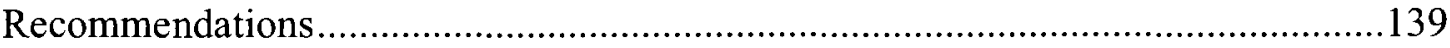

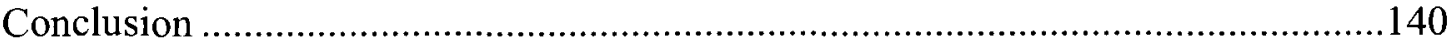

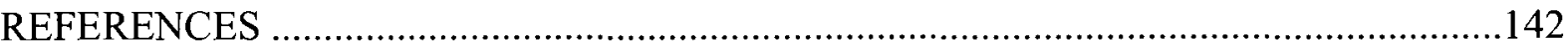

APPENDICES

A. Provider Characteristics Coding Scheme.....................................................153

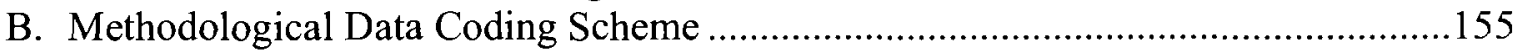

C. Evaluations Included in Meta-Analysis .................................................... 156

D. Math Effect Sizes Included in Analysis........................................................ 160

E. Reading Effect Sizes Included in Analysis ................................................171

VITA 


\section{LIST OF TABLES}

Table

Page

1. Title I Students Receiving Services as Percent of Title I Eligible for SES 7

2. Scale Score Point Differences between White and Black Students and White and Hispanic Students by Year. 16

3. Coding Scheme for Provider and Methodological Moderator Variables .46

4. Summized Values of $d / \sigma^{2}\left(d_{i}\right), 1 / \sigma^{2}\left(d_{i}\right)$, and $d^{2} / \sigma^{2}\left(d_{i}\right)$ for Math Analysis

5. Summized Values of $d / \sigma^{2}\left(d_{i}\right), 1 / \sigma^{2}\left(d_{i}\right)$, and $d^{2} / \sigma^{2}\left(d_{i}\right)$ for Math Moderator Variables

6. $Q_{w}, Q_{w 1}, Q_{w 0}, Q_{b}$, and $p$ values for Local District Math Providers

7. $Q_{w}, Q_{w l}, Q_{w}, Q_{b}$, and $p$ values for Nationally or Locally Based Math Providers

8. $Q_{w}, Q_{w l}, Q_{w 0}, Q_{b}$, and $p$ values for Nationally or Locally Based Math Providers With Local District Providers Removed

9. $Q_{w}, Q_{w 1}, Q_{w 0}, Q_{b}$, and $p$ values for Online or Face-to-Face Math Providers.....

10. $Q_{w}, Q_{w 1}, Q_{w 0}, Q_{b}$, and $p$ values for Newly Established or Pre-Existing Math Providers

11. $Q_{w}, Q_{w l}, Q_{w 0}, Q_{b}$, and $p$ values for Newly Established or Pre-Existing Math Providers with Local District Providers Removed.

12. $Q_{w}, Q_{w 1}, Q_{w 0}, Q_{b}$, and $p$ values for Profit or Non-Profit Math Providers

13. $Q_{w}, Q_{w 1}, Q_{w}, 0, Q_{b}$, and $p$ values for Profit or Non-Profit Math Provider with Local District Providers Removed.

14. $Q_{w}, Q_{w 1}, Q_{w 0}, Q_{b}$, and $p$ values for Math Providers Offering ELL Services 75

15. $Q_{w}, Q_{w 1}, Q_{w 0}, Q_{b}$, and $p$ values for Math Providers Offering SPED Services. 76 
16. $Q_{w}, Q_{w l}, Q_{w}, Q_{b}$, and $p$ values for Math Providers Offering Math \& Reading Tutoring.

17. $Q_{w}, Q_{w l}, Q_{w 0}, Q_{b}$, and $p$ values for Math Providers Offering 1:1 Tutoring. .78

18. $Q_{w}, Q_{w}, Q_{w 0}, Q_{b}$, and $p$ values for Math Provider Staff Qualifications .79

19. $Q_{w}, Q_{w l}, Q_{w 0}, Q_{b}$, and $p$ values for Math Providers Offering Initial Training For Tutors. 80

20. $Q_{w}, Q_{w l}, Q_{w}, Q_{b}$, and $p$ values for Math Providers Offering On-going Training For Tutors.

21. $Q_{w}, Q_{w 1}, Q_{w 0}, Q_{b}$, and $p$ values for Math Providers Using Prescribed Curriculum ...83

22. $Q_{w}, Q_{w l}, Q_{w 0}, Q_{b}$, and $p$ values for Math Providers Average Cost Per Hour. .84

23. $Q_{w}, Q_{w 1}, Q_{w 0}, Q_{b}$, and $p$ values for Math Providers Currently Approved to Offer SES

24. $Q_{w}, Q_{w l}, Q_{w 0}, Q_{b}$, and $p$ values for Evaluating Agency Type - Math

25. $Q_{w}, Q_{w 1}, Q_{w 0}, Q_{b}$, and $p$ values for Evaluations Which Included ELL Students Math

26. $Q_{w}, Q_{w 1}, Q_{w 0}, Q_{b}$, and $p$ values for Evaluations Which Included SPED Students Math

27. $Q_{w}, Q_{w l}, Q_{w 0}, Q_{b}$, and $p$ values for Evaluations Using Matched Pairs Approach Math

28. $Q_{w}, Q_{w 1}, Q_{w 0}, Q_{b}$, and $p$ values for Minimum Hours for Inclusion in Analysis Math .90

29. Summized Values of $d / \sigma^{2}\left(d_{i}\right), 1 / \sigma^{2}\left(d_{i}\right)$, and $d^{2} / \sigma^{2}\left(d_{i}\right)$ for Reading Analysis .92

30. Summized Values of $d / \sigma^{2}\left(d_{i}\right), 1 / \sigma^{2}\left(d_{i}\right)$, and $d^{2} / \sigma^{2}\left(d_{i}\right)$ for Reading Moderator Variables .95

31. $Q_{w}, Q_{w 1}, Q_{w 0}, Q_{b}$, and $p$ values for Local District Reading Providers 101 
32. $Q_{w}, Q_{w l}, Q_{w}, Q_{b}$, and $p$ values for Nationally or Locally Based Reading Providers 102

33. $Q_{w}, Q_{w l}, Q_{w 0}, Q_{b}$, and $p$ values for Online or Face-to-Face Reading Providers 103

34. $Q_{w}, Q_{w 1}, Q_{w 0}, Q_{b}$, and $p$ values for Newly Established or Pre-Existing Reading Providers. 104

35. $Q_{w}, Q_{w l}, Q_{w 0}, Q_{b}$, and $p$ values for Newly Established or Pre-Existing Reading Providers with Local District Providers Removed .105

36. $Q_{w}, Q_{w l}, Q_{w 0}, Q_{b}$, and $p$ values for Profit or Non-Profit Reading Providers 106

37. $Q_{w}, Q_{w l}, Q_{w 0}, Q_{b}$, and $p$ values for Reading Providers Offering ELL Services 107

38. $Q_{w}, Q_{w l}, Q_{w}, Q_{b}$, and $p$ values for Reading Providers Offering SPED Services 108

39. $Q_{w}, Q_{w l}, Q_{w}, Q_{b}$, and $p$ values for Reading Providers Offering Math \& Reading Tutoring.

40. $Q_{w}, Q_{w 1}, Q_{w 0}, Q_{b}$, and $p$ values for Reading Providers Offering 1:1 Tutoring 110

41. $Q_{w}, Q_{w l}, Q_{w 0}, Q_{b}$, and $p$ values for Reading Provider Staff Qualifications

42. $Q_{w}, Q_{w l}, Q_{w 0}, Q_{b}$, and $p$ values for Reading Providers Offering Initial Training For Tutors

43. $Q_{w}, Q_{w l}, Q_{w 0}, Q_{b}$, and $p$ values for Reading Providers Offering On-going Training For Tutors

44. $Q_{w}, Q_{w 1}, Q_{w 0}, Q_{b}$, and $p$ values for Reading Providers Using Prescribed Curriculum

45. $Q_{w}, Q_{w l}, Q_{w 0}, Q_{b}$, and $p$ values for Reading Providers Average Cost Per Hour .116

46. $Q_{w}, Q_{w l}, Q_{w 0}, Q_{b}$, and $p$ values for Reading Providers Currently Approved to Offer SES

47. $Q_{w}, Q_{w I}, Q_{w 0}, Q_{b}$, and $p$ values for Evaluating Agency Type - Reading .118 
48. $Q_{w}, Q_{w l}, Q_{w 0}, Q_{b}$, and $p$ values for Evaluations Which Included ELL Students Reading

49. $Q_{w}, Q_{w}, Q_{w 0}, Q_{b}$, and $p$ values for Evaluations Which Included SPED Students Reading

50. $Q_{w}, Q_{w l}, Q_{w 0}, Q_{b}$, and $p$ values for Evaluations Using Matched Pairs Approach Reading

51. $Q_{w}, Q_{w 1}, Q_{w 0}, Q_{b}$, and $p$ values for Minimum Hours for Inclusion in Analysis Reading 


\section{LIST OF FIGURES}

Figure $\quad$ Page

1. Distribution of Weighted Effect Sizes for Math Analysis ..................................59

2. Distribution of Weighted Effect Sizes for Reading Analysis ...............................93

3. Mean Effect Sizes By Subject Area for Local District Providers as Compared To Overall Mean Effect Sizes and Non-District Providers 128

4. Mean Math Provider Moderator Variable Effect Sizes for Nationally or Locally Based Providers and Profit or Non-Profit Providers.

5. Mean Math Effect Sizes for Provider Moderator Variables with Statistically Significant Between-Class Differences

6. Mean Math Effect Sizes for Provider Moderator Variables with Small to Moderate Between-Class Differences.

7. Mean Math Effect Sizes for Provider Moderator Variables without Significant Between-Class Differences

8. Mean Reading Effect Sizes for Provider Moderator Variables with Statistically Significant Between-Class Differences

9. Mean Reading Effect Sizes for Provider Moderator Variables with Moderate Between-Class Differences

10. Mean Math Effect Sizes for Methods Moderator Variables

11. Mean Reading Effect Sizes for Methods Moderator Variables 


\section{CHAPTER I}

\section{INTRODUCTION}

The No Child Left Behind (NCLB) legislation (2001), signed into action in January 2002 reauthorizing the Elementary and Secondary Education Act (ESEA), was established to improve academic achievement of United States'(U.S.) K12 students by requiring them to reach levels of proficiency in core academic subjects by the year 2014 . As part of this legislation, the NCLB identifies schools which have not reached Adequate Yearly Progress (AYP) for two years as being in need of improvement. NCLB also reauthorized the U.S.'s Title I program, which provides additional funding for schools with high enrollments of students at or below the poverty level (U.S. Government Accountability Office [USGAO], 2006). Title I schools which have been identified as being in need of improvement are required to offer options to low-income students aimed at increasing academic performance to proficiency levels. One option is the School Choice option, which allows students in Title I schools needing improvement to transfer to another public school (Stullich, Abrams, Eisner, \& Lee, 2009). The other option is Supplemental Educational Services (SES).

SES are of out-of-school tutoring services provided by public or private agencies approved at the state level. Title I schools which have not met AYP goals for three consecutive years are required to offer SES to low-income students. SES guidelines identify low-income students as those who are eligible to receive free or reduced-price lunch (Bathon \& Spradlin, 2007). Funds to pay for SES are allocated from districts' Title I funds and can account for up to $20 \%$ of these funds. In 2007 , the national Title I budget was $\$ 12.8$ billion, with available SES funds totaling approximately $\$ 2.5$ billion (U.S. 
Department of Education, 2007a). The Los Angeles Unified School District alone allocated $\$ 141$ million of its Title 1 budget to SES provider payments. As the Title I budget continues to grow each year (Stullich et al., 2009), the projected SES budget will also increase.

Much of the responsibility for SES programs lies with individual state departments of education. Just as individual states set performance goals and standards for their districts, they are also required to determine the criteria for approving and overseeing SES providers. Additionally, states are responsible for evaluating SES providers. Though the U. S. Department of Education has provided guidelines to assist states in performing SES evaluations, there are no specific federal regulations for evaluating SES providers (Peterson, 2005). Consequently, states have been slow to perform statewide provider evaluations. Furthermore, despite the high stakes nature of the SES program, there is little information relating SES provider traits with differential effects on student achievement. In part, this is because relatively few providers are represented in any single state or district-level evaluation, so within the context of a single evaluation there are too few providers to permit a proper analysis of these effects.

\section{Title I Efforts}

The Title I program was created in 1965 as part of the Elementary and Secondary Education Act of 1965. The purpose of the program was to ensure that historically underserved students would receive a high-quality education. Specifically, the Title I program provides federal funds to schools with large populations of economically disadvantaged students (USGAO, 2006). The program has been continuously renewed since 1965 , most recently as part of the NCLB (2001) legislation. 
Funding for the Title I program has been identified as the "single largest federal investment in K-12 education" (Bathon \& Spradlin, 2007, p.1). The Title I budget has grown nearly $35 \%$ since its renewal in 2001 to $\$ 12.8$ billion for the $2006-2007$ academic year (U.S. Department of Education, 2007a). Over 90\% of school districts nationally receive Title I funds, with a large percentage (74\%) going to public elementary schools (U.S. Department of Education, 2007a). Most of these funds (about 74\%) are allocated to schools with high percentages of low-income students $(50 \%$ or higher eligible for free or reduced lunch). Though schools with low percentages of low-income students do receive Title I funds, these schools only accounted for about $6 \%$ of the Title I budget in the 20042005 school year (U.S. Department of Education, 2007a).

Title I funds traditionally have been used for instructional purposes, including salaries and materials. In the 2004-2005 academic year, $73 \%$ of Title I funds were spent on salaries and benefits for teachers and aides. The other $27 \%$ was spent on materials to support instruction, such as curricular materials and technology tools, and administrative support for the district's or school's Title I program. This $27 \%$ also includes funds used to pay for the two most recent Title I provisions, School Choice and SES (U.S.

Department of Education, 2007a).

As part of the latest Title I program renewal, Congress instituted new provisions intended to provide further assistance for schools to improve the achievement of all students, particularly those most in danger of failing (Stullich et al., 2009). One provision is the School Choice option which allows students in Title I schools in their first year of improvement status to transfer to either a non-Title I school or a Title I school which is not in need of improvement (Bathon \& Spradlin, 2007). The other provision, which has 
proven more popular, was the creation of the SES program, an out-of-school tutoring program for low-income students in Title I schools in their second year of improvement. These changes in Title 1 policy reflect a major shift of emphasis from improving the schools that serve economically disadvantaged children through school-wide projects (SWP) and comprehensive school reform to facilitating individual choice to pursue educational options outside the school.

\section{Rationale and Goals of the SES Program}

Historically, there has been a gap in the achievement scores between white and minority students, and between impoverished and non-impoverished students. These gaps exist nationwide despite some progress in narrowing the gaps in the last decade (National Center for Education Statistics, 2008). According to the U.S. Department of Education (2007a), two-thirds of the Title I population consists of minority students. Upon recognizing "the essential need to focus on improving the learning opportunities and academic achievement of minority and low-income students" (Bennett et al., 2004, p.31), Congress incorporated SES to provide additional out-of-school academic instruction in the form of tutoring, remediation, or other enrichment services. Earlier versions of Title I had authorized tutoring, but as pull-out programs where students were taken out of classes during the school day for instruction (Viadero, 2007). Congress further mandated that these new services support states' academic goals and standards and be high-quality to improve student achievement (U.S. Department of Education, 2005). Specific details of the SES program, such as selecting criteria for approving, overseeing, and evaluating providers and overall program implementation, were delegated to individual state departments of education. 


\section{SES Guidelines}

According to the U. S. Department of Education (2005), responsibility for the SES program lies in various areas. The state departments of education bear the heaviest burden for this program. State educational agency responsibilities require the state to:

- Publicly notify potential providers of the opportunity to obtain approval to provide SES services

- Create and fairly implement criteria for approving SES providers

- Publicly maintain a list of approved providers statewide

- Publicly list the per-pupil amount for SES services

- Develop and implement techniques for overseeing and evaluating providers

- Withdraw providers from the approved list which have not shown evidence of academic improvement of students served for 2 years

- Develop and implement techniques for overseeing districts' SES program implementation (U.S. Department of Education, 2005)

Local education agencies, or districts, are also responsible for a substantial share of the duties of implementing an SES program. Districts are responsible for:

- Identifying schools which are required to offer SES to eligible students

- Identifying students eligible to receive SES

- Notifying parents of eligible students that their children may receive SES and assisting parents in choosing SES providers, if parents request assistance

- Creating a fair policy for providing services if budget does not allow for all eligible students to receive services 
- Entering into agreements with chosen providers, to include paying for services rendered (U. S. Department of Education, 2005)

Those organizations which are approved to perform SES must also maintain strict roles in the implementation of an SES program. Responsibilities require providers to:

- Consult with students' schools and parents (if applicable) to create environments which will most strongly enable students to succeed

- Assess students' progress

- Adhere to SES program timelines provided by the district (if applicable)

- Strictly follow specific health, safety, and civil laws (U. S. Department of Education, 2005)

Under SES guidelines, parents of participating students maintain the responsibility of selecting a provider or providers for their child and ensuring that their child attends scheduled sessions (U.S. Department of Education, 2005). These guidelines also imply that parents should contact the provider or their child's school if providers fail to report progress, but this guideline is not echoed in state SES guidelines nor is it enforced at the state or district level (Peterson, 2005).

\section{SES Eligibility \& Participation}

Since the inception of the SES program in 2003, participation has grown each year. Participation rates are reported at the state level and vary from state to state (Center for Improvement \& Innovation, 2008). In 2006-2007, approximately 3.6 million students were eligible for SES nationally, though only about 530,000 received services (Stullich et al., 2009). The most recent national participation rate (2006-2007) average was $14 \%$, with less than one-fourth of states having participation rates higher than $20 \%$ of those 
eligible to receive services (Stullich et al., 2009). Table 1 shows the national SES participation rates from 2003-2007 as percentages of those eligible to receive services.

Table 1

Title I Students Receiving Services as Percent of Title I Eligible for SES

Academic Year Number of Students Number of Students Students Receiving Eligible for SES Receiving SES SES as Percent of Students Eligible

2003-2004

1.7 million

244,000

$14 \%$

2004-2005

2.5 million

446,000

$19 \%$

2005-2006

3.6 million

498,000

$14 \%$

2006-2007

3.8 million

530,000

$14 \%$

Note: Adapted from the Center for Innovation and Improvement's website (www.cii.org), 2008

Additionally, hundreds of public and private tutoring agencies have been approved to provide services across the nation. Bathon and Spradlin (2007) estimated that 1,800 providers offered services nationally in 2007 , with about 3,200 reportedly approved to provide SES (Stullich et al., 2009). An air of competitiveness has emerged among 
providers, with larger, commercial agencies spreading services to multiple states while still remaining profitable (Peterson, 2005). It is important to note that school districts themselves, even districts with failing schools, are permitted to provide SES (USGAO, 2006); "a district classified as needing improvement or corrective action because it failed to meet state AYP goals for several years may not be an SES provider though its (individual) schools not identified as needing improvement may provider services” (USGAO, 2006, p. 5). Not all districts provide SES services, but with districts having a strong influence in the delivery of and payment for SES services, this is a potential conflict-of-interest worth noting.

Purpose \& Implications of Study

According to the NCLB legislation, states must withdraw those providers from the approved list who failed to provide evidence of improved academic achievement of students served for two consecutive years (USGAO, 2006). This has proved difficult, however, without empirical evidence from rigorous evaluations of SES programs and without a clear definition of improved academic achievement (K. Wong, personal communication, April 2009). A number of state and local school districts have conducted rigorous evaluations of provider effects since 2003 (e.g. Chicago Public Schools [Jones, 2009], Los Angeles Unified School District [Rickles \& Barnhart, 2007], Maryland [Pribesh \& Nunnery, 2009], and Jefferson County, KY [Munoz \& Ross, 2008]), with most revealing a positive trend in the achievement scores of SES students over their nonSES peers, though effect sizes are often small or not significant (Nunnery, Pribesh, \& Chappell, 2009). There are now enough individual provider effect estimates from highquality studies to permit a synthesis of effects to gauge the overall effectiveness of the 
SES policy in improving student achievement and to identify provider characteristics that may be associated with variations in student outcomes.

With billions of federal dollars allocated for this program annually, and with the program's intent to narrow or close the achievement gap by improving achievement in historically low-performing populations, the need for rigorous, unbiased evaluation is clear. Though there are now numerous evaluations of state and local SES programs, there has been no synthesis of effect size estimates nor an association of provider characteristics and student achievement to guide decisions on how to effectively structure SES programs. The purpose of this study is to develop this information by synthesizing and modeling provider effects, so providers can design more effective programs and state departments of education will have scientifically-based criteria upon which to base approval and continuance decisions.

\section{Research Questions}

1. What are the mean provider effect size estimates in mathematics and reading?

2. How do provider effects vary as a function of provider characteristics, such as the qualifications of tutors, student/tutor ratio, and provider's use of a prescribed curriculum?

3. How do provider effects vary as a function of the methodology employed to estimate them? 


\section{Definition of Terms}

The following definitions will be used throughout this study:

Achievement: individual student scores on state assessments; the Title I program (and, in many cases, state departments of educations) uses these scores as the primary criterion for measuring school success.

Achievement gap: the difference in standardized achievement assessment scores between white and minority students; scores have historically been recorded by the National Assessment on Educational Progress (NAEP) assessments and gaps are reported according to race/ethnicity by the National Center for Educational Statistics (NCES).

Adequate Yearly Progress $(A Y P)$ : an increase in the percentages of students scoring at or above proficiency levels on state standardized assessments; AYP goals are set at the state and/or district level. Schools and districts not meeting AYP goals are expected to receive assistance from the state to help them achieve AYP goals in succeeding years.

Impoverished: students considered to be deprived of resources, especially financial resources.

In need of improvement: a school or district which has not met AYP for two consecutive years; Title I provisions require states to provide assistance to such schools and districts to help them meet AYP goals. Schools in their second year of in need of improvement status must offer SES to low-income students.

Low-income students: students who qualify for free- or reduced-lunch status.

No Child Left Behind: legislation signed into law in 2002 which mandates that all students must reach levels of proficiency on state-administered assessments in core 
academic subjects by the 2013-2014 academic year. This legislation reauthorized the national Title I program and instituted features under which states and districts became more accountable for student progress.

Non-impoverished: students who are not considered to be deprived of resources, especially financial resources.

Provider: a public or private agency approved by a state to provide after-school tutoring services to low-income students according to state guidelines under the Supplemental Educational Services option of Title I.

Supplemental Educational Services (SES): out-of-school tutoring services for lowincome students attending Title I schools which have not met AYP for three consecutive years. SES are provided by public or private agencies which have been approved at the state level. Services may be implemented at the students' schools, homes, providers' offices, or online. These services are paid for with a portion of the individual district's Title I funds.

Title I: program created in 1965 and renewed continuously as part of the Elementary and Secondary Education Act of 1965 (ESEA); the purpose of the program is to ensure that all students receive a high-quality education.

Tutor: instructor, whether professional or volunteer, providing services in a tutoring program.

Tutee: student receiving services in a tutoring program. 


\section{CHAPTER II}

\section{LITERATURE REVIEW}

Millions of dollars in federal funds are spent on the Supplemental Educational Services (SES) program nationally each year. Implementation and evaluations of the program occurs at individual state and district levels. Assistance to perform evaluations, however, has not been provided to states, either in funding or in strict rules or guidelines. Consequently, only a small percentage of states have performed SES evaluations. Most of these evaluations measure student achievement before and after participating in SES programs, but there have also been evaluations which have focused on individual provider effects on student achievement. However, despite the high stakes nature of the SES program, there have been no studies to identify characteristics which differentiate successful providers from the others.

The SES program is part of Title I efforts nationwide to improve educational opportunities to economically disadvantaged students. Various facets of the program, from its initial purpose to evidence of its effectiveness in improving achievement, will be discussed here. First, since closing the achievement gap between white and minority students is one of the primary goals of SES, this review will cover the history and relevance of the gap. Next, a theoretical perspective of tutoring, with an emphasis on what educational authorities feel are the most influential characteristics of tutors and tutoring services, will be discussed. Following the theoretical perspective of tutoring will be a review of empirical studies and meta-analyses of tutoring programs, focusing on outof-school tutoring, to provide evidence that tutoring can be linked with improvements in student achievement. States have cited several reasons for not conducting SES program 
evaluations, and these reasons will be discussed next and will be supplemented with strategies and ideas from research organizations and the federal government for conducting proper and thorough evaluations. Then, this review will provide details and results from state and local SES evaluations which have been performed; this section will be categorized by the methodologies used in the respective studies. These areas are addressed to provide the reader with a thorough view of the SES program and the issues which surround it. Finally, this review will include background information and a description of the meta-analytic method used in this analysis.

Achievement Gap

Historically, there has been a gap in the achievement scores between white and minority students. This gap exists nationwide and, despite some gains in narrowing the gap in the last decade (National Center for Education Statistics [NCES], 2008), continues to be present between whites and blacks and whites and Hispanics. While progress is also being made within minority groups (NCES, 2008), educational and political leaders warn that the gap remains and call for attention to the issue. Authorities agree that closing, or at least narrowing, this gap is essential in improving our educational system and also in assisting in our nation's economic, social, and moral success (Evans, 2005, Bennett et al., 2004).

The National Center for Education Statistics (NCES) reports details of student performance on the National Assessment of Educational Progress (NAEP) administered each year. The NAEP identifies patterns and trends in education by assessing students at grades four and eight. The NCES and, in turn, the U. S. Department of Education, base 
their reports and statistics on information attained from assessing these two grade levels and all information included here will be based on these results.

Programs such as the national Title I program were created by U. S. lawmakers to ensure that all students receive a high-quality education by providing federal funds to schools with large populations of economically disadvantaged students (USGAO, 2006). Past Title I participants were most likely to be minority, and statistics show that this trend continues; in 2005, about two-thirds of Title I students were minorities (U. S. Department of Education, 2007a). This is despite the 2005 national race/ethnicity population in the United States being $66.9 \%$ white, $14.4 \%$ Hispanic, and $12.3 \%$ black (U. S. Department of Education, 2007b). Furthermore, schools generally identify those students who qualify for free or reduced lunch as being low-income; in $2005,24 \%$ of white students, $70 \%$ of black students, and $77 \%$ of Hispanic students qualified as such (U. S. Department of Education, 2007a). Clearly, minority students (black and Hispanic, in this context) comprise the majority of the low-income population of students and it is these students for whom programs to narrow the achievement gap are created.

Since 1992, the NAEP scores of white, black, and Hispanic students have improved in both grades four and eight. The exception to this is Hispanic eighth grade students, for whom there was no significant change in 2007 (Stullich et al., 2009). These improvements, however, did not translate to significant reductions in the achievement gap between whites and blacks and whites and Hispanics. The gap did narrow between white and black fourth grade students when measured by the NAEP in 2007, but the gap between whites and blacks at the eighth grade level, and between whites and Hispanics at both levels, showed no discernable change (U. S. Department of Education, 2007b). 
Table 2 illustrates the achievement gap, in scale score points, for the NAEP assessments in reading and math for white and black and white and Hispanic students for various years between 1992 and 2005 (NCES, 2008). This data reveals that the achievement gap in reading scores between groups is slowly getting smaller (except the white-black gap for eighth grade); the gap in math scores, on the other hand, has shown a substantial decrease at both grade levels and between both whites and blacks and whites and Hispanics. Maintaining this progress, while improving the reading gap, is a primary goal of federal, state, and local education officials. 
Table 2

Scale Score Point Differences between White and Black Students and White and Hispanic

Students by Year

White-Black Gap

White-Hispanic Gap

$\begin{array}{lllllllll}\text { Reading } & 1992 & 1998 & 2002 & 2005 & 1992 & 1998 & 2002 & 2005\end{array}$

$\begin{array}{lllllllll}\text { Grade } 4 & 32 & 32 & 30 & 29 & 27 & 32 & 28 & 26\end{array}$

Grade $8 \quad 30$

26

27

28

26

27

26

25

White-Black Gap

\begin{tabular}{lllllllll}
\hline Math & 1992 & 1998 & 2002 & 2005 & 1992 & 1998 & 2002 & 2005 \\
\hline Grade 4 & 35 & 34 & 31 & 26 & 25 & 25 & 27 & 20 \\
Grade 8 & 40 & 41 & 40 & 34 & 28 & 30 & 31 & 27 \\
\hline
\end{tabular}

Note: From "Trends in the Achievement Gaps in reading and mathematics," National

Center for Education Statistics, 2008.

White-Hispanic Gap

25


The gap also extends beyond achievement scores to college enrollments. This gap appears to be widening at a considerable rate, though enrollment percentages for both black and white students are increasing; Hispanic enrollment remains stagnant (State Legislatures, 2008). For example, in 1995 , college enrollment rates were $64 \%, 51 \%$, and $54 \%$ for whites, blacks, and Hispanics, respectively. Those rates in 2000 were $66 \%$ for whites, $56 \%$ for blacks, and $53 \%$ for Hispanics, with 2005 rates of $72 \%$ for whites, $57 \%$ for blacks, and 54\% for Hispanics (State Legislatures, 2008). Obviously, there is a substantial disparity among the percentages of white and minority students who proceed to college, which further compounds efforts to provide opportunities for high-quality education at all levels, to all students.

Suggestions for closing the achievement gap come from educational policy makers, educators, politicians, and others. Some offer ideas for improving the education of minority students and some offer plans for programs or policies to help students in need. Examples of these suggestions include involving students' families in the educational process (Darling, 2008), strengthening community and school ties (Bennett et al., 2004), and providing after-school and summer programs for youth at risk of failing (Mathis, 2005). With minority populations projected to increase in the next decade (U. S. Department of Education, 2007b), it is imperative that these suggestions be substantiated through research and implemented on a wide scale if successful (Mathis, 2005). Initially, however, the literature implies that those programs already in place which provide evidence for success should be increased to reach more students. 
Guidelines for Successful Tutoring Experiences

Tutoring programs share a long history with American education. The literature on tutoring is extensive, but a thorough review reveals that most effective tutoring programs include some common characteristics. In fact, the literature now includes numerous books and articles dedicated to outlining the guidelines and practices which have most consistently resulted in successful tutoring programs (Fashola, 1998; Wasik, 1998; Gordon, 2003; Sanderson, 2003). Although there is no model of effectiveness for all tutoring programs, and while there are some traits about which researchers and authors disagree, the literature on tutoring programs themselves often includes several of these suggested practices (Cohen, Kulik, \& Kulik, 1982; Juel, 1996; Burns, Senesac, \& Symington, 2004; Lauer et al., 2006).

One characteristic of a quality tutoring program focuses on the training and staff development of tutors. Though experts do not always agree on the level of expertise of tutors, they unanimously agree that tutors, whether they are certified teachers, college students, peers, or community volunteers, should be provided with clear, focused training before the tutoring program begins (Fashola, 1998; Wasik, 1998; Sanderson, 2003). Most also agree that training of tutors should continue throughout the program to help tutors provide individualized instruction and to keep tutors abreast of best practices in corresponding subjects (Wasik, 1998; Topping, 2000).

Concerning tutors' instructional abilities, researchers vary in opinion. Fashola (1998), Gordon (2003), and Sanderson (2003), for example, believe that having only well-qualified teachers (those who are certified, in most cases) tutors will provide the best experience for students, while others feel that volunteers who may not be experienced 
instructors can provide tutoring services which result in improved achievement for students (Wasik, 1998; Burns et al., 2004). In support of this claim, Juel (1996) conducted a study in which student-athletes who were characterized as struggling readers acted as one-to-one reading tutors; the study's results indicated that the tutees' scores on reading skills tests surpassed those of a control group after participating in the year-long project. Juel (1996) concluded that other characteristics of this program must have had a greater impact than the skill level of the tutors themselves.

That other characteristic may have been the student-to-tutor ratio. This is another characteristic of tutoring programs about which experts feel similarly; the effect of oneto-one tutoring has been cited by Juel (1996), Wasik (1998), Fashola (1998), and Lauer et al. (2006). Though Lauer et al. (2006) believe that small-group (1 instructor to 2-4 students) can be an effective strategy for math tutoring, one-to-one tutoring has had the strongest impact on the improvement of reading skills for tutees. This strategy, however, has proved cost-inefficient for some programs, resulting in the use of volunteers or smallgroup instruction to help reduce costs. Given the extent of research surrounding this characteristic, most program officials have chosen to use volunteers rather than resort to small-group instruction for reading tutoring (Cohen et al., 1982; Juel, 1996; Wasik, 1998).

A structured but flexible framework is another characteristic of successful tutoring programs. Programs which follow an organized strategy for recruiting students, providing instruction, and assessing progress have historically been those which have shown improvement in achievement (Fashola, 1998; Wasik, 1998; Sanderson, 2003). These program officials maintain enough rigidity to keep tutors on task but are flexible 
enough to allow tutors to individualize instruction based on students' needs (Wasik, 1998). Other aspects of a structured program include the use of quality materials and instructional strategies that correspond with and support the school's curricula (Topping, 2000). Finally, a structured tutoring program is one which insists upon collaborative relationships between program officials, tutors, and classroom teachers to ensure students' needs are met in a timely, efficient manner (Fashola, 1998; Gordon, 2003).

Some researchers feel that tutoring services need to be administered on a consistent basis to be effective in improving achievement (Juel, 1996; Wasik, 1998). Consistency is usually defined as services offered each week over a semester or schoolyear. Programs vary on the number of hours tutoring services are offered to students each week, with most providing services between 1-1/2 and 4 hours per week. This characteristic of tutoring programs is evident in some SES program evaluations which have been performed across the nation. In their 2006-2007 evaluation of SES in Maryland, Pribesh and Nunnery (2009) excluded students from the analysis who had received less than 18 hours of tutoring. Similarly, other evaluations conducted by the Center for Research in Educational Policy (CREP) have also limited inclusion in the analysis to students who had received at least 18 hours of SES (McKay et al., 2008; Munoz \& Ross, 2008). Currently, there is no suggested specific number of hours for tutoring programs, but the literature supports the concept that consistency in administering services is a characteristic which should at least bear consideration by tutoring program officials.

Successful tutoring programs often include continual assessment of students throughout the program. Sanderson (2003) states that on-going assessment is necessary to 
monitor student progress and to inform subsequent instructional efforts. Assessment is often required at the beginning of programs to identify students for participation, and Gordon (2003) feels that this is the first step in building a program that will meet its goals by addressing particular needs. Wasik (1998) includes on-going assessment in her list of important components for successful tutoring; she advises that tutors use a variety of assessments, including formal and informal, as diagnostic tools and as evaluation instruments. Some experts feel that continual assessment requires more experienced educators (Topping, 2000; Gordon, 2003), which could hamper volunteer tutoring efforts. With the ultimate goal of improving student achievement by providing additional instruction, however, continual assessment emerges as an important part of any tutoring program.

Other characteristics of tutoring programs are mentioned in the literature and are worthy of noting here. Some researchers discuss the need for parental involvement (Sanderson, 2003) and observation of tutors by education specialists as necessary for success in tutoring (Wasik, 1998). Others debate the impact of after-school vs. pull-out programs (Lauer et al., 2006; Juel, 1996). Though these issues are not as widespread in the literature, each author offers a sound argument in favor of these components of tutoring programs; they may indeed be beneficial for certain populations. Fashola's (1998) statement sums this issue up concisely: programs that "provide greater structure, a stronger link to the school-day curriculum, well-qualified and well-trained staff, and opportunities for one-to-one tutoring seem particularly promising" (p. 55), and these should be foundational elements of any tutoring program. 
Non-SES Tutoring's Academic Impact

Over the past three decades, extensive research has been conducted to determine the effectiveness of tutoring on academic achievement. Researchers hoping to identify trends and patterns, including characteristics of quality programs, have also published meta-analyses to further contribute to the body of knowledge on tutoring. A review of these studies reveals that many tutoring programs contain samples sizes too small to analyze with advanced statistical designs and employ quasi-experimental research methods because participants aren't randomly assigned to treatment and control groups (Cohen et al., 1982; Ritter, Barnett, Denny, \& Albin, 2009). This review of the literature on tutoring programs focuses on a variety of published journal articles spanning the last thirty years and covers professional and volunteer literacy and math programs.

A seminal project focusing on 65 studies of 1970's-era tutoring programs was conducted by Cohen et al. (1982). This meta-analysis included only studies which employed quantitative analysis methods and used peer (or student) tutors. To measure the effect of tutoring on student performance, the authors identified several variables. Two of these variables, whether the program was structured and whether the tutors were trained (Cohen et al., 1982), are two of the characteristics which experts recommend for a successful tutoring program (Fashola, 1998; Wasik, 1998). Other variables described the subject being tutored, duration of the tutoring, and assessment scores. An overwhelming majority of the studies included in this analysis revealed higher assessment scores for the tutored group (Cohen et al., 1982). Effect sizes of the studies ranged from large to small with the majority (11) revealing moderate effects. The results indicated that structured 
programs and those programs which offered math tutoring had the largest effect sizes (Cohen et al., 1982).

Another study evaluated a program in which university students who were described as struggling readers acted as tutors in a literacy tutoring program (Juel, 1996). The tutors in this study were enrolled in a college course and therefore received credit for their participation. Though the architects of this program did embrace some of the characteristics recommended for successful tutoring (consistency and duration of services, one-to-one tutoring), the program also included components about which tutoring experts may not agree (Wasik, 1998; Gordon, 2003). For example, the use of unqualified tutors was unconventional; the program also operated as a pull-out program, meaning students were removed from their normal classroom during regular school hours (though not during instructional time) (Juel, 1996). Despite these atypical components, assessment scores revealed that the tutored group, by the end of the school year, was outperforming their non-tutored counterparts (Juel, 1996). Juel (1996) concludes that the results of this study support the principle that individualized instruction through one-toone tutoring have a significant impact on students' reading skills.

Similarly, the Americorps*State/National Literacy Program was studied to determine its effectiveness on reading skills (Moss, Swartz, Obeidallah, Stewart, \& Greene, 2001). This study evaluated 68 Americorps*State/National Literacy Programs offered across the country to first through third grade students in select schools during the 1999-2000 academic year (Moss et al., 2001). To evaluate the effectiveness of this program, the researchers employed hierarchical linear modeling (HLM) to create a predictor model for student achievement. This evaluation explained that the Americorps 
reading programs followed a structured plan of action, provided training for its tutors (non-professionals), coordinated its efforts with school curricula, and used one-to-one tutoring when available (small-group tutoring was used in some circumstances) (Moss et al., 2001). The results revealed that tutored students, whose reading skills were below grade-level before the program, had gains higher than the predicted scores on standardized reading tests after receiving tutoring. These gains were statistically significant and extended across all three grade levels and ethnic/racial groups (Moss et al., 2001). This study appears to further support Juel's (1996) assertion that a successful tutoring program does not necessarily require professional teachers as tutors.

An evaluation of the Helping One Student to Succeed (HOSTS) literacy tutoring program was performed by Burns, Senesac, and Symington (2004). The HOSTS programs was designed in alignment with Wasik's (1998) guidelines for successful volunteer tutoring programs, incorporating all eight of the components suggested by Wasik. Though some experts believe that tutors and tutees be paired throughout the duration of a program (Gordon, 2003), the HOSTS program did not follow this method but often paired tutees with different tutors to allow the students a variety of experiences and attitudes (Burns et al., 2004). Student achievement was measured by four standardized reading skills tests; the results indicated that the tutored students had increases greater (significantly greater for reading fluency, comprehension, and phonological awareness) than the non-tutored control group (Burns et al., 2004). While the results suggest that the 5-month HOSTS program was successful in improving literacy skills in at-risk students, the authors recommend a year-long study, with more 
intensive pre-treatment measures, be performed to more clearly identify the effects of the program.

One tutoring program partnering a local university and school district has been in effect for twelve years in Pennsylvania. The University Tutors + Elementary Students $=$ A Successful Partnership program offers tutoring for students in grades three through six (Baker, Rieg, \& Clendaniel, 2006). This program offers a unique perspective of tutoring not found in many current programs: the program focuses on a rural school district and offers only math services. This program, like others, includes criteria suggested by experts for successful tutoring, such as offering one-to-one services, following a structured plan of action, providing training for tutors, and maintaining continual assessment of tutees (Wasik, 1998; Gordon, 2000). However, it appears that the assessment of learning used in this study consists of a math inventory (commonly from a math text) rather than a state assessment (Baker et al., 2006). While the authors discuss a gain in achievement for the majority of tutees $(72 \%)$, they do not compare the program participants to a control group nor do they provide data on whether the gains were statistically significant over pre-test scores (Baker et al., 2006). Also, as samples sizes for this program appear to be small, this program (and its results) may not be generalizable to other districts, including those within the same geographic region.

A large percentage of studies on the effectiveness of tutoring focuses on literacy skills rather than math skills. Though Cohen et al. (1982) found that programs which offered math tutoring revealed the largest effect size in improving student achievement, other researchers, more recently, have concluded that not enough is known about the effect of tutoring (volunteer, specifically) on math scores (Ritter et al., 2009). This is 
echoed in the literature on math tutoring programs, which often does not include precise details on statistical analyses to indicate significant growth (Baker et al., 2006). With NCLB requiring research-based evidence on the effectiveness of strategies, the need for current, rigorous research in math tutoring (as well as continued research on literacy tutoring) is obvious.

\section{SES Evaluations: Obstacles and Suggestions}

The No Child Left Behind (NCLB) act of 2001 was established to improve academic achievement of K12 students by requiring them to reach levels of proficiency in reading and math by the year 2014. NCLB also reauthorized the national Title I program, which provides additional funding for schools with high enrollments of students at or below the poverty level (USGAO, 2006). Title I schools which have been identified as being in need of improvement are required to offer options to low-income students aimed at increasing academic performance to proficiency levels. One such option is Supplemental Educational Services (SES), out-of-school tutoring services. Funds to pay for SES are allocated from districts' Title I funds and can account for up to $20 \%$ of the Title I resources; in 2007 , the national Title I budget was $\$ 12.8$ billion, with available SES funds totaling about $\$ 2.5$ billion (U.S. Department of Education, 2007a).

Much of the responsibility for these SES programs lies with individual state departments of education. Individual states are required to determine the criteria for approving and overseeing SES providers. Additionally, states are responsible for evaluating SES providers, though there are no federal rules for the evaluation of providers (Peterson, 2005). Consequently, only about one-fourth of states have performed statewide provider evaluations. Furthermore, despite the high stakes nature of the SES 
program, there have been no thorough evaluations of individual SES provider traits to help identify those characteristics which may make providers more successful in improving achievement of students served. Though states are required by the federal government to conduct SES provider evaluations, only about one-fourth of states have actually performed such evaluations. Moreover, many of the evaluations which have been performed have been inconclusive due to inadequate or incomplete data sources.

States cite several reasons for not performing evaluations. The primary reason that evaluations are not being conducted surrounds budget issues; no federal funds have been allocated to perform evaluations (Sunderman \& Kim, 2004). State departments of education thus have limited personnel to adequately oversee SES providers. With national SES participation rates hovering around 14\% (Center for Innovation \& Improvement [CII], 2008), states have placed a low priority status on performing evaluations which are often time and labor intensive (Barley \& Wegner, 2007).

Some state efforts to conduct evaluations have been met with problems at the provider level. Insufficient attendance and performance records kept by providers have hampered evaluations in Tennessee (Potter, Ross, Paek, McKay, \& Sanders, 2007) and Michigan (Public Policy Assoc. Inc, 2008), for example. The state of Michigan hired an external evaluation agency which attempted to conduct an evaluation using a sophisticated statistical analysis model. However, the data available from providers and the state was not sufficient for conduct a thorough analysis (Public Policy Assoc. Inc., 2008). Tennessee faced a similar situation; only two of the 33 approved agencies which had provided services had sufficient data for researchers to analyze the program's effects on student achievement (Potter et al., 2007). 
In an effort to assist states with SES provider evaluations, research organizations have published reports and briefs highlighting strategies and examples designed to guide states through the evaluation process. To appropriately measure student achievement, for example, states are encouraged to make sure providers align SES with state curricular standards, though not all providers have shown evidence of this (Colasanti, 2007). The U.S. Department of Education (USDOE) recommends that states have providers collect data on academic progress, measured by valid and reliable state or provider assessments (Ross, 2005); the USDOE also recommends that providers maintain detailed enrollment, attendance, and dates of service records, that providers show evidence of instruction plans or programs, including instructional methods employed, and that providers maintain communication logs between themselves and schools and parents (Ross, 2005). Finally, states are urged to collect data on the individual tutors employed by providers, including their experience and qualifications (Ross, 2005; Colasanti, 2007).

Obviously, states, districts, and providers must cooperate to gather the data needed to conduct evaluations of SES programs. As states as burdened with monitoring and evaluating providers, however, it is no surprise that districts are not getting the guidance and assistance from state level administrators (Saifer \& Speth, 2007). It appears that districts and states need clearly defined guidelines for conducting thorough but economical SES evaluations, especially as state educational budgets continue to tighten.

\section{SES Evaluation Methods}

Despite the obstacles states face in evaluating SES providers, some have successfully performed SES program evaluations. Most states which have conducted evaluations have employed external evaluation agencies to complete these studies. 
Various research analysis methods were used to conduct these evaluations and sampling methods include matched-samples comparison and within-school matched-pairs comparisons. Each of these methods will be discussed here within the context of the evaluation(s) in which it was used. Other evaluation inclusion criteria, such as the minimum hours necessary for inclusion in the analysis, will also be discussed within the context of each study.

\section{Matched Samples Comparison}

Matched samples analyses were conducted in Hawaii (Inazu et al., 2007), Kentucky (Munoz \& Ross, 2008), and Virginia (McKay et al., 2008). Each matched samples analysis compared state assessment scores for SES students with the average score of a comparison group that did not receive services. In each of these evaluations, ANCOVA tests were conducted to determine differences in group performances. For the ANCOVA analyses, pretest scores (scores from the previous year's assessment) were covariates in the analyses with treatment as the between-subjects factor.

For the Hawaii 2005-2006 analysis, the researchers compared two treatment groups to a comparison group; the first treatment group received $\geq 80 \%$ of contracted services and the second treatment group received $<80 \%$ of contracted services (Inazu et al., 2007). All students for whom the state had been billed for SES services were included in this analysis; other sampling criteria included the students' status as "disadvantaged" (Inazu et al., 2007, p. 19) or not, with disadvantaged status equaling SES eligibility. The only other inclusion criterion was that participants (both treatment and control) had both 2005 and 2006 state assessment scores. The results showed that there were no significant differences between the three groups in reading scores, but the $\geq 80 \%$ SES group did 
score significantly higher than the non-SES group in math. Though the $\geq 80 \%$ SES group did show a significant increase in math, however, the mean score of the group still fell substantially below the minimum score needed for a passing rate (Inazu et al., 2007). Similarly, individual analyses were conducted for each subject for the Jefferson County, Kentucky 2006-2007 analysis. This analysis included only students in grades three through eight as test scores for other grades were unavailable. To create the treatment and control groups, the researchers created groups based on students' SES status (both groups were eligible, one received services and one did not), previous year's state assessment scores, gender, race, and grade level. For reading, there were no significant effects associated with SES; in fact, the non-SES group's mean was slightly higher (Munoz \& Ross, 2008). For math, the SES group showed a small but statistically significant increase over the control group (Munoz \& Ross, 2008).

The Virginia 2006-2007 evaluation also compared SES students with a nontreatment comparison group. This analysis matched students on previous year's state assessment scores, grade level, and English language learner (ELL) status; where possible, students were also matched by school, division, race, socio-economic status, and gender. Exclusion criteria for this analysis included those providers with less than 10 students, students who received less than 18 hours of contracted SES, students with alternative assessment scores, and Special Education students (McKay et al., 2008). There were no significant differences in math scores for the two groups (McKay et al., 2008). For the reading analysis, the control group achieved higher results on the post-test than the treatment group, though the increases were not statistically significant (McKay et al., 2008). 


\section{Within-School Matched Pairs}

The matched-pairs approach was employed for the Louisiana (Paek et al., 2008), Maryland (Pribesh \& Nunnery, 2009), and Tennessee (Potter et al., 2007) evaluations. In these studies, results focus on provider effects on students as opposed to student achievement differences by group; to meet the assumptions of the design, only providers who served groups of students of 10 to 20 (varies by individual study) were included in these analyses.

The 2005-2006 evaluation of SES in Louisiana included only those students in grades four through nine and those students who had previous and current year state assessment scores. No other inclusion or exclusion criteria were cited in the report, but this analysis was performed the year after Hurricanes Katrina and Rita severely damaged much of the state and the researchers noted that not all districts in the state were able to implement SES during this time period, making participation rates lower than anticipated (Paek et al., 2008). The analysis revealed significantly positive effects for two providers and significantly negative effects for one provider offering reading tutoring (Paek et al., 2008). Other results for reading providers included positive effects for four providers and negative effects for three providers, though none of these effects were statistically significant. For math providers, none showed either positive or negative significant effects; however, eight of the nine providers showed improvement in student achievement while one showed a negative effect (Paek et al., 2008).

Showing similar results, the Maryland evaluation used a matched-pairs analysis to determine provider effects on student achievement. This study pooled effects from individual analyses of the 2005-06 and 2006-07 academic years. This analysis matched 
students on previous year's state assessment scores and grade level; where possible, students were also matched by school, division, race, socio-economic status, and gender. Exclusion criteria for this analysis included those providers with less than 10 students, students who received less than 18 hours of contracted SES, students with alternative assessment scores, Limited English Proficiency students, and Special Education students (Pribesh \& Nunnery, 2009). The results showed that none of the nine math providers included in the analysis showed significant gains in student achievement, though seven of the nine had adjusted means which were higher for the SES group than for the control group (Pribesh \& Nunnery, 2009). Adversely, two of the nine had adjusted means that were lower for the treatment group. However, one reading provider did show a significant gain in mean scores for the SES group. Of the other six reading providers included in the analysis, three showed gains, though not significant, for the SES group and three had adjusted means whose scores were lower for the treatment group (Pribesh \& Nunnery, 2009).

Tennessee also used the matched-pairs design in its 2005-2006 evaluation of SES (Potter et al., 2007). The researchers created a predictor model to predict students' scores on the 2006 Tennessee state assessment. This model was based on students' previous test scores, students' grade level, SES provider, and classroom teacher. Only students in grades four through eight were included in the predictor model, and only providers who served 20 or more students per district were included (Potter et al., 2007). For the matched-pair block, students were matched with the closest non-SES student by previous year's score where possible. Unfortunately, there were insufficient data to adequately determine provider effects for all but two of the 33 providers which performed services 
during this school year. The two providers which were deemed to have enough data to analyze provider effects on student achievement were both found to have "below standards outcomes" (Potter et al., 2007, p. 3). Potter et al. (2007) noted in their conclusions that providers, local education agencies, and schools were working to improve communications and data collection to ultimately improve student achievement through SES.

\section{Regression Analyses}

Simple linear regression is a statistical tool that allows researchers to determine the extent to which two variables (one dependent, one independent) are related. Multiple regression extends the use of this concept to allow insight into the relationship of multiple variables (Sprinthall, 2007). Regression analyses allow the researcher to investigate how actual scores compare to predicted scores by creating a model using predictor variables. These research methods were employed in SES evaluations for the Los Angeles Unified School District (Rickles \& Barnhart, 2007) and Chicago Public Schools (Jones, 2007).

The Los Angeles evaluation (Rickles \& Barnhart, 2007) revealed statistically significant gains for those students who received SES overall, though these gains accounted for less than 5 scale score points. The evaluation indicated that SES had a stronger impact on elementary students' achievement than secondary students (Rickles \& Barnhart, 2007). The Chicago evaluation also revealed significant gains in both math and reading scores, with SES students showing a 5\% reading gain and a $13 \%$ math gain over the non-SES control group (Jones, 2007).

The 2007-2008 Chicago Public School SES evaluation (Jones, 2009) used the Hierarchical Linear Model research method, an advanced regression analysis method in 
which data are nested into groups and analyzed to detect the effects of variables of each group (within-groups and between-groups) on a dependent variable. The groups, or levels, often consist of naturally occurring clusters (classrooms, schools, neighborhoods, etc.) for which within-group variances may be too influential to ignore if analyzed independently (Bryk \& Raudenbush, 1992). HLM is often termed multilevel modeling, but Bryk and Raudenbush use the term HLM almost exclusively, so that term will be used here.

Students were nested on two levels - the student level comprised model 1 and the school level comprised model 2 (Jones, 2009). This analysis focused on the performance of individual providers rather than the SES population subset. Results revealed that students attending two of the reading providers and six of the math providers had statistically significant gains over non-SES students. Interestingly, the Chicago Public School local district provider "A.I.M. High" was among the providers who showed significant, though small, gains in both math and reading (Jones, 2009).

\section{Comments on Methods}

Generally, these evaluations have revealed a positive trend in the achievement scores of SES students over their non-SES peers, though effect sizes are often small or not significant (Nunnery, Pribesh, \& Chappell, 2009). It is also important to note that due to the self-selection nature of the SES program (eligible parents and/or students can choose not to participate, for example), a true experimental design in which random assignment to treatment and control groups cannot be applied. Thus, variables which have not been considered in these studies may have an influential, unmeasured effect. 


\section{Meta-Analysis Methodology}

The meta-analytic approach to research, established by Glass, McGaw, and Smith (1981), is a method which combines effect size outcomes from various studies and analyzes these effect sizes to determine an overall effect or impact of a given treatment. Generally, the studies included in meta-analyses must meet stringent criteria, including the use of rigorous statistical analysis tools, the use of valid and reliable measures, and the inclusion of clearly described experimental and control groups. As noted in the literature, less emphasis should be placed on studies which result in statistically significant outcomes than on thoroughly conducted studies in which empirical research methods have been employed (Glass, et al., 1981; Rosenthal \& DiMatteo, 2001; Lietz, 2006; Sprinthall, 2007).

The meta-analytic approach also requires the researcher to conduct an exhaustive search for appropriate studies, both published and non-published, for inclusion in the meta-analysis. Such a search allows the researcher to establish an in-depth, detailed knowledge or familiarity with the background, methods, and research questions upon which the data being analyzed are based (Rosenthal \& DiMatteo, 2001). Conducting an exhaustive search can also help address limitations and criticisms of the meta-analytic approach by incorporating studies which employ a variety of research methodologies and which include diverse samples to expand the generalizability of results (Glass, et al., 1981). The researcher must be careful, though, to note such differences among studies and treat them as methodology or "moderator variables" (Rosenthal \& DiMatteo, 2001, p. 68) to measure the effect of any of these differences. 
Ultimately, the meta-analytic approach has its strengths and weaknesses. But, as with other research methodologies, the researcher can take steps to reduce the limitations of the method to enhance the validity and reliability of the results. Similarly, the steps taken to reduce limitations may also expand or strengthen the generalizability of metaanalytic results.

\section{Conclusion}

With millions, if not billions, of federal dollars being spent on the SES program nationally each year, the need for effective evaluation of SES's impact on student achievement is clear. If states were provided with a clear and concise policy for program implementation, maintenance, and evaluation, perhaps programs could focus on attaining services from successful providers for all students who qualify. The ultimate goal would be providing high-quality educational opportunities for all students and narrowing, or closing, the achievement gap between white and minority students, as these are the students who most commonly qualify for SES. 


\section{CHAPTER III}

\section{METHOD}

Millions of dollars in federal funds are spent on the Supplemental Educational Services (SES) program nationally each year. Implementation and evaluations of the program occurs at individual state and district levels. Assistance to perform evaluations, however, has not been provided to states, either in funding or in strict rules or guidelines. Consequently, only a small percentage of states have performed SES evaluations. Most of these evaluations measure student achievement before and after participating in SES programs, but there have also been evaluations which have focused on individual provider effects on student achievement. However, despite the high stakes nature of the SES program, there is no research to help states identify characteristics which differentiate successful providers from the others.

The purpose of this study was to synthesize provider effects reported in SES provider evaluations to generate estimates of the overall effectiveness of the SES program in terms of improving student achievement, and to identify provider characteristics that are associated with variation in student achievement. Hedges and Olkin's (1985) meta-analytic parametric estimation of effect sizes methodology was employed to estimate an overall or mean effect size of math and reading outcomes in the evaluations included in this meta-analysis and to fit fixed effect models to variables based on the methods used to perform the evaluations and variables based on SES provider characteristics. The meta-analytic approach used here does not require approval by an Institutional Review Board (IRB). The following research questions were addressed:

1. What are the mean provider effect size estimates in mathematics and reading? 
2. How do provider effects vary as a function of provider characteristics, such as the qualifications of tutors, student/tutor ratio, and provider's use of a prescribed curriculum?

3. How do provider effects vary as a function of the methodology employed to estimate them?

Sources of Data

To conduct this meta-analysis, all available SES evaluations were examined. To gather state and district SES evaluations which have been performed, first I accessed the Center for Innovation and Improvement's (CII) website (CII, 2008). The CII is an online clearinghouse, maintained through funds from a federal grant, containing information about SES and other educational initiatives. Several SES evaluations which have been conducted were retrieved from the CII website. The CII website also provides direct hyperlinks to individual states' SES or Title I web pages. Review of individual state SES web pages also provided access to SES evaluations. Ultimately, SES and/or Title I coordinators in all 50 states were contacted for SES evaluations. In addition, many of the nation's largest school districts were contacted directly seeking SES evaluations; this information was accessed through the Council of Great City Schools' (CGCS) website.

Additionally, database searches were conducted seeking SES evaluations. ERIC (Education Resources Information Center), a source for full-text articles and abstracts from educational journals, and PsycINFO, a database containing full-text and summarized scholarly articles, books, and dissertations, were accessed in this search. Keyword searches included "supplemental educational services" and "evaluation." Reference sections and bibliographies from evaluations found through these search 
methods were also reviewed for additional studies which were included in this analysis. Any evaluation which met the inclusion criteria was included regardless of the date it was conducted.

Inclusion Criteria

To conduct this analysis, the following inclusion criteria for SES evaluations were used:

- Evaluations must have been conducted using quantitative research methods.

- Evaluations must contain a sample size $(n)$.

- Evaluations must report an effect size (Cohen's $d$ ) by provider or contain enough data to establish an effect size.

- Evaluations must measure student achievement using SES participation as the independent variable.

- Evaluations must compare SES students to a matched control group.

- Evaluations must measure student achievement by a valid, reliable standardized achievement test, not a provider assessment.

- Evaluations must contain data describing (by name and certain characteristics) SES providers.

Appendix $\mathrm{C}$ contains a list of the 28 evaluations included in the meta-analysis.

\section{Data Extraction}

Data from each evaluation was extracted for both the control and treatment groups for this analysis. First, the sample sizes $(n)$ for each evaluation were recorded. Means and standard deviations for each group (from each evaluation) were also extracted where available. Other data which was extracted included the effect size of the SES treatment 
variable, as reported by Cohen's $d$. For those evaluations which did not report effect sizes, effect sizes were computed by dividing the difference of the means of the groups by the standard deviation of the control group (Sprinthall, 2007). Sprinthall (2007) and Rosenthal (2002) describe various other methods of calculating effect sizes from known statistics such as $t$ scores and $p$ values which were used to compute effect sizes in some cases as described in the Data Screening and Transformation section below.

Certain SES provider data was also extracted from each evaluation. This data included provider names and number of students served by each provider. Other data that were gathered from the evaluations included subject area(s) tutored, grade level(s) served, and tutoring location. In cases where this information was not available from the evaluation reports, the data were obtained from the states' or districts' department of education websites and/or from the individual providers' websites when appropriate. These variables were not all included in the analysis but were collected, where available, to create a complete database of provider information. Appendix A contains the Provider Characteristics Coding Scheme used to gather this data.

Finally, data concerning the evaluation methodology were also extracted from each report included in this analysis. This data identified the sampling method used, student populations which were or were not included in the evaluation, the type of evaluating agency (internal or external), and the minimum hours of service necessary for inclusion in the evaluation analysis. Appendix B contains the Methodological Data Coding Scheme used to collect this information. 


\section{Reliability and Validity}

This study was conducted under the assumption that student achievement figures within each evaluation were measured by valid and reliable assessment instruments as this is a requirement of NCLB (2001) legislation. One example is the Maryland State Assessment (MSA), which is administered annually to students in grades three through eight in the state of Maryland and which is published by Harcourt Publishers (Maryland State Department of Education [MSDE], 2005). To enhance content validity (Salkind, 2006), the MSDE and Harcourt used a blueprint to align the MSA with Maryland's Voluntary State Curriculum (MSDE, 2005), which defines the content and measurable objectives that students are required to know (MSDE, 2008). The MSDE and Harcourt determined that each math and reading standard included on the MSA had a reliability coefficient of .80 or higher (Pribesh \& Nunnery, 2009) which is well within the acceptable range (Salkind, 2006). Coefficients for parallel form reliability were also well above the acceptable range, with coefficients ranging between .90 and .94 (MSDE, 2007a; MSDE, 2007b). Following the assumption that other state and districts implemented similar achievement measures, I concluded that the effect sizes estimates extracted from the evaluations were both valid and reliable.

Title I guidelines for SES provided by the U. S. Department of Education (2005) suggested that a list of foundational information about each provider, titled Basic Program Information, be completed by all agencies applying to provide tutoring services under the SES program. This information summarized the details of the services that would be provided and supplied background data about the organization seeking to provide services. After careful review of the information contained in these Basic 
Program Information plans, I determined that many of the items included in the plans are those which have been recommended in the literature by researchers and educational experts for successful tutoring experiences. I also felt that this contributed to the content and construct validity of the provider characteristic dataset. To ensure the information was reliable, I verified the data in each provider's Basic Program Information with data from the provider's full application for approval (where available), from evaluation reports, and from states' and providers' websites.

\section{Variables}

In addition to the effect sizes extracted from each evaluation, other extracted data were coded for the analysis. These variables included SES provider characteristics and methodology characteristics to be included in the fixed effect models for categorical, or moderator, variables (Hedges \& Olkin, 1985). These variables are:

Provider Characteristic Variables:

- Local district provider (yes/no)

- Nationally or locally based provider

- Online or face-to-face services

- Newly established or pre-existing provider

- Profit or non-profit provider

- Offers English Language Learner (ELL) services (yes/no)

- Offers Special Education (SPED) services (yes/no)

- Tutors math \& reading or just one subject

- Offers one-to-one tutoring (yes/no)

- Uses prescribed curriculum (yes or no) 
- Staff qualifications (tutors hold 4yr degree or no)

- Provides initial training for tutors (yes/no)

- Provides on-going professional development for tutors (yes/no)

- Currently approved to provide services (yes/no)

- Average cost (per hour)

Methodology Variables:

- Externally or internally evaluated

- Analysis included ELL students

- Analysis included SPED students

- Used matched samples or matched pairs method

- Minimum hours served for inclusion in analysis

Data Screening \& Transformation

For this analysis, each effect size (400 math effects and 401 reading effects for a grand total of 801 effect sizes) was treated as an individual case. Before an analysis could be conducted, the data were reviewed to identify those cases which did not contain an effect size, reported as Cohen's $d$. During data extraction, data (means, standard deviations, $t$ scores, and $p$ values) were collected for those cases which did not include an effect size. Ultimately, the evaluations from Chicago (Office of Research, Evaluation, \& Accountability, 2007; Jones, 2007; Jones, 2009), Florida (Allen, 2008), Hawaii (Social Science Research Institute [SSRI], 2007; SSRI, 2008), New Mexico (Marquez \& Kovacic, 2007), and Virginia (Potter \& Ross, 2005) contained data which was transformed into effect sizes. 
When transforming the $t$ score values from the three Chicago evaluations as described by Glass, McGaw, and Smith (1981), it became apparent that the evaluator used the overall n's by provider for both the math and reading values. For example, for the 2007-2008 academic year (Jones, 2009), the AIM High provider had 9,412 total participants for its reading and math services, though the report states an analysis sample of 2,140 for math. When transforming reported $t$ values, I discovered that the effect size outcomes for both subjects for this provider were most accurately calculated by using the overall participant $n$ 's per provider (the report included only eight effect sizes; for the remaining cases, only $t$ scores were reported thus warranting the transformations). Thus, the Chicago $t$ score values were transformed using Glass et al.'s (1981)

$$
d=t \sqrt{ } 2 / n
$$

using the overall participant $n$ 's per provider.

Using the same formula from Glass et al. (1981), the New Mexico (Marquez \& Kovacic, 2007) $t$ scores were also transformed into effect sizes. However, the New Mexico report included only enough data to transform effect sizes for math outcomes.

For the Virginia 2004 evaluation (Potter \& Ross, 2007) and both Hawaii evaluations (SSRI, 2007, 2008), effect sizes were calculated by subtracting the population (eligible but not tutored) mean from the tutored mean and then dividing by the population standard deviation (Sprinthall, 2007). These values were appropriate for this transformation as treatment and control group $n$ 's were equal. The Hawaii evaluations included more than one treatment group by percentage of contracted SES services received; the only group included in this analysis was the group which received $80 \%$ or 
more of contracted services to allow for the most influential impact of treatment ( $\mathrm{J}$. Nunnery, personal communication, September 2009).

The Florida (Allen, 2008) evaluation included in this meta-analysis contained $p$ values for those providers which were found to be most influential in each of the six counties studied. Using Rosenthal and Rubin's (2003) method, $t$ scores were obtained from an extended table of $t$ statistics using $d f=n-2$. Effect size estimates were then calculated using

$$
d=2 t / \sqrt{ } n-2
$$

with the reported $t$ scores and $n$ 's as described by Rosenthal and Rubin (2003).

Next, the provider and methodological variables were transformed into categorical variables to identify classes or groups for fitting fixed effect models (of these classes or groups) to effect sizes (Hedges \& Olkin, 1985). This allowed each categorical variable to be independently analyzed to determine an overall effect size for each class within the variable and then to determine if there was homogeneity of effect sizes within each class (Hedges \& Olkin, 1985). For each variable, dummy codes were created and each case containing data for the given variable was placed in class zero or class one. The codes and descriptions of the provider and methodological variables are reported in Table 3. 
Table 3

Coding Scheme for Provider and Methodological Moderator Variables

Variable Name

Code 0

Code 1

Descriptor

Descriptor

Nationally or locally based

Locally based provider

Nationally based provider

provider

(non-franchise)

(included national

franchises)

Online or face-to-face

Face-to-face services

Online services

services

Newly established or pre- $\quad$ Yes

No

existing provider *

Profit or non-profit

Non-profit

For profit

provider

Offers ELL services

No

Yes

Offers SPED services

No

Yes 
Table 3 Continued

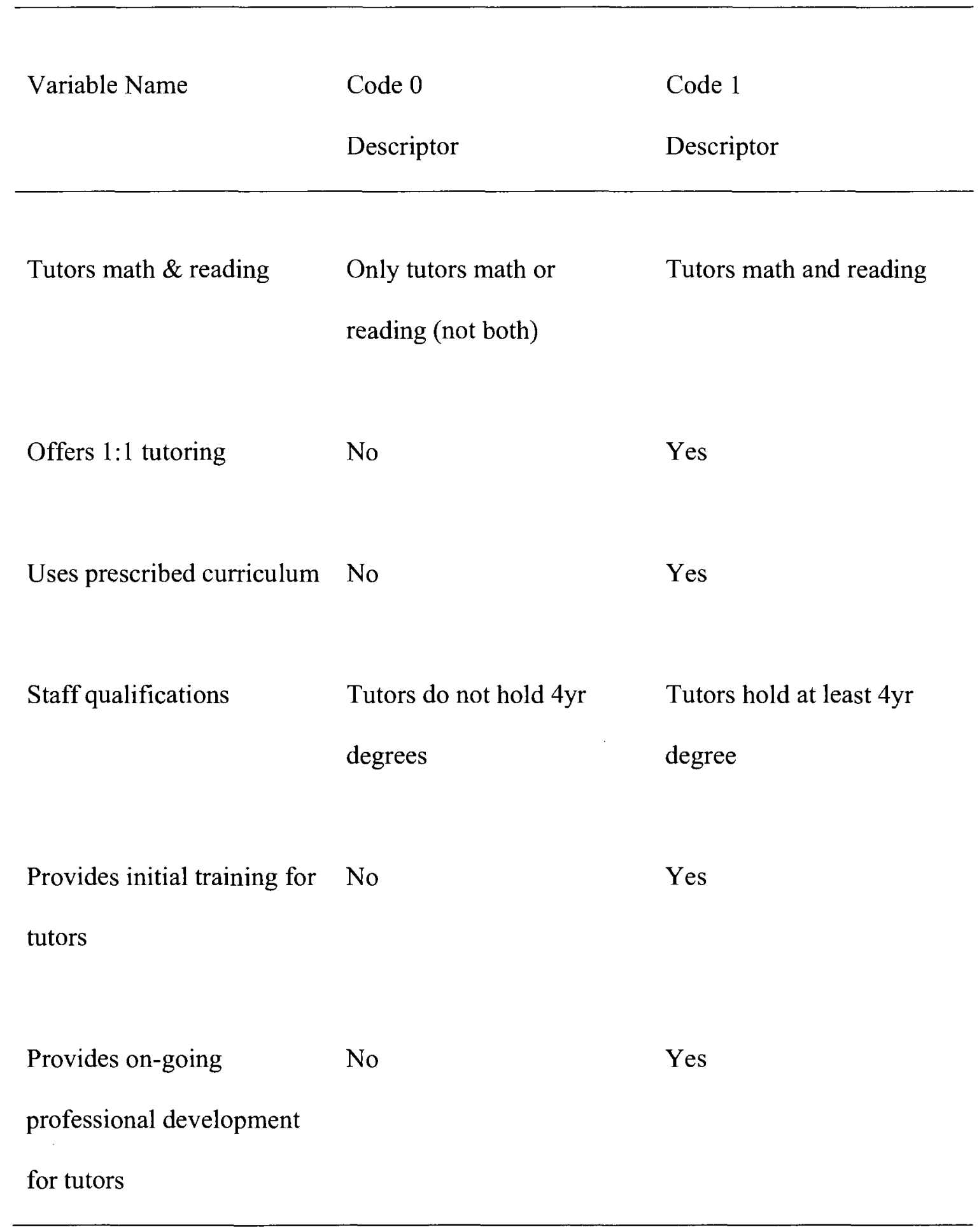


Table 3 Continued

Variable Name

Code 0

Code 1

Descriptor

Descriptor

Average cost per hour

Cost per hour $<\$ 52$ (mean Cost per hour $>\$ 52$

cost for both reading and

math providers)

Currently approved to

No

Yes

provide services

Type of evaluation

provider

Analysis included ELL

students
Local (LEA) or State

(SEA) education agency
External evaluator

No

Yes

No

Yes

students 
Table 3 Continued

Variable Name

Code 0

Code 1

Descriptor

Descriptor

Evaluator used matched

Matched sample method

Matched pairs method used

sample method

used

$\begin{array}{lll}\text { Minimum hours of SES } & \text { Required less than } 15 \text { hrs } & \text { Required more than } 15 \\ \text { received for inclusion in } & \text { of SES for inclusion in } & \text { hours of SES for inclusion } \\ \text { evaluation } & \text { study } & \text { in study }\end{array}$

* Newly established was defined as being established during or after the year 2002. Those agencies without an establishment date were assumed to be newly established.

\section{Analytic Approach}

To conduct this analysis, I employed Hedges and Olkin's (1985) meta-analytic parametric estimation of effect sizes methodology to estimate an overall or mean effect size of math and reading outcomes and to fit fixed effect models to variables based on SES provider characteristics and variables based on the methods used to perform the evaluations. Because the studies included in the analysis varied by sample size, it was necessary to create a weighted linear combination of estimators from each evaluation (Hedges \& Olkin, 1985). In the analysis, each effect size was treated as an individual case. Using the weighted linear combination approach allowed cases with higher sample 
sizes, whose effect sizes are considered to be more precise due to higher statistical power, to carry more weight and thus to more accurately estimate the overall mean effect (Hedges \& Olkin, 1985).

Overall, 400 math effects and 401 reading effects were collected and analyzed, with a grand total of 801 effects. The math and reading effects were analyzed independent of one another to determine an overall mean effect size of the treatment, SES, on the outcome, student achievement in math and in reading. To answer the first research question, what are the mean provider effect size estimates in reading or English/Language Arts and mathematics, a variance was computed for each effect size. The variance, or $\sigma^{2}\left(d_{i}\right)$, was calculated using

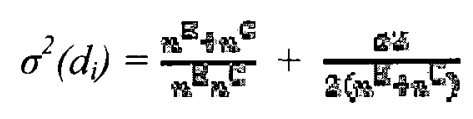

Sample sizes $(n)$ and effect sizes $(d)$ for each case were used here. Next, weights were calculated for each effect size using

$$
w_{i} \approx \check{n}_{i} / \sum_{j=l}^{k} \check{n}_{j}
$$

where

$$
\check{n}_{i=} n_{i}^{E} n_{i}^{C} /\left(n_{i}^{E}+n_{i}^{C}\right)
$$

An overall weighted estimator was then obtained by using

$$
d_{w}=w_{l} d_{l}+\cdots+w_{k} d_{k}
$$

To obtain an overall effect size $\left(d_{+}\right)$, three new variables were created, $d / \sigma^{2}\left(d_{i}\right), 1 / \sigma^{2}\left(d_{i}\right)$, and $d^{2} / \sigma^{2}\left(d_{i}\right)$. Each of these variables were then summed to create the values used to calculate the overall mean effect, $d_{+}$, and the lower and upper confidence intervals, $\delta_{\mathrm{L}}$ and $\delta_{\mathrm{U}}$, for each subject area. The formula for the overall mean effect is

$$
d_{+}=\sum_{j=1}^{k} d / \sigma^{2}\left(d_{i}\right) / \sum_{j=1}^{k} 1 / \sigma^{2}\left(d_{i}\right)
$$


To test for statistical significance, upper and lower confidence intervals for each subject area, were calculated using a variance of

$$
\sigma^{2}\left(d_{+}\right)=1 / \sum_{j=I}^{k} 1 / \sigma^{2}\left(d_{i}\right)
$$

Using $d_{+}$and the standard error of the mean, which is equal to the square root of $\sigma^{2}\left(d_{+}\right)$, the upper and lower confidence intervals were calculated to determine if the overall mean effect was equal to zero at the .05 level of significance. The standard normal distribution values of $+/-1.96$ were used to calculate these values as

$$
\delta_{\mathrm{L}}=d_{+}-C_{\alpha / 2} \sqrt{ } \sigma^{2}\left(d_{+}\right) \text {and } \delta_{\mathrm{U}}=d_{+}+C_{\alpha / 2} \sqrt{ } \sigma^{2}\left(d_{+}\right)
$$

If the confidence interval determined by these calculations does not contain zero, then it can be assumed that the overall mean effect is not statistically significant (Hedges \& Olkin, 1985).

The next step in the meta-analytic procedure was to test for homogeneity of effects overall (Hedges \& Olkin, 1985). To do this, it was necessary to calculate a $Q$ value using summations of the weighted effect sizes calculated in the previous step. The $Q$ value is analogous to a chi-square value and its probability can be determined by consulting a chi-square table using the $Q$ value and $d f=k-1$ where $k=$ number of effect sizes in the analysis. To obtain the $Q$ value, I used the formula

$$
Q=\sum_{j=I}^{k} d^{2} / \sigma^{2}\left(d_{i}\right)-\left(\sum_{j=I}^{k} d / \sigma^{2}\left(d_{i}\right)\right)^{2} / \sum_{j=I}^{k} 1 / \sigma^{2}\left(d_{i}\right)
$$

This value is also referred to as $Q_{l}$, or $Q$ total.

As the $Q_{t}$ values for the math and reading analyses were statistically significant, then within- and between-classes values were created to determine if effect sizes are homogeneous across and between levels of categorical variables. It was then also 
possible to determine an overall effect size by class for the categorical variables (Hedges \& Olkin, 1985).

To calculate within and between-class $Q$ values, the following calculations were summed for each class within each moderator variable: $d / \sigma^{2}(d), 1 / \sigma^{2}(d)$, and $d^{2} / \sigma^{2}(d)$. To do this, I used the SUMIF formula in the Microsoft Office 2007 Excel software program. Each moderator variable in this analysis included only two classes; therefore, for each variable, two within-class $Q_{w}$ values and one between-class $Q_{b}$ value were calculated using

$$
Q_{w 1}=\sum_{j=1}^{k} d^{2} / \sigma^{2}\left(d_{i j}\right)_{1}-\left(\sum_{j=1}^{k} d / \sigma^{2}\left(d_{i j}\right)\right)_{1}{ }_{1} / \sum_{j=1}^{k} l / \sigma^{2}\left(d_{i j}\right)_{1}
$$

and

$$
Q_{w 0}=\sum_{j=1}^{k} d^{2} / \sigma^{2}\left(d_{i j}\right)_{0}-\left(\sum_{j=1}^{k} d / \sigma^{2}\left(d_{i j}\right)\right)^{2}{ }_{0} / \sum_{j=1}^{k} l / \sigma^{2}\left(d_{i j}\right)_{0}
$$

and then an overall within-class $Q_{w}$ was created using

$$
Q_{w}=Q_{w l}+Q_{w 0}
$$

and a between-class $Q_{b}$ was calculated using

$$
Q_{b}=Q_{t}-Q_{w} .
$$

The $Q_{w}, Q_{b}, Q_{w l}$, and $Q_{w} 0$ values for each moderator variable were evaluated for statistical significance using a chi-square table to determine $p$ values using $d f=k-p$ for $Q_{w}, d f=p-1$ for $Q_{b}$, and $d f=k_{I}-1$ for $Q_{w l}$ and so on, where $k=$ number of effect sizes, $p=$ number of classes, and $k_{l}=$ number of effect sizes by class.

An overall effect size by class for each moderator variable was determined using

$$
d_{1+}=\sum_{j=I}^{k} d_{i j} / \sigma^{2}\left(d_{i j}\right) / \sum_{j=I}^{k} 1 / \sigma^{2}\left(d_{i j}\right)
$$

and

$$
d_{0+}=\sum_{j=l}^{k} d_{i j} / \sigma^{2}\left(d_{i j}\right) / \sum_{j=l}^{k} 1 / \sigma^{2}\left(d_{i j}\right)
$$


Hedges and Olkin (1985) state that statistically significant within values of $Q$ for either class reveal that there remain differences in the effect sizes across the classes of the variable in which case the classes should be further subdivided and the within- and between-class tests of homogeneity of moderator variables be iterated. For some of the moderator variables in this analysis, further subdivision and analysis were possible, but for others there were insufficient data to conduct these extended tests of homogeneity. Results for the extended analyses are reported where available.

\section{File Drawer Problem}

A common concern surrounding the meta-analytic research method used here focuses on the quality of studies or evaluations included in the overall analysis (Glass et al., 1981; Hedges \& Olkin, 1985; Rosenthal, 2002). As published studies are more easily obtained, it is more likely that a meta-analysis contains the highest quality studies of a given subject area, which are also often those containing statistically significant effect size outcomes (Rosenthal, 2002). This theory was given the name "file drawer problem" by Rosenthal (1979), who devised a computational formula to determine a "fail-safe $n$," the number of nil effect sizes needed to bring a statistically significant finding to a level of non-significance. Working from Rosenthal's (1979) initial formula, Orwin (1983) developed a similar computation which determined the number of nil effect sizes needed to lower a significant finding to a level of non-significance.

Using Orwin's (1983) method, a fail-safe $n$ was computed using

$$
\mathrm{N}_{\mathrm{s}}=\mathrm{N}_{\mathrm{o}}\left(\mathrm{d}_{\mathrm{o}}-\mathrm{d}_{\mathrm{c}}\right) / \mathrm{d}_{\mathrm{c}}-\mathrm{d}_{\mathrm{s}}
$$

where $N_{s}$ is the number of effect sizes needed to counter a statistically significant finding, $N_{0}$ is the number of effect sizes in the analysis, $d_{o}$ is the mean effect size for the analysis, 
$d_{c}$ is the criterion effect size (non-significant level), and $d_{s}$ is the mean effect size of the nil-outcome effect sizes.

As overall mean effect sizes in this analysis were predicted to be quite small (given the small effect sizes included in the analysis), I used a nil-outcome effect size of 0.00 for $\mathrm{d}_{\mathrm{s}}$ as described by Orwin (1983), and created a scenario in which varying criterion effect size values were used $(.00, .01, .02)$ as $\mathrm{d}_{\mathrm{c}}$ to conduct a "what if" analysis to determine the number of nil effect sizes needed to make the already small overall mean effect size even smaller (Long, 2001).

For the math analysis, 28 SES evaluations were included from 12 states or local school districts. These 28 evaluations included a total of 400 effect sizes, each of which was analyzed independently (often, a study or evaluation will result in a single effect size and thus effect sizes are often referred to in meta-analyses as study outcomes). For the math analysis, the average number of effect sizes per state or district is 14 . Using a niloutcome effect size of 0.00 for $d_{s}$ as described by Orwin (1983), and creating a scenario in which varying criterion effect size values were used $(.01, .02, .03)$ as $\mathrm{d}_{\mathrm{c}}$, I conducted a "what if" analysis to determine the number of nil effect sizes needed to make the already small overall mean effect size even smaller (Long, 2001). I then divided the number of effect sizes by the average number of effects per evaluation in this analysis (14) to determine the number of evaluations needed to bring the overall mean effect size to the criterion level.

For the reading analysis, 27 SES evaluations were included from 11 states or local school districts. These 27 evaluations included a total of 401 effect sizes, each of which was analyzed independently (often, a study or evaluation will result in a single effect size 
and thus effect sizes are often referred to in meta-analyses as study outcomes). Using a nil-outcome effect size of 0.00 for $d_{s}$ as described by Orwin (1983), and using a criterion effect size values of 0.01 as $d_{c}$, the number of nil effect sizes needed to make the already small overall mean effect size even smaller (Long, 2001) were determined. The number of effect sizes was then divided by the average number of effects per evaluation in this analysis (14) to determine the number of evaluations needed to bring the overall mean effect size to the criterion level.

\section{Contributions \& Limitations}

This study contains several potential implications and contributions. First, as no current literature focuses on SES provider characteristics, this study will provide insight into those traits which may influence an SES provider's impact on student achievement. Despite the fact that SES services are implemented in practically every state in the U.S., only one evaluation included an analysis of provider characteristics as indicators of success (Marquez \& Kovacic, 2007); however, that particular study did not link provider traits with student achievement but rather with program satisfaction overall. This study is not intended to replicate the studies performed by other SES evaluators but rather to further contribute to the body of knowledge concerning the SES program overall. I also hope that this study will contribute to the body of knowledge on tutoring in general by identifying both strong and weak characteristics of tutoring.

There are also limitations to this study. First, since not all states have conducted SES evaluations, the results may not be generalizable to SES programs in all areas. Additionally, the participants were chosen purposefully by their participation in the SES programs. There may be inherent differences which have not been measured by the 
studies included in this meta-analysis which may account for any differences in achievement scores (and in turn, effect sizes), further limiting generalizability of any improvement in student achievement. There were also numerous SES providers for each state and district which were not included in the original evaluations due to evaluation criteria (determined by the individual evaluator) and which were not included in this meta-analysis; these excluded providers may have positively or negatively impacted the overall mean effect sizes for math and/or reading, and this is information which will remain unknown. However, conducting a thorough search of SES evaluations, including both published and non-published studies from across the U.S., and using rigorous research methods should enhance the generalizability of this study. 


\section{CHAPTER IV}

\section{RESULTS}

The purpose of this study was to synthesize provider effects reported in SES provider evaluations to generate estimates of the overall effectiveness of the SES program in terms of improving student achievement, and to identify provider characteristics that are associated with variation in student achievement. Hedges and Olkin's (1985) metaanalytic parametric estimation of effect sizes methodology was employed to estimate an overall or mean effect size of math and reading outcomes in the evaluations included in this meta-analysis and to fit fixed effect models to variables based on the methods used to perform the evaluations and variables based on SES provider characteristics. Separate analyses were conducted by subject area (math and reading) to address the following research questions:

1. What are the mean provider effect size estimates in mathematics and reading?

2. How do provider effects vary as a function of provider characteristics, such as the qualifications of tutors, student/tutor ratio, and provider's use of a prescribed curriculum?

3. How do provider effects vary as a function of the methodology employed to estimate them?

\section{Math Analysis}

Once all effect size transformations were complete, it was possible to compute a mean effect size of the math outcomes to answer research question number one. First, variances, or $\sigma^{2}\left(d_{i}\right)$, were calculated for each of the 400 math effect sizes. These variances were then used to calculate three new variables for each math effect size, $d / \sigma^{2}\left(d_{i}\right)$, 
$1 / \sigma^{2}\left(d_{i}\right)$, and $d^{2} / \sigma^{2}\left(d_{i}\right)$. Summations of each of these variables were used to create the values used to calculate the overall mean effect, $d_{+}$, and the lower and upper confidence intervals, $\delta_{\mathrm{L}}$ and $\delta_{\mathrm{U}}$, for the math subject area. Table 4 reports the summized values of these three variables for the math analysis.

Table 4

Summized Values of $d / \sigma^{2}\left(d_{i}\right), 1 / \sigma^{2}\left(d_{i}\right)$, and $d^{2} / \sigma^{2}\left(d_{i}\right)$ for Math Analysis

Number of Effect Summized Value of Summized Value of Summized Value of

Sizes $\quad d / \sigma^{2}\left(d_{i}\right) \quad 1 / \sigma^{2}\left(d_{i}\right) \quad d^{2} / \sigma^{2}\left(d_{i}\right)$

The overall mean weighted effect $d_{+}$was .043 with an estimated overall variance of .00001 and a range of -1.01 to .69 . The standard error of the mean was .0032 . Figure One illustrates the distribution of weighted effect sizes $(n=400)$ for this analysis. Since the distribution's skewness was within the acceptable range of $+/-1.00$, no outliers were removed and no other transformations to the distribution values were performed. 


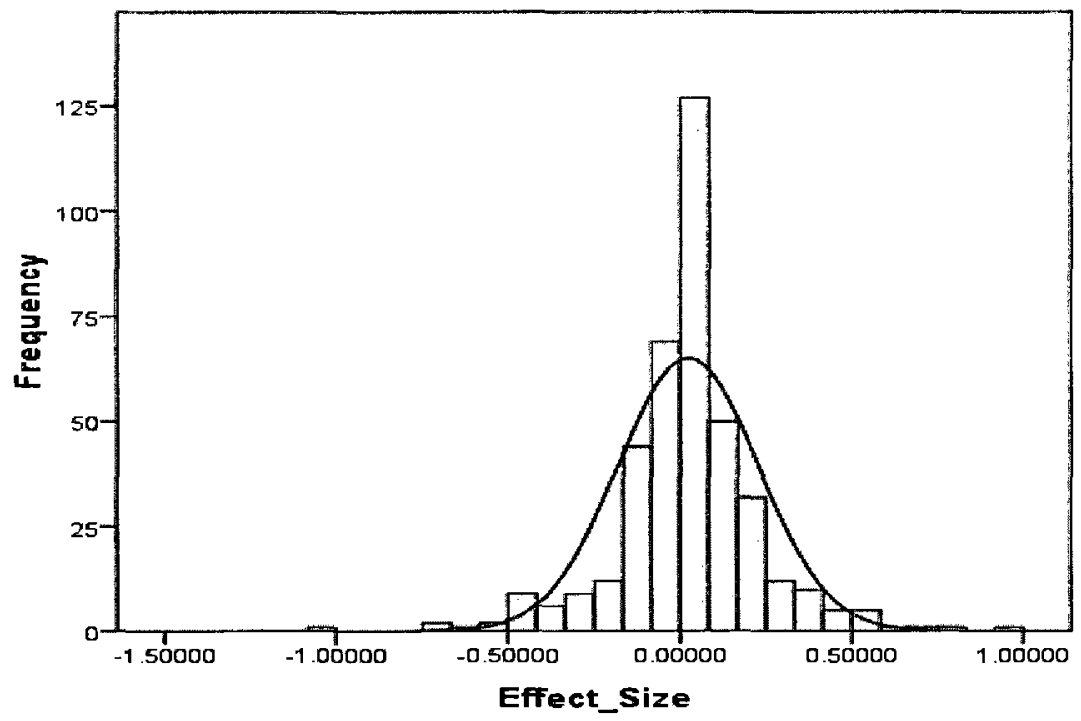

Figure 1. Distribution of weighted effect sizes for math analysis

To test for statistical significance of the overall effect size, $95 \%$ confidence intervals were calculated with the standard error of the mean, where $\delta_{\mathrm{L}}=.0353$ and $\delta_{U}=.0499$ (Hedges \& Olkin, 1985).

The test of homogeneity of effect sizes across the math subject area revealed a $Q$ value of 600.1658 using

$$
Q=\sum_{j=1}^{k} d^{2} / \sigma^{2}\left(d_{i}\right)-\left(\sum_{j=1}^{k} d / \sigma^{2}\left(d_{i}\right)\right)^{2} / \sum_{j=1}^{k} 1 / \sigma^{2}\left(d_{i}\right)
$$

Results for the test of homogeneity were $Q=600.1658, \mathrm{df}=399, p<.0001$, indicating that the effect sizes were not homogeneous across studies (Hedges \& Olkin, 1985). Because this value was significant, further analysis was necessary and the overall (or total) $Q$ will be referred to as $Q_{t}$.

The math moderator variables were then tested for homogeneity of effect sizes within and between classes of each variable. Each of the moderator variables included in this analysis was separated into two classes and analyzed for homogeneity to answer 
research question number two. First, values of $d / \sigma^{2}(d), 1 / \sigma^{2}(d)$, and $d^{2} / \sigma^{2}(d)$ were summized by class and variable using the SUMIF formula in the Microsoft Office 2007 Excel software program. The summized values of $d / \sigma^{2}(d), l / \sigma^{2}(d)$, and $d^{2} / \sigma^{2}(d)$ for each math moderator variable are reported in Table 5. 
5

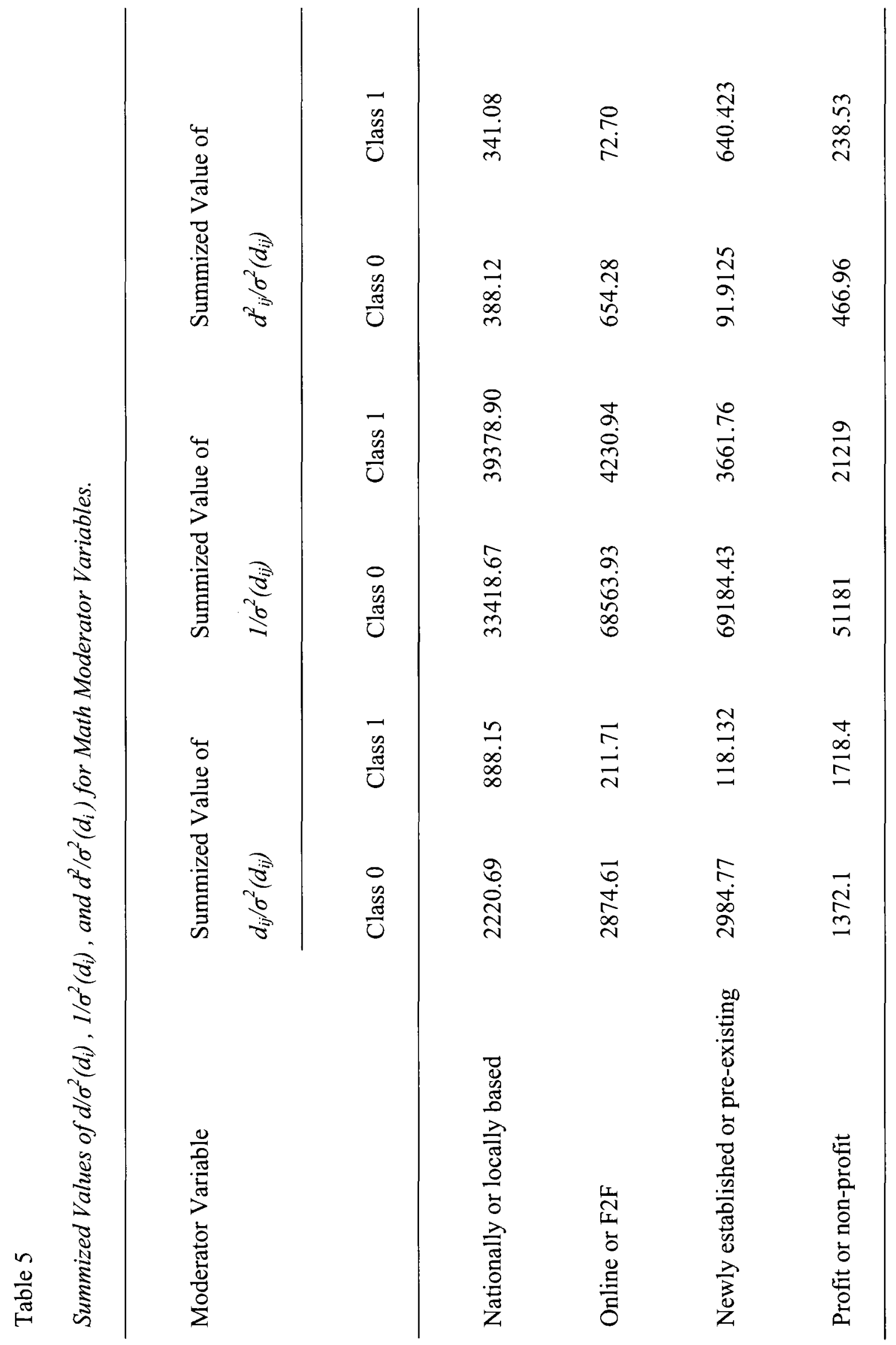


ธิ

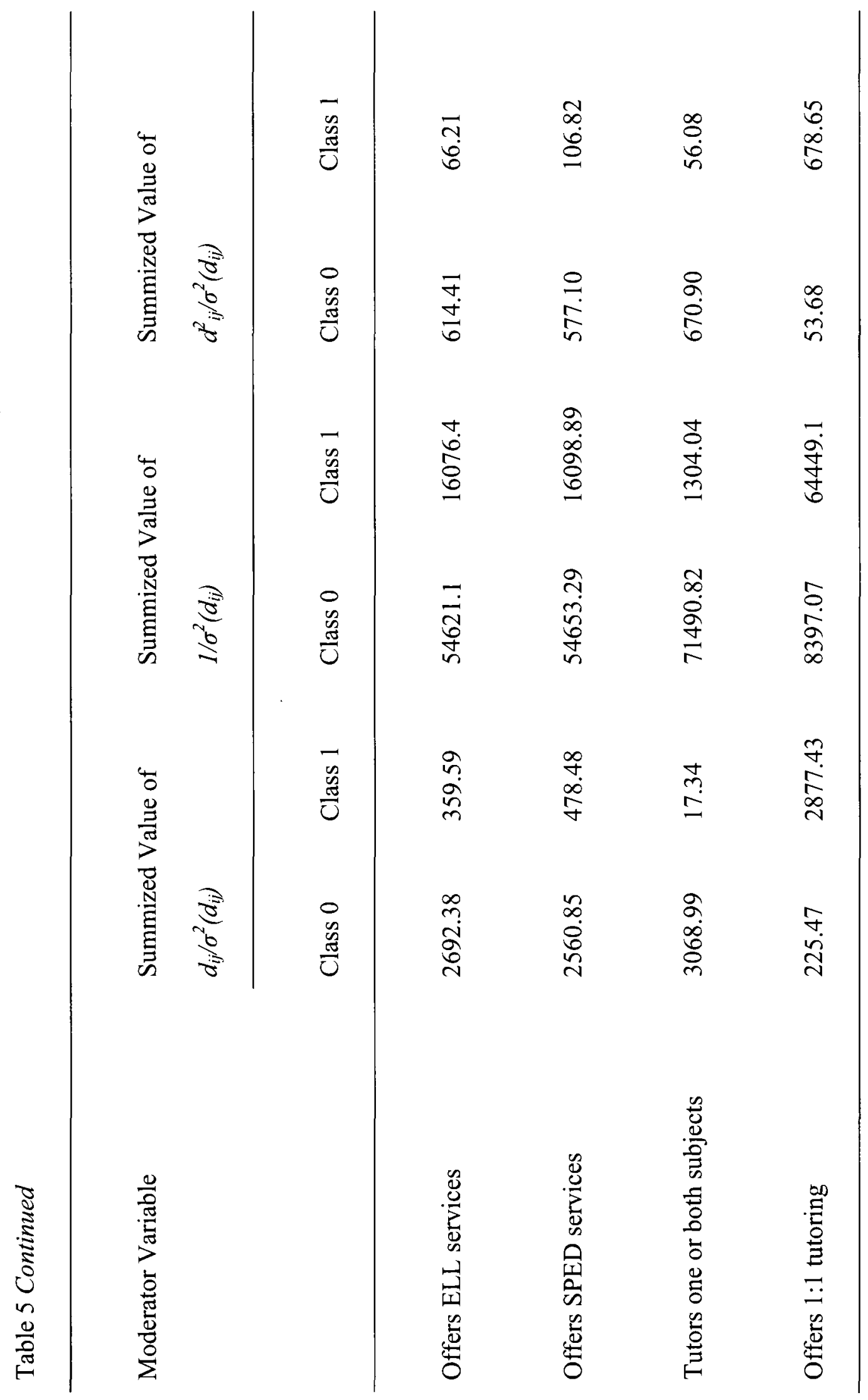


8

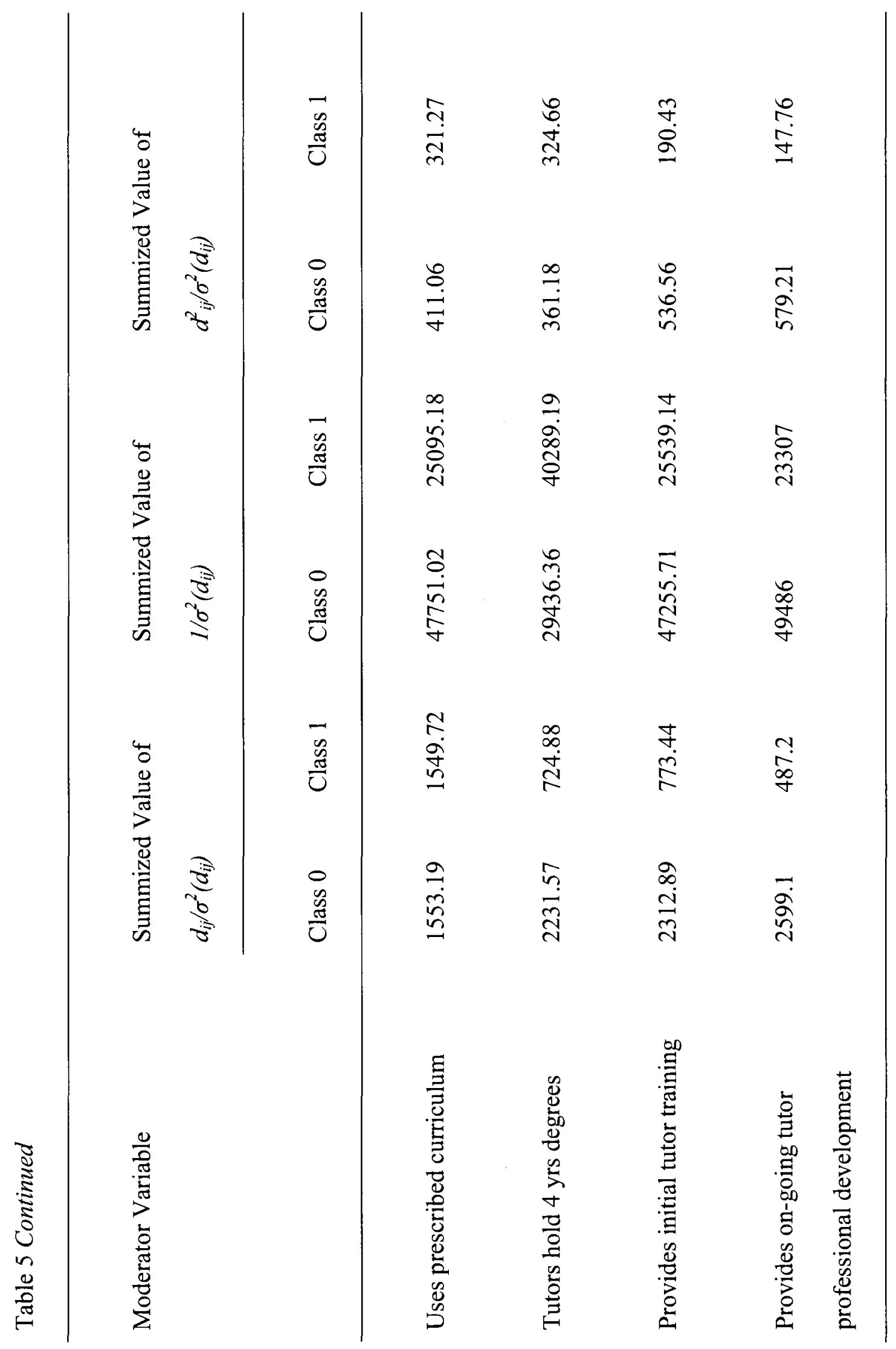


t

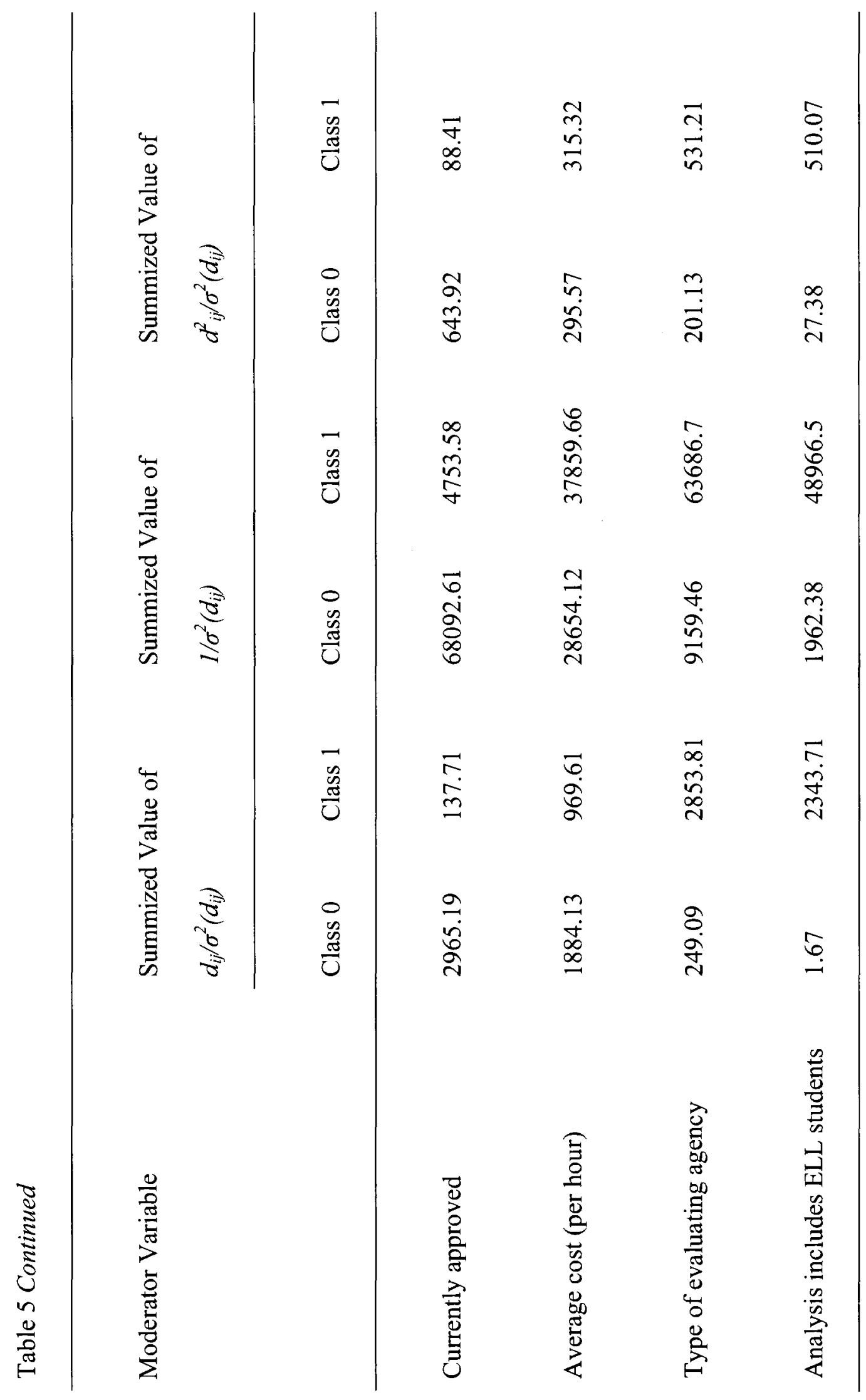


6

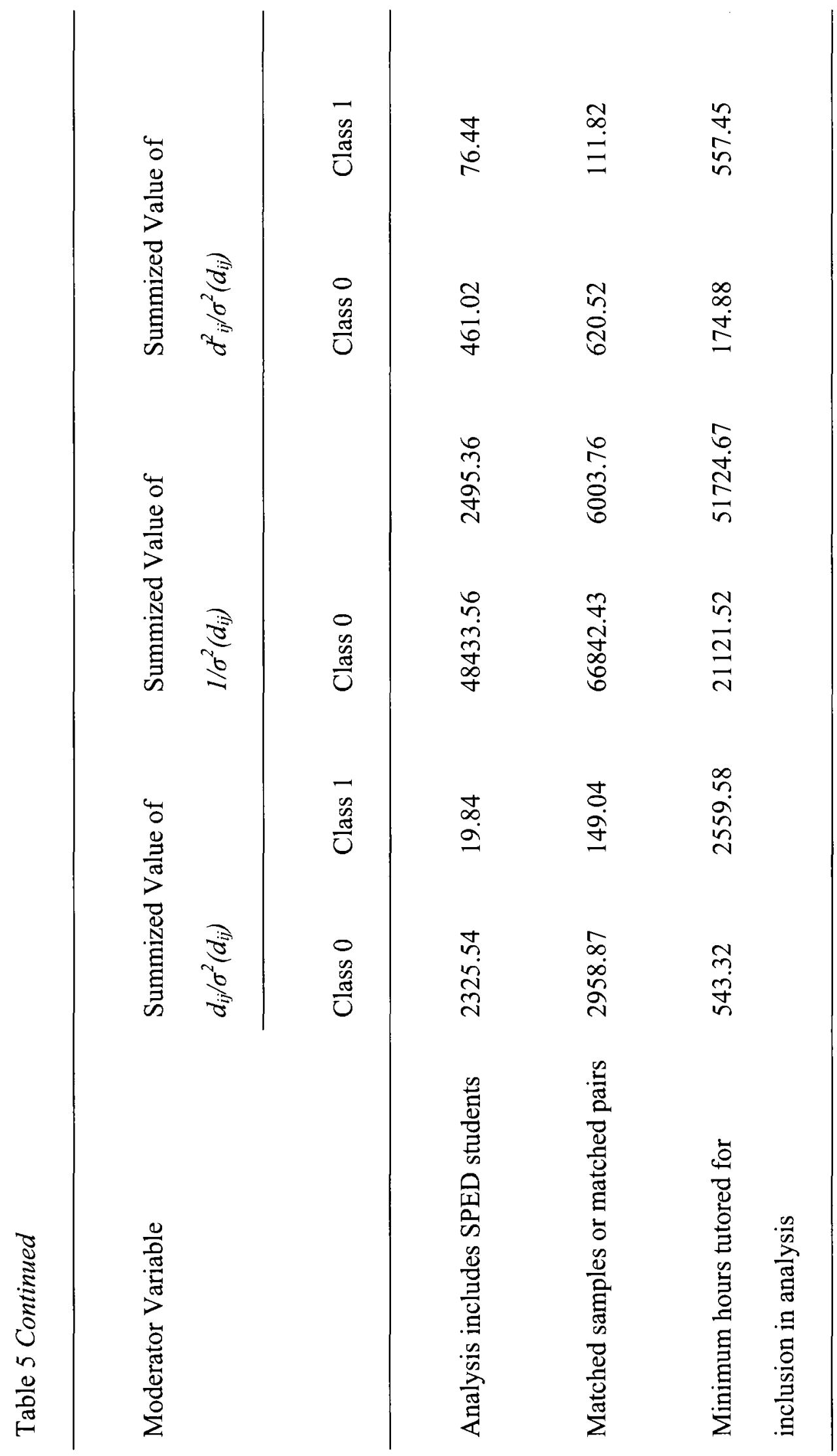


Each moderator variable in this analysis included only two classes; therefore, for each variable, two within-class $Q_{w}$ values were calculated. Then, overall within-class $Q_{w}$ and between-class $Q_{b}$ fit statistics were created using $d f=k-p$ for $Q_{w}, d f=p-1$ for $Q_{b}$, and $d f=k_{1}-1$ for $Q_{w l}$, and so on, where $k=$ number of effect sizes, $p=$ number of classes,

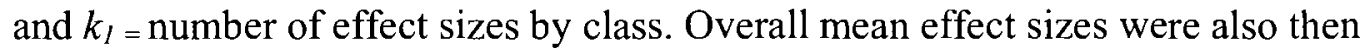
calculated for each class within each moderator variable.

Moderator variables containing data about SES provider characteristics were analyzed first to answer research question number two. For the math provider moderator variable "Local District Providers," class 0 represents providers who were not local district providers and class 1 represents providers who were local district providers. The effect size of the non-district group, $d_{+0}=.027$, was lower than the overall mean of $d_{+}=$ .043 and was substantially lower than the district providers' effect size of $d_{+l}=.094 . Q_{w}$, $Q_{w 1}, Q_{w 2,}$ and $Q_{b}$ values along with $p$ values for each of the within and between class fit statistics are reported in Table 6. 
Table 6

$Q_{w}, Q_{w l}, Q_{w 0}, Q_{b}$, and $p$ values for Local District Math Providers

Fit Statistic Degrees of

Local District Providers $\quad\left(X^{2}\right.$ value $) \quad$ Freedom $\quad p$ Value

$Q_{w}$ - Overall within-variable $\quad 543.13 \quad 398 \quad p<.0001$

$Q_{w l}$ - Non district providers $\quad 31.36 \quad 6 \quad p<.0001$

$Q_{w 0}-$ District providers

511.77

392

$p<.0001$

$Q_{b}-$ Between Class

57.04

1

$p<.0001$

For the math provider moderator variable "Nationally or locally based providers," class 0 represents locally based providers and class 1 represents nationally based providers, including national franchises. The effect size of the locally based providers $d_{+0}=.067$ was higher than the overall mean of $d_{+}=.043$ and, when compared to the nationally based providers, was substantially higher, where $d_{+I}=.023$. Table 7 illustrates the $Q_{w}, Q_{w l}, Q_{w 2,}$ and $Q_{b}$ values along with $p$ values for each of the within and between class fit statistics. 
Table 7

$Q_{w}, Q_{w l}, Q_{w 0}, Q_{b}$, and $p$ values for Nationally or Locally Based Math Providers

\begin{tabular}{llll} 
Nationally or locally based & Fit Statistic & Degrees of & \\
provider & $\left(X^{2}\right.$ value $)$ & Freedom & $p$ Value \\
\hline$Q_{w}-$ Overall within-variable & 561.72 & 396 & $p<.0001$ \\
$Q_{w 1}$ - National providers & 321.18 & 215 & $p<.0001$ \\
& & 179 & $p=.0017$ \\
$Q_{w 0}-$ Local providers & & & $p<.0001$ \\
$Q_{b}-$ Between Class & 240.55 & 1 &
\end{tabular}

Because the within-class $p$ value for the locally based providers was statistically significant $(p=.0017)$, those providers which were local school district providers were removed from the analysis so that only commercial providers remained in the analysis. In this analysis, the overall effect size of locally based providers decreased to .039 and was not statistically significant ( $p=.26$ ); the nationally based providers' effect size remained .023 Fit statistic and $p$ values for this analysis are illustrated in Table 8 . 
Table 8

$Q_{w}, Q_{w 1}, Q_{w 0}, Q_{b}$, and $p$ values for Nationally or Locally Based Math Providers with

Local District Providers Removed

Nationally or locally based

providers (without district

Fit Statistic Degrees of

providers)

$\left(X^{2}\right.$ value $)$

Freedom

$p$ Value

$Q_{w}$ - Overall within-variable

505.12

389

$p<.0001$

$Q_{w l}$ - National providers

321.18

215

$p<.0001$

$Q_{w 0}-$ Local non-district providers

183.94

172

$p=.2529$

$Q_{b}-$ Between Class

95.04

1

$p<.0001$

For the math provider moderator variable "Online or face-to-face services," class 0 represents face-to-face services and class 1 represents online only services. The effect size of the face-to-face class $d_{+0}=.042$ was essentially equivalent to the overall mean of $d_{+}=.043$ but was lower than the online class mean effect size of $d_{+1}=.05$. The withinclass fit statistics for both $Q_{w 0}$ and $Q_{w l} \quad(p<.01$ for both) revealed that there still remained a significant difference among the effect sizes in each class at the $\alpha=.01$ level. However, 
there was not sufficient data to allow subdivision of either class to allow for further analysis. Table 9 illustrates the $Q_{w}, Q_{w 1}, Q_{w 2}$, and $Q_{b}$ values along with $p$ values for each of the within and between class fit statistics.

Table 9

$Q_{w}, Q_{w}, Q_{w 0}, Q_{b}$, and $p$ values for Online or Face-to-Face Math Providers

Online or Face-to-Face

Fit Statistic

Degrees of

Providers

$\left(X^{2}\right.$ value $)$

Freedom

$p$ Value

$Q_{w}$ - Overall within-variable $\quad 595.87$

397

$p<.0001$

$Q_{w 1}$ - Online providers

62.105

34

$p=.0023$

$Q_{w 0}-$ Face-to-face providers

533.76

363

$p<.0001$

$Q_{b}-$ Between Class

1

$p=.0381$

For the math provider moderator variable "Newly established or pre-existing providers," class 0 represents providers whose businesses were established during or after the year 2002 (the first year that SES were offered) and class 1 represents providers whose businesses were already established at the onset of the SES program. Those 
providers for whom an establishment date was not available were assumed to be newly established. It should also be noted that local district providers were classified as being newly established. The effect size of the newly established providers, $d_{+0}=.043$, was equal to the overall mean of $d_{+}=.043$ but was higher than the effect size of the preexisting providers $d_{+I}=.032$. Table 10 illustrates the $Q_{w}, Q_{w 1}, Q_{w 2,}$ and $Q_{b}$ values along with $p$ values for each of the within and between class fit statistics.

Table 10

$Q_{w}, Q_{w 1}, Q_{w 0}, Q_{b}$, and $p$ values for Newly Established or Pre-Existing Math Providers

$\begin{array}{llll}\text { Newly established or pre-existing } & \text { Fit Statistic } & \text { Degrees of } \\ \text { providers } & \left(X^{2} \text { value }\right) & \text { Freedom } & p \text { Value }\end{array}$

$Q_{w}$ - Overall within-variable

$Q_{w l}-$ Newly established providers

$Q_{w 0}-$ Pre-existing providers

$Q_{b}-$ Between Class
599.75

88.101

511.65

.412
398

$p<.0001$

88

$p=.5070$

310

$p<.0001$

$p=.5211$ 
Because the within-class $p$ value for the newly established providers was statistically significant, $p<.0001$, those providers which were local school district providers were removed from the analysis so that only newly established commercial providers remained in the analysis. In this analysis, the overall effect size of newly established providers decreased to .03 , which is equal to the pre-existing providers' effect size of .03 . However, the significant within-class $p$ value for the newly established class $(p<.001)$ still indicated differences among the effect sizes for the class 0 providers. Fit statistic and $p$ values for this analysis are illustrated in Table 11.

Table 11

$Q_{w}, Q_{w 1}, Q_{w 0}, Q_{b}$, and $p$ values for Newly Established or Pre-Existing Math Providers with Local District Providers Removed

Newly establish or Fit Statistic Degrees of

pre-existing providers $\left(X^{2}\right.$ value $) \quad$ Freedom $\quad p$ Value

$Q_{w}$

511.58

391

$p<.0001$

$Q_{w l}$

86.72

88

$p=.5186$

$Q_{w 0}$

424.85

302

$p<.0001$

$Q_{b}$

88.59

1

$p<.0001$ 
For the math provider moderator variable "Profit or non-profit providers," class 0 represents non-profit providers and class 1 represents for-profit providers. It should be noted that the local school district providers were classified as being non-profit providers. The effect size of the non-profit providers, $d_{+0}=.081$, was substantially higher than the overall mean of $d_{+}=.043$ and the for-profit providers' effect size, $d_{+1}=.027$. Table 12 illustrates the $Q_{w}, Q_{w 1}, Q_{w 2}$, and $Q_{b}$ values along with $p$ values for each of the within and between class fit statistics.

Table 12

$Q_{w}, Q_{w 1}, Q_{w 0}, Q_{b}$, and $p$ values for Profit or Non-profit Math Providers

Profit or Non-profit

Providers
Fit Statistic

$\left(X^{2}\right.$ value $)$
Degrees of

Freedom

$p$ Value
$Q_{w}$ - Overall within-variable $\quad 529.54$

$Q_{w l}-$ For-profit providers

430.18

$Q_{w 0}-$ Non-profit providers $\quad 99.362$

$Q_{b}-$ Between Class

70.62
382

$p<.0001$

303

$p<.0001$

79

$p=.0605$

1

$p<.0001$ 
Though the $p$ value reflected homogeneity of effects within-class for the nonprofit providers, a subsequent analysis was conducted in which local school district providers, classified as non-profit, were removed from the dataset. The results of this analysis revealed that the effect size of non-profit providers (without local district providers) decreased to .034 , which was lower than the overall mean math effect of .043 and was not substantially different from the for-profit providers' effect size of .027 . Table 13 reports $Q_{w}, Q_{w 1}, Q_{w 2,}$ and $Q_{b}$ values along with $p$ values for each of the within and between class fit statistics.

Table 13

$Q_{w}, Q_{w l}, Q_{w 0}, Q_{b}$, and $p$ values for Profit or Non-profit Math Providers With District Providers Removed

\begin{tabular}{llll}
\hline Profit or Non-profit Providers & Fit Statistic & Degrees of & \\
& $\left(X^{2}\right.$ value $)$ & Freedom & $p$ Value \\
\hline$Q_{w}$ - Overall within-variable & 485.05 & 375 & $p<.0001$ \\
& & & \\
$Q_{w 1}-$ For-profit providers & 430.18 & 303 & $p<.0001$ \\
& & & $p=.9336$ \\
$Q_{w 0}-$ Non-profit (non-district) providers & 54.87 & 72 & $p<.0001$ \\
\hline
\end{tabular}


For the math provider moderator variable "Providers offering ELL services," class 0 represents providers who did not offer services to ELL students and class 1 represents providers who did offer services to ELL students. The effect size of the providers not offering ELL services, $d_{+0}=.022$, was lower than the overall mean of $d_{+}=$ .043 and was also lower than the effect size of providers offering ELL services, $d_{+1}=$ .049 There was not sufficient data available to further sub-divide the class 1 group though its statistically significant value, $p<.0001$, reflected that differences remained within the class's effect sizes. Table 14 illustrates the $Q_{w}, Q_{w 1}, Q_{w 2}$, and $Q_{b}$ values along with $p$ values for each of the within and between class fit statistics.

Table 14

$Q_{w}, Q_{w l}, Q_{w 0}, Q_{b}$, and $p$ values for Math Providers Offering ELL Services

Fit Statistic Degrees of

Providers Offering ELL Services $\quad\left(X^{2}\right.$ value $) \quad$ Freedom $\quad p$ Value

$Q_{w}$ - Overall within-variable

$Q_{w l}$ - Providers offering ELL services

$Q_{w 0}-$ Providers not offering ELL services

$Q_{b}-$ Between Class
539.87

481.70

58.17

60.29
355

$p<.0001$

302

$p<.0001$

53

$p=.2908$

1

$p<.0001$ 
Analysis of the math provider moderator variable "Providers offering SPED services," in which class 0 represents providers not offering services to SPED students and class 1 represents providers who did offer services to SPED students was conducted next. The effect size of the providers not offering SPED services, $d_{+0}=.030$, was lower than the overall mean of $d_{+}=.043$ and the effect size of the providers who did offer

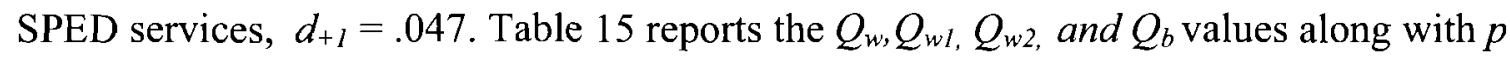
values for the within and between class fit statistics.

Table 15

$Q_{w}, Q_{w l}, Q_{w 0}, Q_{b}$, and $p$ values for Math Providers Offering SPED Services

Providers Offering SPED services

$Q_{w}$ - Overall within-variable

$Q_{w 1}-$ Providers offering SPED services

$Q_{w 0}-$ Providers not offering SPED

services

$Q_{b}-$ Between Class
Fit Statistic Degrees of

$\left(X^{2}\right.$ value $) \quad$ Freedom $\quad p$ Value

549.71

357

$p<.0001$

457.11

281

$p<.0001$

92.60

76

$p=.0947$

50.46

1

$p<.0001$ 
For the math provider moderator variable "Providers offering math and reading tutoring," class 0 represents providers who offered only math tutoring and class 1 represents providers offering tutoring for both math and reading subject areas. The effect size of the providers offering only math tutoring, $d_{+0}=.013$, was substantially lower than the overall mean of $d_{+}=.043$ and was also lower than the effect size of the providers offering math and reading tutoring, $d_{+1}=.043$. Table 16 illustrates the $Q_{w}, Q_{w 1}, Q_{w 2 \text {, and }}$ $Q_{b}$ values along with $p$ values for each of the within and between class fit statistics.

Table 16

$Q_{w}, Q_{w I}, Q_{w 0}, Q_{b}$, and $p$ values for Math Providers Offering Math \& Reading Tutoring

\begin{tabular}{llll} 
Providers Offering Math \& & Fit Statistic & Degrees of & \\
Reading Tutoring & $\left(X^{2}\right.$ value $)$ & Freedom & $p$ Value \\
\hline$Q_{w}-$ Overall within-variable & 595.00 & 397 & $p<.0001$ \\
$Q_{w 1}-$ Math \& reading providers & 539.15 & 361 & $p<.0001$ \\
$Q_{w 0}-$ Math only providers & 55.85 & & $p=.0241$ \\
$Q_{b}-$ Between Class & & 36 & $p=.0231$ \\
\hline
\end{tabular}


For the math provider moderator variable "Providers offering one-to-one tutoring," class 0 represents providers who did not offer one-to-one tutoring and class 1 represents providers who did offer one-to-one tutoring. The effect size of the non one-toone group, $d_{+0}=.045$, was slightly higher than the overall mean of $d_{+}=.043$ and was somewhat higher than the one-to-one group's effect size of $d_{+1}=.027$. Table 17 illustrates the $Q_{w}, Q_{w 1}, Q_{w 2}$, and $Q_{b}$ values along with $p$ values for each of the within and between class fit statistics.

Table 17

$Q_{w}, Q_{w l}, Q_{w 0}, Q_{b}$, and $p$ values for Math Providers Offering 1:1 Tutoring

Providers Offering 1:1 Student to Fit Statistic Degrees of

$\begin{array}{llll}\text { Tutor Ratio } & \left(X^{2} \text { value }\right) & \text { Freedom } & \text { Value }\end{array}$

$Q_{w}$ - Overall within-variable $\quad 597.81$

398

$p<.0001$

$Q_{w I}-1: 1$ providers

47.63

73

$p=.9927$

$Q_{w 0}-$ Non $1: 1$ providers

550.19

325

$p<.0001$

$Q_{b}-$ Between Class

2.35

1

$p=.1250$ 
The analysis for the math provider moderator variable "Provider staff qualifications," class 0 represents providers whose tutors do not hold at least a 4-year degree and class 1 represents providers whose tutors hold at least a 4-year degree. The effect size of the non-degreed group was $d_{+0}=.018$, which was substantially lower than both the overall mean of $d_{+}=.043$ and the degreed group's effect size of $d_{+1}=.076$. Table 18 reports the $Q_{w}, Q_{w I}, Q_{w 2}$, and $Q_{b}$ values along with $p$ values for each of the within and between class fit statistics.

Table 18

$Q_{w}, Q_{w l}, Q_{w 0}, Q_{b}$, and $p$ values for Math Provider Staff Qualifications

Fit Statistic Degrees of

Provider Staff Qualifications $\quad\left(X^{2}\right.$ value $) \quad$ Freedom $\quad p$ Value

$Q_{w}$ - Overall within-variable $\quad 503.63$

344

$p<.0001$

$Q_{w l}-$ Providers using only

192.01

132

$p=.0006$

degreed tutors

$Q_{w 0}$-Providers using tutors $\quad 311.62$

212

$p<.0001$

with less than 4-yr degree

$Q_{b}-$ Between Class

96.53

1

$p<.0001$ 
For the math provider moderator variable "Providers offering initial training for tutors," class 0 represents providers who did not indicate that they offered initial training for its tutors and class 1 represents providers who did offer initial training for its tutors. The effect size of providers not offering initial training was $d_{+0}=.030$, which was lower than the overall mean of $d_{+}=.043$ and also lower than the effect size of providers offering initial training, $d_{+1}=.049$. Table 19 illustrates the $Q_{w}, Q_{w 1}, Q_{w 2}$, and $Q_{b}$ values along with $p$ values for each of the within and between class fit statistics.

Table 19

$Q_{w}, Q_{w l}, Q_{w 0}, Q_{b}$, and $p$ values for Math Providers Offering Initial Training for Tutors

Providers Offering Initial Training for Fit Statistic Degrees of

Tutors ( $X^{2}$ value $) \quad$ Freedom $p$ Value

$Q_{w}$ - Overall within-variable

$Q_{w l}-$ Providers offering initial training

$Q_{w 0}-$ Providers not offering initial

training

$Q_{b}-$ Between Class

$$
Q_{b}-\text { Between Class }
$$

590.35

423.35

167.00

184

213

$p<.0001$

397

$p<.0001$ 
Analysis of the math provider moderator variable "Providers offering on-going professional development for tutors," in which class 0 represents providers who did not indicate that they offered on-going professional development for tutors and class 1 represents providers who did offer on-going professional development for tutors was conducted next. The effect size of the providers not offering on-going training, $d_{+0}=$ .021 , was lower than the overall mean of $d_{+}=.043$ and was also lower than the effect size of providers who did offer on-going training for tutors, $d_{+l}=.053$. Table 20 illustrates the $Q_{w}, Q_{w 1}, Q_{w 2,}$ and $Q_{b}$ values along with $p$ values for each of the within and between class fit statistics. 
Table 20

$Q_{w}, Q_{w l}, Q_{w 0}, Q_{b}$, and $p$ values for Math Providers Offering On-going Training

Providers Offering On-going Training for Fit Statistic Degrees of

Tutors $\left(X^{2}\right.$ value $) \quad$ Freedom $p$ Value

$Q_{w}$ - Overall within-variable

580.28

397

$p<.0001$

$Q_{w 1}-$ Providers offering on-going training

442.70

211

$p<.0001$

to tutors

$Q_{w 0}-$ Providers not offering on-going

137.57

186

$p=.996$

training to tutors

$Q_{b}-$ Between Class

19.88

1

$p<.0001$

For the math provider moderator variable "Providers using a nationally prescribed curriculum," class 0 represents providers who did not indicate that they use a nationally prescribed curriculum and class 1 represents providers who did use a nationally prescribed curriculum. Some national providers use a proprietary curriculum; for this analysis, providers using a proprietary curriculum were classified as class 0 . The effect size of providers not using a prescribed curriculum, $d_{+0}=.033$, was lower than the 
overall mean of $d_{+}=.043$ and was also lower than the effect size of providers using a prescribed curriculum, $d_{+1}=.062$. Table 21 reports $Q_{w}, Q_{w 1}, Q_{w 2,}$ and $Q_{b}$ values.

Table 21

$Q_{w}, Q_{w l}, Q_{w 0}, Q_{b}, \& p$ values for Math Providers Using Prescribed Curriculum

Providers using a nationally Fit Statistic Degrees of

$\begin{array}{llll}\text { prescribed curriculum } & \left(X^{2} \text { value }\right) & \text { Freedom } & p \text { Value }\end{array}$

$\begin{array}{llll}Q_{w} \text { - Overall within-variable } & 586.11 & 398 & p<.0001\end{array}$

$\begin{array}{llll}Q_{w 1}-\text { Providers using } & 225.57 & 108 & p<.0001\end{array}$

prescribed curriculum

$Q_{w 0}-$ Providers not using $\quad 360.54 \quad 290 \quad p=.0030$

prescribed curriculum

$Q_{b}$ - Between Class $\quad 14.05 \quad 1 \quad p=.0002$

For the math provider variable "Average Cost per hour," class 0 represents those providers whose cost per hour was less than $\$ 52.35$, the mean cost per hour for all providers in the analysis, and class 1 represents those providers whose cost per hour was 
greater than $\$ 52.35$. The effect size for the providers whose cost per hour was less than $\$ 52.35, d_{+0}=.066$, was higher than the overall mean effect size of $d_{+}=.047$ and was also higher than the effect size for providers whose cost per hour was greater than $\$ 52.35, d_{+I}$ $=.026 . Q_{w}, Q_{w 1}, Q_{w 2}$, and $Q_{b}$ values along with $p$ values for each of the within and between class fit statistics for this variable are reported in Table 22.

Table 22

$Q_{w}, Q_{w 1}, Q_{w 0}, Q_{b}$, and $p$ values for Math Providers Average Cost per Hour

Fit Statistic Degrees of

Providers Average Cost Per Hour $\quad\left(X^{2}\right.$ value $) \quad$ Freedom $\quad p$ Value

$Q_{w}$ - Overall within-variable

460.86

266

$p<.0001$

$Q_{w 1}-$ Providers with cost $/ \mathrm{hr}>\$ 52.35 \quad 290.48$

150

$p<.0001$

$Q_{w 0}-$ Providers with cost $/ \mathrm{hr}<\$ 52.35$

170.37

113

$p=.0004$

$Q_{b}-$ Between Class

139.31

1

$p<.0001$

For the math provider moderator variable "Providers currently approved to offer SES," class 0 represents providers who are not currently approved to provide SES and 
class 1 represents providers who are currently approved to provide SES (currently approved is defined as being on the approved list for the academic year 2009-2010 for any state included in this analysis). The effect size for providers not currently approved was $d_{+0}=.029$ which was lower than the overall mean of $d_{+}=.043$ and was also lower than the effect size of currently approved providers, $d_{+1}=.044$. Table 23 reports the $Q_{w}$, $Q_{w 1}, Q_{w 2,}$ and $Q_{b}$ values along with $p$ values for each of the within and between class fit statistics.

Table 23

$Q_{w}, Q_{w l}, Q_{w 0}, Q_{b}$, and $p$ values for Math Providers Currently Approved to Offer SES

Providers Currently Approved to
Offer SES

Fit Statistic

$\left(X^{2}\right.$ value $)$

599.22

$Q_{w}$ - Overall within-variable

$Q_{w l}-$ Currently approved providers

$Q_{w 0}-$ Not currently approved

providers
514.80

84.42

.944
Degrees of

Freedom

$p$ Value

398

$p<.0001$

313

$p<.0001$

$Q_{b}-$ Between Class

1

$p=.3313$ 
Analyses on the moderator variables containing data about the research methods used in the evaluations included in this analysis were conducted next to answer research question number three. For the methods moderator variable "Evaluating agency type," class 0 represents local (LEA) or state education agencies (SEA) (also referred to as internal) and class 1 represents an external evaluation agency. The effect size of the internal evaluator group was $d_{+0}=.045$, which was slightly higher than the overall mean of $d_{+}=.043$ but was moderately higher than the external evaluator effect size of $d_{+I}$ $=.027$. Table 24 reports the $Q_{w}, Q_{w l}, Q_{w 2,}$ and $Q_{b}$ values along with $p$ values for each of the within and between class fit statistics.

Table 24

$Q_{w}, Q_{w 1}, Q_{w 0}, Q_{b}$, and $p$ values for Evaluating Agency Type - Math

\begin{tabular}{llll} 
Evaluating Agency Type & Fit Statistic & Degrees of & \\
(internal or external $)$ & $\left(X^{2}\right.$ value $)$ & Freedom & $p$ Value \\
\hline$Q_{w}-$ Overall within-variable & 597.68 & 398 & $p<.0001$ \\
& & & $p=.9015$ \\
$Q_{w l}-$ External evaluators & 194.36 & 221 & \\
& & & $p<.0001$ \\
$Q_{w 0}-$ Internal evaluators & 403.33 & 177 & $p=.1150$ \\
& & 1 &
\end{tabular}


For the methods moderator variable "Evaluations which included ELL students," class 0 represents evaluations which did not include ELL students in the analysis and class 1 represents evaluations which did include ELL students in the analysis. The effect size of the group which excluded ELL students was $d_{+_{0}}=.048$ which was slightly higher than the overall mean of $d_{+}=.043$ and but was substantially higher than the effect size of evaluations which included ELL students, $d_{+1}=.0008$. Table 25 illustrates the $Q_{w}, Q_{w l}$, $Q_{w 2,}$ and $Q_{b}$ values along with $p$ values for each of the within and between class fit statistics.

Table 25

$Q_{w}, Q_{w 1}, Q_{w 0}, Q_{b}$, and $p$ values for Evaluations Which Included ELL Students - Math

Evaluations Which Included Fit Statistic Degrees of

ELL Students $\quad\left(X^{2}\right.$ value $) \quad$ Freedom $\quad p$ Value

$Q_{w}$ - Overall within-variable $\quad 425.27$

174

$p<.0001$

$Q_{w 1}-$ ELL students included $\quad 27.38$

31

$p=.6531$

$Q_{w 0}-$ ELL students excluded

397.90

143

$p<.0001$

$Q_{b}-$ Between Class

174.89

1

$p<.0001$ 
For the methods moderator variable "Evaluations which included SPED students," class 0 represents evaluations which did not include SPED students in the analysis and class 1 represents evaluations which included SPED students in the analysis. The effect size of the group which excluded SPED students was $d_{+0}=.008$ which was substantially lower than the overall mean of $d_{+}=.043$ and was also substantially lower than the effect size of the group which included SPED students $d_{+1}=.048$. Table 26 illustrates the $Q_{w}, Q_{w 1}, Q_{w 2}$, and $Q_{b}$ values along with $p$ values for each of the within and between class fit statistics.

Table 26

$Q_{w}, Q_{w l}, Q_{w 0}, Q_{b}$, and $p$ values for Evaluations Which Included SPED Students - Math

$\begin{array}{llll}\text { Evaluations Which Included } & \text { Fit Statistic } & \text { Degrees of } \\ \text { SPED Students } & \left(X^{2} \text { value }\right) & \text { Freedom } & p \text { Value }\end{array}$

$Q_{w}$ - Overall within-variable $\quad 425.64$

174

$p<.0001$

$Q_{w l}$-SPED students included $\quad 349.36$

101

$p<.0001$

$Q_{w 0}-$ SPED students excluded 76.28

73

$p=.3735$

$Q_{b}-$ Between Class

174.53

1

$p<.0001$ 
For the methods moderator variable "Evaluations which used matched pairs approach," class 0 represents evaluations which a matched sample approach in the analysis and class 1 represents evaluations which used a matched pairs approach in the analysis. The effect size of the group using matched samples was $d_{+0}=.025$ which was lower than the overall mean of $d_{+}=.043$ and was also lower than the effect size of groups using matched pairs, $d_{+l}=.044$. Table 27 illustrates the $Q_{w}, Q_{w 1}, Q_{w 2}$, and $Q_{b}$ values along with $p$ values for each of the within and between class fit statistics.

Table 27

$Q_{w}, Q_{w l}, Q_{w 0}, Q_{b}$, and $p$ values for Evaluations Using Matched Pairs Approach - Math

\begin{tabular}{llll} 
Evaluations Using Matched & Fit Statistic & Degrees of & \\
Pairs vs. Matched Samples & $\left(X^{2}\right.$ value $)$ & Freedom & $p$ Value \\
\hline$Q_{w}$ - Overall within-variable & 598.10 & 398 & $p<.0001$ \\
$Q_{w l}-$ Matched pairs & 489.98 & 262 & $p<.0001$ \\
& & & $p=.9625$ \\
$Q_{w 0}-$ Matched samples & 108.12 & 136 & \\
$Q_{b}-$ Between Class & & 1 & $p=.1506$
\end{tabular}


For the methods moderator variable "Minimum hours tutored for inclusion in analysis," class 0 represents evaluations which required less than 15 hours of SES to be included in the analysis and class 1 represents evaluations which required more than 15 hours of SES to be included in the analysis. The effect size of the group requiring less than 15 hours was $d_{+0}=.026$ which was lower than the overall mean of $d_{+}=.043$ and was also lower than the effect size of group requiring more than 15 hours of SES, $d_{+1}$ $=.05$. Table 28 illustrates the $Q_{w}, Q_{w 1}, Q_{w 2}$, and $Q_{b}$ values along with $p$ values for each of the within and between class fit statistics.

Table 28

$Q_{w}, Q_{w 1}, Q_{w 0}, Q_{b}$, and $p$ values for Minimum Hours for Inclusion in Analysis - Math

\begin{tabular}{llll} 
Minimum Hours for inclusion & Fit Statistic & Degrees of & \\
in analysis & $\left(X^{2}\right.$ value $)$ & Freedom & $p$ Value \\
\hline$Q_{w}-$ Overall within-variable & 591.70 & 229 & $p<.0001$ \\
$Q_{w 1}-$ More than 15 hours & 430.79 & 195 & $p<.0001$ \\
$Q_{w 0}-$ Less than 15 hours & 160.91 & & $p<.0001$ \\
$Q_{b}-$ Between Class & & 34 & $p=.0036$
\end{tabular}


Because the within-class $p$ value for the evaluations including only students who received 15 or more hours of SES was statistically significant, $p<.0001$, subclassification and reanalysis were performed for those providers in this class. A frequency count of this class revealed that for minimum hours for inclusion $=18$ there was an $n$ of 123 , and for minimum hours for inclusion $=30$, there was an $n$ of 70 . Two new variables were created, one comparing effect sizes from evaluations which only included students receiving 18 or more hours of SES as compared to all other effect sizes and one comparing effect sizes from evaluations which only included students receiving 30 or more hours of SES as compared to all other students.

In the analysis comparing the 18-hour group to all others, the effect size of the 18hour group was $d_{+1}=.044$ and the effect size of the comparison group was $d_{+o}=.043$, revealing no differences among these effect sizes or among the effects as compared to the overall mean effect of $d_{+}=.044$. However, in the analysis comparing the 30 -hour group to all others, the effect size of the 30-hour group was $d_{+1}=.05$ and the effect size of the comparison group was $d_{+0}=.03$, with a between-class fit statistic of $Q_{b}=.0079$, revealing a statistically significant difference between classes.

\section{File Drawer Problem}

Using Orwin's (1983) fail-safe $n$ approach, the results revealed that for a criterion effect size of $.01,39,996$ effect sizes of 0.00 would be necessary, or 2,857 evaluations. For a criterion effect size of .02, 19,999 effect sizes (or 1,429 evaluations) would be needed, and for a criterion effect size of .03, 13,332 effect sizes (or 952 evaluations) would be needed. 


\section{Reading Analysis}

The analysis of reading effects was conducted next. To answer research question number one, a mean effect size of the reading outcomes was calculated. First, variances, or $\sigma^{2}\left(d_{i}\right)$, were calculated for each of the 401 reading effect sizes. Variances for each effect size were then used to calculate three new variables for each reading effect size, $d / \sigma^{2}\left(d_{i}\right), 1 / \sigma^{2}\left(d_{i}\right)$, and $d^{2} / \sigma^{2}\left(d_{i}\right)$. Summations of each of these variables were then used to create the values used to calculate the overall mean effect, $d_{+}$, and the lower and upper confidence intervals, $\delta_{\mathrm{L}}$ and $\delta_{\mathrm{U}}$, for the reading subject area. Table 29 reports the summized values of these three variables for the reading analysis.

Table 29

Summized Values of $d / \sigma^{2}\left(d_{i}\right), 1 / \sigma^{2}\left(d_{i}\right)$, and $d^{2} / \sigma^{2}\left(d_{i}\right)$ for Reading Analysis

Number of Effect Summized Value of Summized Value of Summized Value of

Sizes $\quad d / \sigma^{2}\left(d_{i}\right) \quad 1 / \sigma^{2}\left(d_{i}\right) \quad d^{2} / \sigma^{2}\left(d_{i}\right)$

The overall mean weighted effect $d_{+}$was .017 with an overall estimated variance of .000014 and a range of -1.01 to .76 . The standard error of the mean was .0037 . Figure 2 illustrates the distribution of weighted effect sizes $(n=401)$ for this analysis. Since the 
distribution's skewness was within the acceptable range of $+/-1.00$, no outliers were removed and no other transformations to the distribution values were performed.

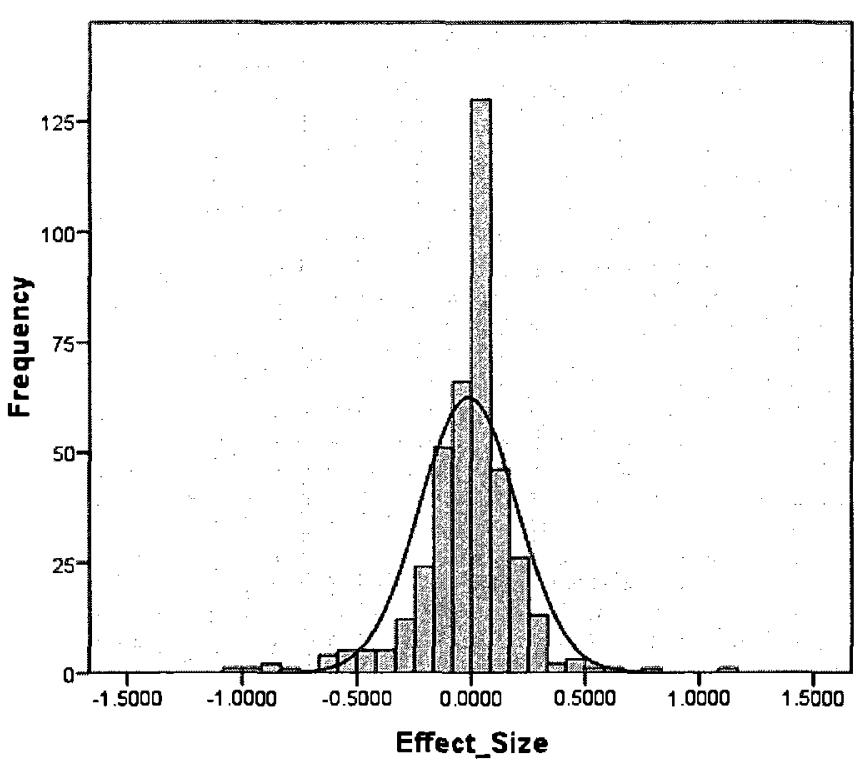

Figure 2. Distribution of weighted effect sizes for reading analysis

To determine the statistical significance of the mean reading effect size, $95 \%$ confidence intervals were calculated with the standard error of the mean, where $\delta_{\mathrm{L}}=.0092$ and $\delta_{\mathrm{U}}=$ .0238 (Hedges \& Olkin, 1985).

Results for the test of homogeneity were $Q=466.4169, d f=400, p<.0001$, indicating that the reading effect sizes were not homogeneous across studies (Hedges \& Olkin, 1985). Because this value was significant, further analysis was necessary and the overall (or total) $Q$ will be referred to as $Q_{t}$.

The reading moderator variables were then tested for homogeneity of effect sizes within and between classes of each variable. Each of the moderator variables included in 
this analysis was separated into two classes and analyzed for homogeneity to answer research question number two. First, values of $d / \sigma^{2}(d), 1 / \sigma^{2}(d)$, and $d^{2} / \sigma^{2}(d)$ were summized by class and variable using the SUMIF formula in the Microsoft Office 2007 Excel software program. The summized values of $d / \sigma^{2}(d), 1 / \sigma^{2}(d)$, and $d^{2} / \sigma^{2}(d)$ for each reading moderator variable are reported in Table 30. 
n

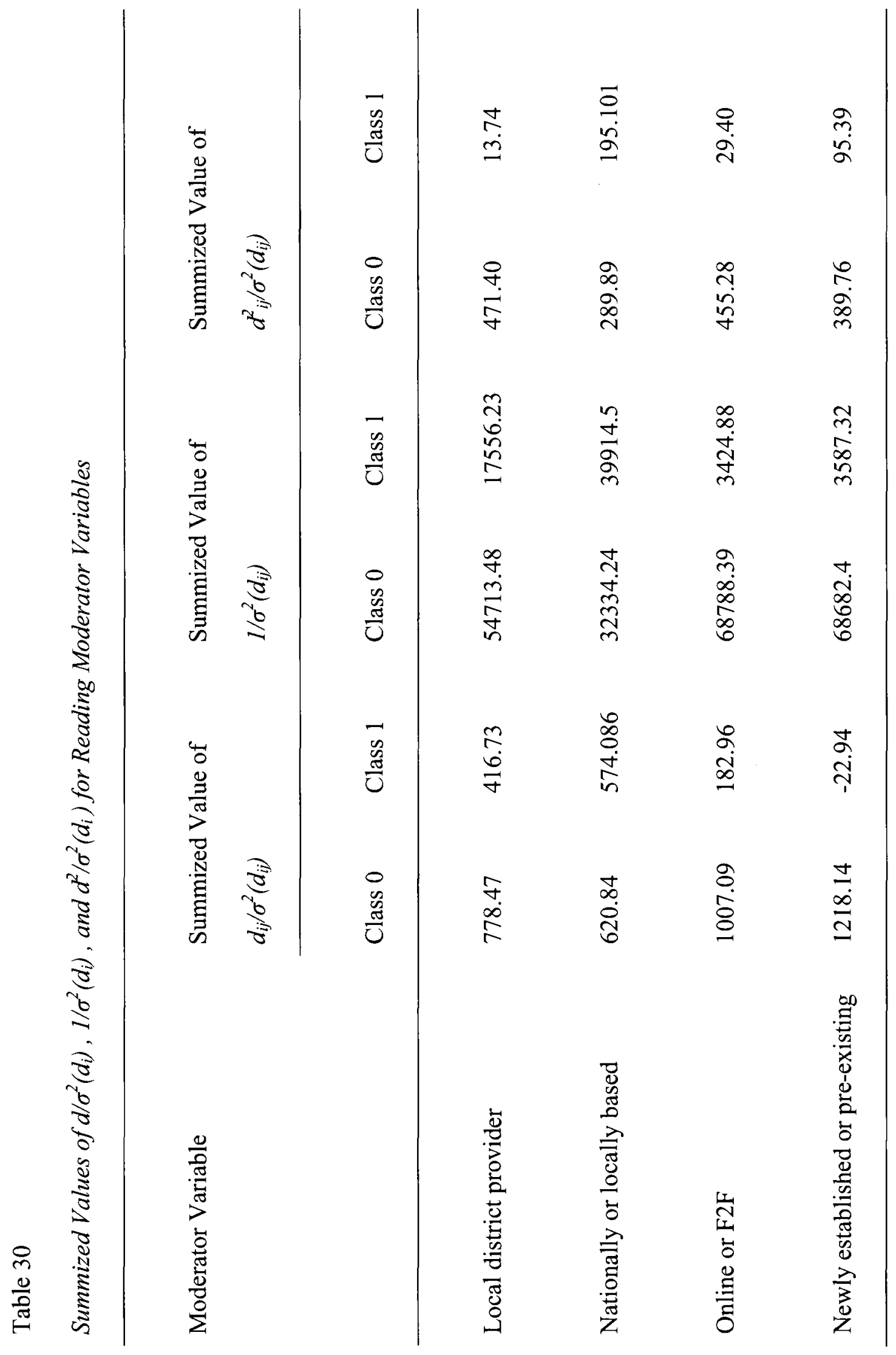


ஃ

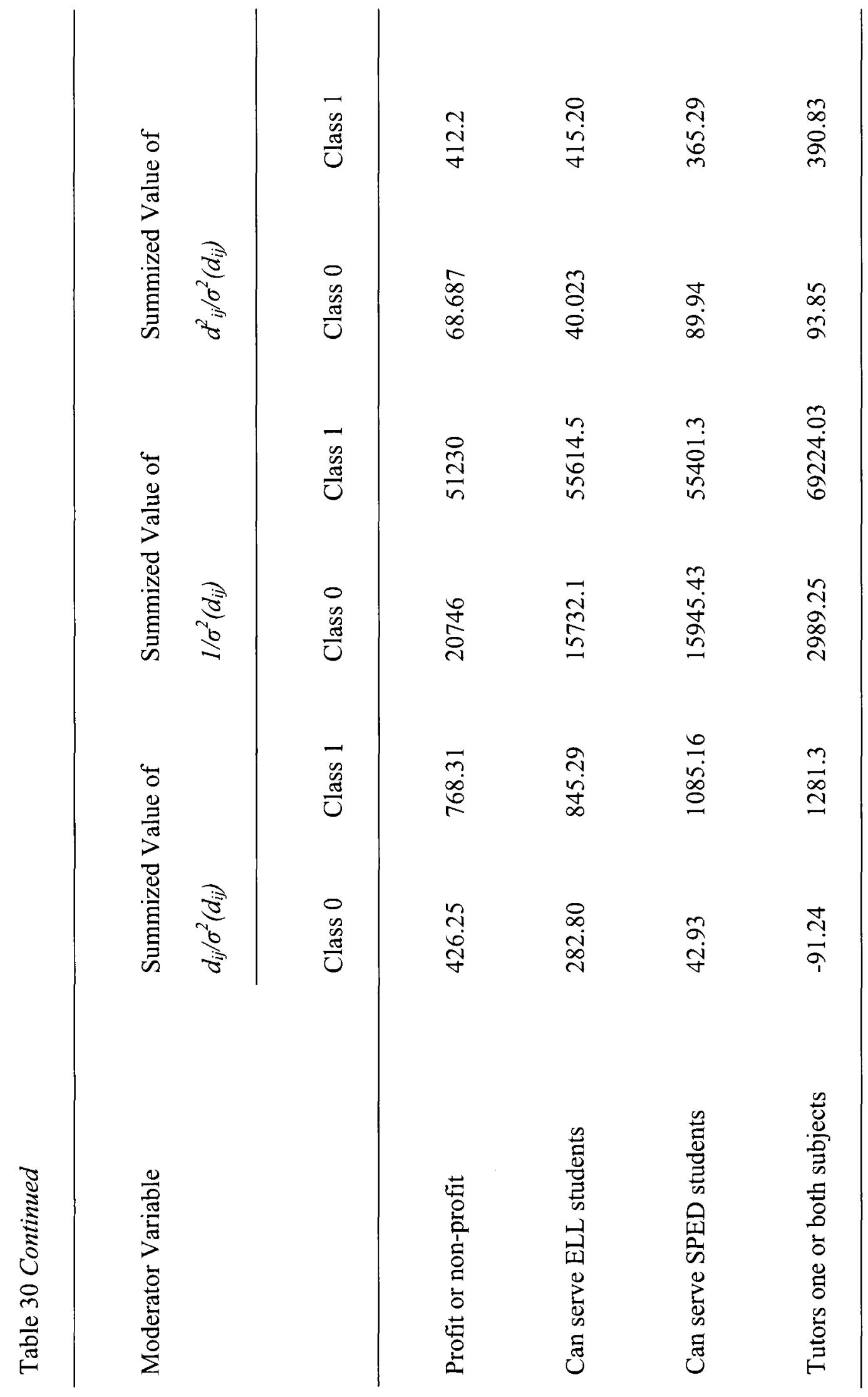


a

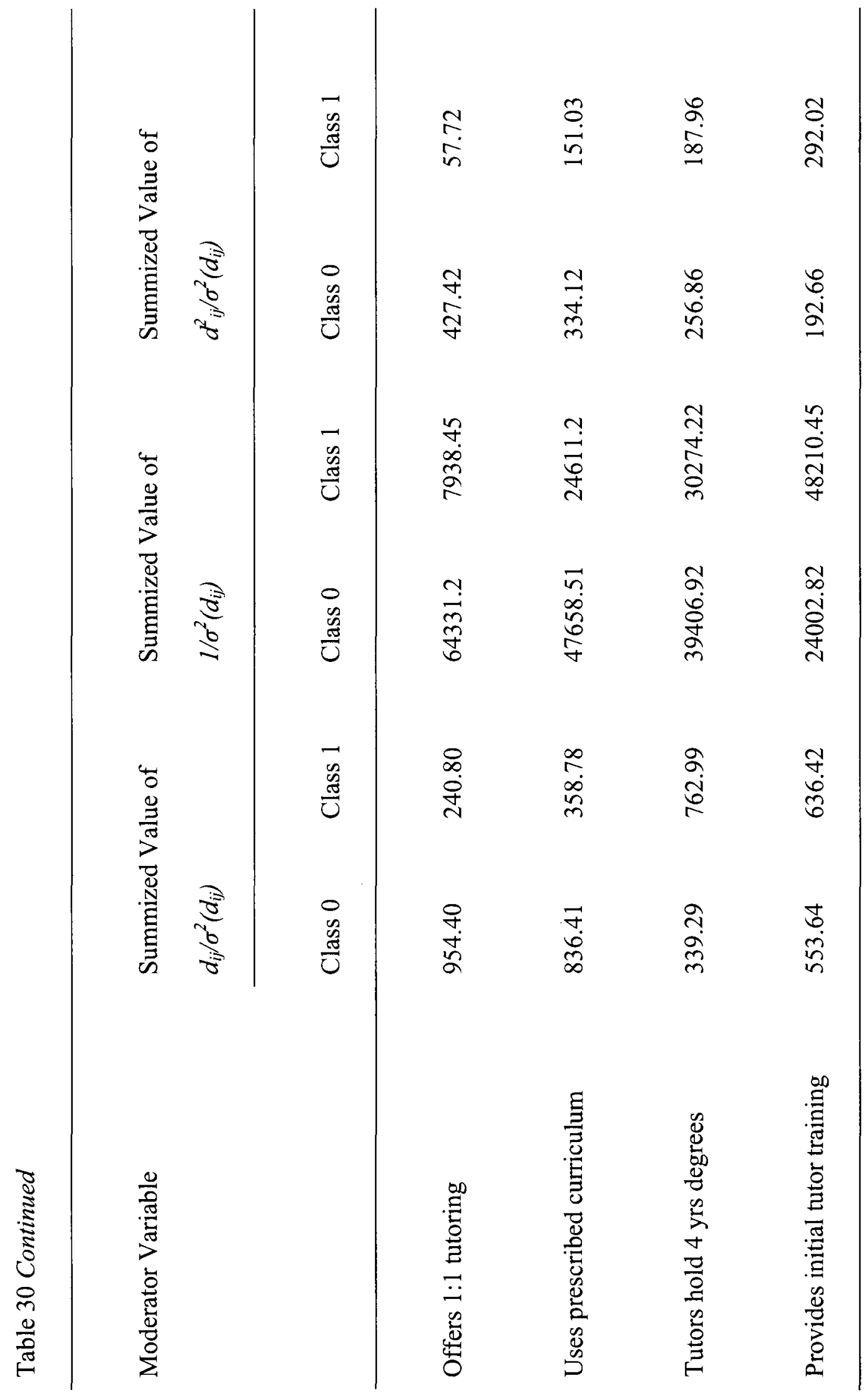


$\infty$

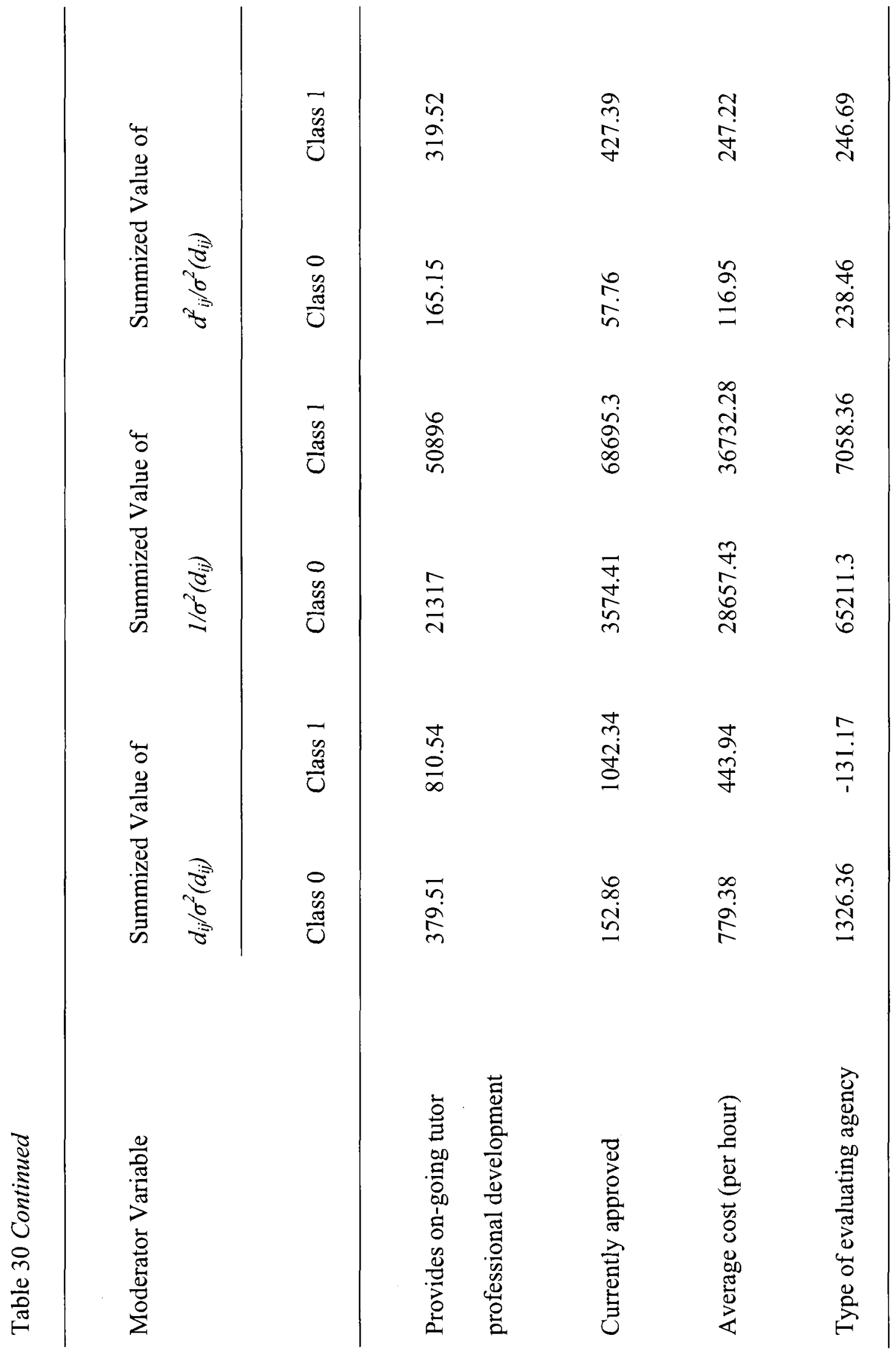


2

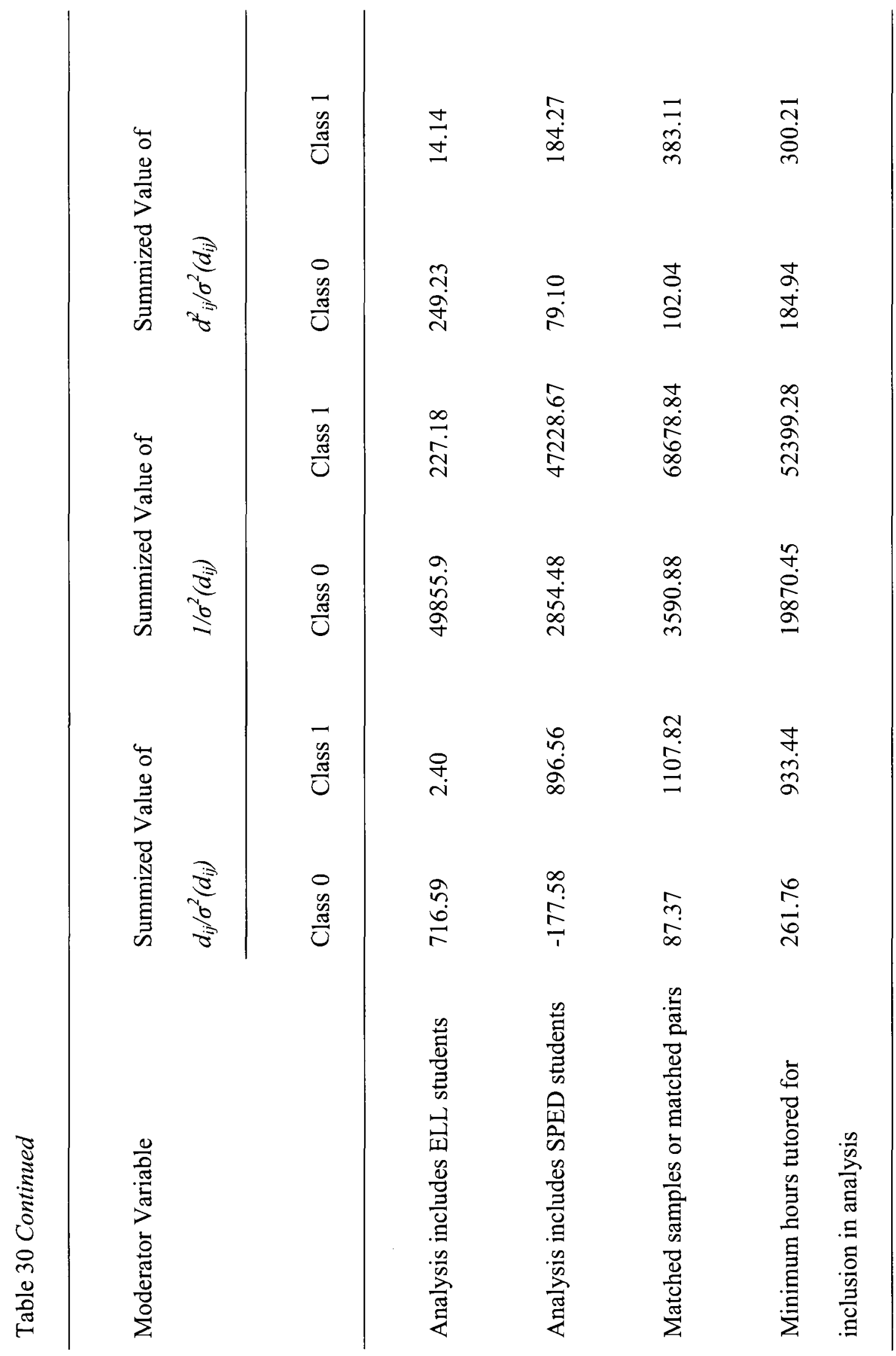


Each moderator variable in this analysis included only two classes; therefore, for each variable, two within-class $Q_{w}$ values were calculated. An overall within-class $Q_{w}$ and a between-class $Q_{b}$ were calculated for each variable using $d f=k-p$ for $Q_{w}, d f=p-1$ for $Q_{b}$, and $d f=k_{1}-1$ for $Q_{w l}$, and so on, where $k=$ number of effect sizes, $p=$ number of classes, and $k_{I}=$ number of effect sizes by class. Effect sizes were also then calculated for each class within each moderator variable.

Moderator variables containing data about SES provider characteristics were analyzed first to answer research question number two. For the reading provider moderator variable "Local District Providers," class 0 represents providers who were not local district providers and class 1 represents providers who were local district providers. The effect size of the non-district group, $d_{+0}=.014$, was slightly lower than the overall mean of $d_{+}=.017$ and was lower than the district group effect size of $d_{+1}=.024 . Q_{w}, Q_{w l}$, $Q_{w 2, \text { and }} Q_{b}$ values along with $p$ values for each of the within and between class fit statistics are reported in Table 31 . 
Table 31

$Q_{w}, Q_{w l}, Q_{w 0}, Q_{b}$, and $p$ values for Local District Reading Providers

Fit Statistic Degrees of

Local District Providers $\quad\left(X^{2}\right.$ value $) \quad$ Freedom $\quad p$ Value

$Q_{w}$ - Overall within-variable $\quad 464.18 \quad 399 \quad p=.0134$

$Q_{w I}-$ Non-district providers $\quad 3.85 \quad 5 \quad p=.5709$

$Q_{w 0}-$ District providers

460.33

394

$p=.0117$

$Q_{b}-$ Between Class

1

$p=.1345$

For the reading provider moderator variable "Nationally or locally based providers," class 0 represents locally based providers and class 1 represents nationally based providers, including national franchises. The effect size of the locally based providers $d_{+0}=.019$ was slightly higher than the overall mean of $d_{+}=.017$ and also slightly higher than the nationally based providers' effect size of $d_{+1}=.014$. Table 32 illustrates the $Q_{w}, Q_{w 1}, Q_{w 2}$, and $Q_{b}$ values along with $p$ values for each of the within and between class fit statistics. 
Table 32

$Q_{w}, Q_{w 1}, Q_{w 0}, Q_{b}$, and $p$ values for Nationally or Locally Based Reading Providers

Nationally or locally based

Fit Statistic

Degrees of

provider

( $X^{2}$ value)

Freedom

$p$ Value

$Q_{w}$ - Overall within-variable

464.82

397

$p=.0106$

$Q_{w 1}$ - Nationally based providers

281.63

226

$p=.007$

$Q_{w 0}-$ Locally based providers

183.19

171

$p=.2483$

$Q_{b}-$ Between Class

1.60

1

$p=.2059$

For the reading provider moderator variable "Online or face-to-face services," class 0 represents face-to-face services and class 1 represents online only services. The effect size of the face-to-face class $d_{+0}=.015$ was close to the overall mean of $d_{+}=.017$ but was substantially lower than the online class mean effect size of $d_{+1}=.053$. Table 33 illustrates the $Q_{w}, Q_{w 1}, Q_{w 2}$, and $Q_{b}$ values along with $p$ values for each of the within and between class fit statistics. 
Table 33

$Q_{w}, Q_{w 1}, Q_{w 0}, Q_{b}$, and $p$ values for Online or Face-to-Face Reading Providers

Online or Face-to-Face

Providers
Fit Statistic

$\left(X^{2}\right.$ value $)$
Degrees of

Freedom $p$ Value
$Q_{w}$ - Overall within-variable

$Q_{w l}-$ Online providers

$Q_{w o}-$ Face-to-face providers

$Q_{b}-$ Between Class
460.16

19.62

440.16

6.26
398

$p=.017$

18

$p=.4176$

380

$p=.0189$

$p=.0124$

For the reading provider moderator variable "Newly established or pre-existing providers," class 0 represents providers whose businesses were established during or after the year 2002 (the first year that SES were offered) and class 1 represents providers whose businesses were already established at the onset of the SES program. Those providers for whom an establishment date was not available were assumed to be newly established. It should also be noted that local district providers were classified as being newly established. The effect size of the newly established providers, $d_{+0}=.018$, was equivalent to the overall mean of $d_{+}=.017$ but was much higher than the effect size of 
the pre-existing providers $d_{+1}=-.006$. Table 34 illustrates the $Q_{w}, Q_{w 1}, Q_{w 2}$, and $Q_{b}$ values along with $p$ values for each of the within and between class fit statistics.

Table 34

$Q_{w}, Q_{w l}, Q_{w 0}, Q_{b}$, and $p$ values for Newly Established or Pre-Existing Reading Providers

Newly establish or pre-existing Fit Statistic Degrees of

providers $\quad\left(X^{2}\right.$ value $) \quad$ Freedom $\quad p$ Value

$Q_{w}$ - Overall within-variable $\quad 463.40 \quad 399 \quad p=.0142$

$Q_{w I}-$ Newly established providers $\quad 95.24 \quad 92 \quad p=.4162$

$Q_{w 0}-$ Pre-existing providers $\quad 368.16 \quad 307 \quad p=.0095$

$Q_{b}-$ Between Class $\quad 3.02 \quad 1 \quad p=.0822$

Although the within-class $p$ value for the newly established providers was not statistically significant, $p=.42$, those providers which were local district providers were removed from the analysis so that only newly established commercial providers remained in the analysis. In this analysis, the overall effect size of newly established providers 
decreased slightly to .016 , while the pre-existing providers' effect size of -.006 remained the same. Fit statistic and $p$ values for this analysis are illustrated in Table 35.

Table 35

$Q_{w}, Q_{w l}, Q_{w 0}, Q_{b}$, and $p$ values for Newly Established or Pre-Existing Reading Providers with Local District Providers Removed

Newly established or pre-

Fit Statistic

Degrees of

existing providers

( $X^{2}$ value)

Freedom

$p$ Value

$Q_{w}$ - Overall within-variable

458.93

392

$p=.0110$

$Q_{w l}-$ Newly established

94.62

92

$p=.4050$

providers with districts removed

$Q_{w 0}-$ Pre-existing providers

346.31

300

$p=.0338$

$Q_{b}-$ Between Class

7.49

1

$p=.0062$

For the reading provider moderator variable "Profit or non-profit providers," class 0 represents non-profit providers and class 1 represents for-profit providers. It should be noted that the local school district providers were classified as being non-profit providers. 
The effect size of the non-profit providers, $d_{+0}=.021$, was higher than the overall mean of $d_{+}=.017$ and the for-profit providers' effect size, $d_{+1}=.015$. Table 36 illustrates the $Q_{w}, Q_{w 1}, Q_{w 2,}$ and $Q_{b}$ values along with $p$ values for each of the within and between class fit statistics.

Table 36

$Q_{w}, Q_{w l}, Q_{w 0}, Q_{b}$, and $p$ values for Profit or Non-profit Reading Providers

\begin{tabular}{llll} 
Profit or Non-profit Providers & $\begin{array}{l}\text { Fit Statistic } \\
\left(X^{2} \text { value }\right)\end{array}$ & $\begin{array}{l}\text { Degrees of } \\
\text { Freedom }\end{array}$ & $p$ Value \\
\hline$Q_{w}-$ Overall within-variable & 460.61 & 388 & $p=.0065$ \\
$Q_{w l}-$ For-profit providers & 400.68 & 313 & $p=.0006$ \\
& & & \\
$Q_{w 0}-$ Non-profit providers & 59.93 & 75 & $p=.8977$ \\
$Q_{b}-$ Between Class & 5.80 & 1 & $p=.016$
\end{tabular}

For the reading provider moderator variable "Providers offering ELL services," class 0 represents providers who did not offer services to ELL students and class 1 represents providers who did offer services to ELL students. The effect size of the group 
not offering services to ELL students, $d_{+0}=.018$, was equivalent with the overall mean of $d_{+}=.017$ and was essentially equivalent to the effect size of the group offering ELL services, $d_{+1}=.015$ The statistically significant $p$ value for class 1 reflected that differences remained within the class's effect sizes but there were not sufficient data to subdivide the class and reanalyze the within- and between-class homogeneity. Table 37 illustrates the $Q_{w}, Q_{w 1}, Q_{w 2,}$ and $Q_{b}$ values along with $p$ values for each of the within and between class fit statistics.

Table 37

$Q_{w}, Q_{w l}, Q_{w 0}, Q_{b}$, and p values for Reading Providers Offering ELL Services

$Q_{w}$ - Overall within-variable

$Q_{w l}-$ Providers offering ELL services 402.36

$Q_{w}-$ Providers not offering ELL services

437.30

34.94
Providers Offering ELL Services

Fit Statistic Degrees of

$\left(X^{2}\right.$ value $) \quad$ Freedom $\quad p$ Value

363

$p=.0045$

313

$p=.0005$

50

$p=.9476$

$Q_{b}-$ Between Class

29.12 
Analysis of the reading provider moderator variable "Providers offering SPED services," in which class 0 represents providers not offering services to SPED students and class 1 represents providers who did offer services to SPED students was conducted next. The effect size of the group not offering SPED services, $d_{+0}=.0027$, was lower than the overall mean of $d_{+}=.017$ and the effect size of the group offering SPED services, $d_{+l}=.0196$. Table 38 reports the $Q_{w}, Q_{w 1}, Q_{w 2,}$ and $Q_{b}$ values along with $p$ values for the within and between class fit statistics.

Table 38

$Q_{w}, Q_{w l}, Q_{w 0}, Q_{b}$, and $p$ values for Reading Providers Offering SPED Services

Fit Statistic Degrees of

Providers Offering SPED services $\quad\left(X^{2}\right.$ value $) \quad$ Freedom $\quad p$ Value

$Q_{w}$ - Overall within-variable

433.86

363

$p=.0062$

$Q_{w 1}$ - Providers offering SPED services

344.04

286

$p=.0105$

$Q_{w 0}-$ Providers not offering SPED

89.82

77

$p=.1506$

services

$Q_{b}-$ Between Class

32.56

1

$p<.0001$ 
For the reading provider moderator variable "Providers offering math and reading tutoring," class 0 represents providers who offered only reading tutoring and class 1 represents providers offering tutoring for both math and reading subject areas. The effect size of the providers offering only reading tutoring, $d_{+0}=-.031$, was substantially lower than the overall mean of $d_{+}=.017$ and was also lower than the effect size of providers offering both math and reading tutoring, $d_{+l}=.0185 . Q_{w}, Q_{w l}, Q_{w 2,}$ and $Q_{b}$ values along with $p$ values for each of the within and between class fit statistics are reported in Table 39.

Table 39

$Q_{w}, Q_{w l}, Q_{w 0}, Q_{b}$, and $p$ values for Providers Offering Math \& Reading Tutoring

Providers Offering Math \& Reading Tutoring Fit Statistic Degrees of Services $\left(X^{2}\right.$ value $) \quad$ Freedom $\quad p$ Value

$Q_{w}$ - Overall within-variable

$Q_{w 1}$-Providers offering math $\&$ reading

tutoring

$Q_{w 0}-$ Providers offering only reading tutoring 91.06

$Q_{b}-$ Between Class

8.24

$Q_{b}-$ Between Class
458.18

367.12

398

$p=.0198$
352

46

$p<.0001$

$p=.2787$

.


For the reading provider moderator variable "Providers offering one-to-one tutoring," class 0 represents providers who did not offer one-to-one tutoring and class 1 represents providers who did offer one-to-one tutoring. The effect size of the non 1:1 group, $d_{+0}=.015$, was slightly lower than the overall mean of $d_{+}=.017$ and was moderately lower than the 1:1 group effect size of $d_{+1}=.030$. Table 40 illustrates the $Q_{w}$, $Q_{w 1}, Q_{w 2,}$ and $Q_{b}$ values along with $p$ values for each of the within and between class fit statistics.

Table 40

$Q_{w}, Q_{w l}, Q_{w 0}, Q_{b}$, and $p$ values for Reading Providers Offering 1:1 Tutoring

Providers Offering 1:1 Student to Tutor Ratio

$Q_{w}$ - Overall within-variable

$Q_{w 1}-$ Providers offering 1:1 tutoring

$Q_{w 0}-$ Providers not offering 1:1

tutoring

$Q_{b}-$ Between Class
Fit Statistic Degrees of $\left(X^{2}\right.$ value $) \quad$ Freedom $\quad p$ Value

463.68

399

$p=.0139$

50.42

73

$p=.9798$

413.27

326

$p=.0007$

2.73
1
$p=.0983$ 
The analysis for the reading provider moderator variable "Provider staff qualifications," class 0 represents providers whose tutors do not hold at least a 4-year degree and class 1 represents providers whose tutors hold at least a 4-year degree. The effect size of the non-degree holding group was $d_{+0}=.0086$, which was lower than both the overall mean of $d_{+}=.017$ and the degree-holding group's effect size of $d_{+1}=.0252$. Table 41 reports the $Q_{w}, Q_{w 1}, Q_{w 2}$, and $Q_{b}$ values along with $p$ values for each of the within and between class fit statistics.

Table 41

$Q_{w}, Q_{w 1}, Q_{w 0}, Q_{b}$, and $p$ values for Reading Provider Staff Qualifications

Fit Statistic Degrees of

Provider Staff Qualifications $\quad\left(X^{2}\right.$ value $) \quad$ Freedom $\quad p$ Value

$Q_{w}$ - Overall within-variable $\quad 422.67$

$p=.0042$

$Q_{w l}-$ Providers using only

167.73

136

$p=.0298$

degreed tutors

$Q_{w 0}-$ Providers using tutors $\quad 253.94$

213

$p=.0287$

with less than 4-yr degree

$Q_{b}$ - Between Class

43.75

1

$p<.0001$ 
For the reading provider moderator variable "Providers offering initial training for tutors," class 0 represents providers who did not indicate that they offered initial training for its tutors and class 1 represents providers who did offer initial training for its tutors. The effect size of the group which did not provide initial training was $d_{+0}=.023$, which was slightly higher than the overall mean of $d_{+}=.017$ but was somewhat higher than the effect size of the group which did provide initial training, $d_{+1}=-.013 . Q_{w}, Q_{w 1}, Q_{w 2}$, and $Q_{b}$ values along with $p$ values for each of the within and between class fit statistics are reported in Table 42 .

Table 42

$Q_{w}, Q_{w I}, Q_{w 0}, Q_{b}$, and $p$ values for Reading Providers Offering Initial Training for Tutors

Providers Offering Initial Training for Fit Statistic Degrees of

Tutors $\left(X^{2}\right.$ value $) \quad$ Freedom $\quad p$ Value

$Q_{w}$ - Overall within-variable

$Q_{w l}-$ Providers offering initial training

$Q_{w 0}-$ Providers not offering initial

training

$Q_{b}-$ Between Class
463.51

283.61

179.90

181
398

217

$p=.0016$

$p=.0129$ 
Analysis of the reading provider moderator variable "Providers offering on-going professional development for tutors," in which class 0 represents providers who did not indicate that they offered on-going professional development for tutors and class 1 represents providers who did offer on-going professional development for tutors was conducted next. The effect size of the group not offering on-going training, $d_{+0}=.0178$, the overall mean effect of $d_{+}=.017$, and the effect size of the group offering on-going training, $d_{+l}=.0159$ are all essentially equivalent. Table 43 illustrates the $Q_{w}, Q_{w l}, Q_{w 2}$, and $Q_{b}$ values along with $p$ values for each of the within and between class fit statistics.

Table 43

$Q_{w}, Q_{w 1}, Q_{w 0}, Q_{b}$, and $p$ values for Reading Providers Offering On-going Professional Development for Tutors

Providers Offering On-going Professional

Development for Tutors
Fit Statistic Degrees of

$\left(X^{2}\right.$ value $) \quad$ Freedom $\quad p$ Value
$Q_{w}$ - Overall within-variable

$Q_{w l}-$ Providers offering on-going training

$Q_{w 0}-$ Providers not offering on-going training

158.39

465.01

306.61

219

$p<.0001$

$Q_{b}-$ Between Class

$p=.8639$ 
For the reading provider moderator variable "Providers using a nationally prescribed curriculum," class 0 represents providers who did not indicate that they use a nationally prescribed curriculum and class 1 represents providers who did use a nationally prescribed curriculum. Note that some national providers use a proprietary curriculum; for this analysis, providers using a proprietary curriculum were classified as class 0 . The effect size of the group not using a prescribed curriculum, $d_{+_{0}}=.018$, was equivalent with the overall mean effect of $d_{+}=.017$ and was also essentially equivalent with the effect size of the group using a prescribed curriculum, $d_{+1}=.015 . Q_{w}, Q_{w 1}, Q_{w 2}$, and $Q_{b}$ values along with $p$ values for each of the within and between class fit statistics are reported in Table 44. 
Table 44

$Q_{w}, Q_{w l}, Q_{w 0}, Q_{b}$, and $p$ values for Reading Providers Using Prescribed Curriculum

Providers using a nationally $\quad$ Fit Statistic Degrees of

prescribed curriculum $\quad\left(X^{2}\right.$ value $) \quad$ Freedom $\quad p$ Value

$Q_{w}$ - Overall within-variable $\quad 465.24 \quad 399 \quad p=.0122$

$Q_{w l}-$ Providers using a prescribed $\quad 145.80 \quad 100 \quad p=.0019$

curriculum

$Q_{w 0}-$ Providers not using a

319.44

299

$p=.1992$

prescribed curriculum

$Q_{b}-$ Between Class

1.18

$1 \quad p=.2774$

For the reading provider variable "Average Cost per hour," class 0 represents those providers whose cost per hour was less than $\$ 52.23$, the mean cost per hour for all providers in the analysis, and class 1 represents those providers whose cost per hour was greater than $\$ 52.23$. The effect size for the providers whose cost per hour was less than $\$ 52.23, d_{+0}=.027$, was higher than the overall mean effect size of $d_{+}=.017$ and was also 
higher than the effect size for providers whose cost per hour was greater than $\$ 52.23, d_{+1}$

$=.012 . Q_{w}, Q_{w 1}, Q_{w 2,}$ and $Q_{b}$ values along with $p$ values for each of the within and between class fit statistics for this variable are reported in Table 45 .

Table 45

$Q_{w}, Q_{w l}, Q_{w 0}, Q_{b}$, and $p$ values for Reading Providers Average Cost per Hour

Fit Statistic Degrees of

Providers Average Cost Per Hour $\quad\left(X^{2}\right.$ value $) \quad$ Freedom $\quad p$ Value

$Q_{w}$ - Overall within-variable $\quad 337.61 \quad 276 \quad p=.0066$

$Q_{w l}-$ Providers with cost $/ \mathrm{hr}>\$ 52.23 \quad 241.86 \quad 158 \quad p<.0001$

$Q_{w 0}-$ Providers with $\operatorname{cost} / \mathrm{hr}<\$ 52.23 \quad 95.76 \quad 120 \quad p=.9496$

$\begin{array}{llll}Q_{b}-\text { Between Class } & 128.81 & 1 & p<.0001\end{array}$

For the reading provider moderator variable "Providers currently approved to offer SES," class 0 represents providers who are not currently approved to provide SES and class 1 represents providers who are currently approved to provide SES (currently approved is defined as being on the approved list for the academic year 2009-2010 for 
any state included in this analysis). The effect size of the not approved group was $d_{+_{0}}=$ .043 which was substantially higher than the overall mean of $d_{+}=.017$ and was also much higher than the currently approved group's effect size of $d_{+1}=.015$. Table 46 reports the $Q_{w}, Q_{w 1}, Q_{w 2}$, and $Q_{b}$ values along with $p$ values for each of the within and between class fit statistics.

Table 46

$Q_{w}, Q_{w l}, Q_{w 0}, Q_{b}$, and $p$ values for Reading Providers Currently Approved to Offer SES

Providers Currently Approved Fit Statistic Degrees of

to Offer SES $\quad\left(X^{2}\right.$ value $) \quad$ Freedom $\quad p$ Value

$Q_{w}$ - Overall within-variable $\quad 462.79$

399

$p=.0149$

$Q_{w l}$ - Providers currently

411.57

329

$p=.0013$

approved to provide services

$Q_{w 0}$ - Providers not currently $\quad 51.22$

70

$p=.9553$

approved to provide services

$Q_{b}-$ Between Class

3.62

1

$p=.057$ 
Analyses on the moderator variables containing data about the research methods used in the evaluations were conducted next to answer research question number three. For the methods moderator variable "Evaluating agency type," class 0 represents local (LEA) or state education agencies (SEA) (also referred to as internal) and class 1 represents an external evaluation agency. The effect size of the internal evaluator group was $d_{+0}=.020$ which was slightly higher than the overall mean of $d_{+}=.017$ and but was substantially higher than the external evaluator effect size of $d_{+1}=-.019$. Table 47 reports the $Q_{w}, Q_{w 1}, Q_{w 2,}$ and $Q_{b}$ values along with $p$ values for each of the within and between class fit statistics.

Table 47

$Q_{w}, Q_{w l}, Q_{w 0}, Q_{b}$, and $p$ values for Evaluating Agency Type - Reading

Evaluating Agency Type $\quad$ Fit Statistic Degrees of

(internal or external)

$\left(X^{2}\right.$ value $)$

Freedom

$p$ Value
$Q_{w}$ - Overall within-variable $\quad 455.73$

$Q_{w l}-$ External evaluation

244.25

$Q_{w 0}-$ Internal evaluation

211.48

185

214

$p=.076$

399

$p=.026$

$Q_{b}-$ Between Class

10.69

$p=.0011$ 
For the methods moderator variable "Evaluations which included ELL students," class 0 represents evaluations which did not include ELL students in the analysis and class 1 represents evaluations which did include ELL students in the analysis. The effect size of the evaluations which did not include ELL students was $d_{+0}=.014$ which was slightly lower than the overall mean effect of $d_{+}=.017$ and was essentially equivalent to the effect size of the evaluations which did include ELL students, $d_{+1}=.011$. Table 48 illustrates the $Q_{w}, Q_{w 1}, Q_{w 2,}$ and $Q_{b}$ values along with $p$ values for each of the within and between class fit statistics.

Table 48

$Q_{w}, Q_{w l}, Q_{w 0}, Q_{b}$, and $p$ values for Evaluations Which Included ELL Students - Reading

$\begin{array}{lll}\text { Evaluations Which Included ELL } & \text { Fit Statistic } & \text { Degrees of } \\ \text { Students } & \left(X^{2} \text { value }\right) & \text { Freedom }\end{array}$

$Q_{w}$ - Overall within-variable

253.04

167

$p<.0001$

$Q_{w 1}$. Evaluations including ELL students 14.11

15

$p=.5171$

$Q_{w 0}-$ Evaluations not including ELL

238.93

152

$p<.0001$

students

$Q_{b}-$ Between Class

213.38

1

$p<.0001$ 
For the methods moderator variable "Evaluations which included SPED students," class 0 represents evaluations which did not include SPED students in the analysis and class 1 represents evaluations which did include SPED students in the analysis. The effect size of the evaluations which did not include SPED students was $d_{+o}$ $=-.062$, which was substantially lower than the overall mean of $d_{+}=.017$ and was also substantially lower than the effect size of the evaluations which did include SPED students, $d_{+1}=.019$. Table 49 reports the $Q_{w}, Q_{w l}, Q_{w 2,}$ and $Q_{b}$ values along with $p$ values for each of the within and between class fit statistics.

Table 49

$Q_{w}, Q_{w 1}, Q_{w 0}, Q_{b}$, and $p$ values for Evaluations Which Included SPED Students - Reading

Evaluations Which Included SPED Fit Statistic Degrees of

Students ( $\quad\left(X^{2}\right.$ value $) \quad$ Freedom $p$ Value

$Q_{w}$ - Overall within-variable

$Q_{w l}$. Evaluations including SPED students

$Q_{w 0}-$ Evaluations not including SPED

students

$Q_{b}-$ Between Class
235.30

167.25

68.05
79

88

$p<.0001$

167

$p=.0004$

88

$$
p<.0001
$$

$p=.8055$ 
For the methods moderator variable "Evaluations which used matched pairs approach," class 0 represents evaluations which a matched sample approach in the analysis and class 1 represents evaluations which used a matched pairs approach in the analysis. The effect size of the matched sample group was $d_{+0}=.024$, which was slightly higher than the overall mean of $d_{+}=.017$ and was also higher than the matched pairs' group effect size of $d_{+1}=.016 . Q_{w}, Q_{w 1}, Q_{w 2,}$ and $Q_{b}$ values along with $p$ values for each of the within and between class fit statistics are reported in Table 50 .

Table 50

$Q_{w}, Q_{w 1}, Q_{w 0}, Q_{b}$, and $p$ values for Evaluations Using Matched Pairs Approach - Reading

Evaluations Using Matched Fit Statistic Degrees of

Pairs vs. Matched Samples $\quad\left(X^{2}\right.$ value $) \quad$ Freedom $\quad p$ Value

$Q_{w}$ - Overall within-variable $\quad 465.15$

399

$p=.0123$

$Q_{w l}$.Evaluations using

365.24

274

$p=.0002$

matched pairs sampling

$Q_{w 0}-$ Evaluations using

99.91

125

$p=.952$

matched samples approach

$Q_{b}-$ Between Class

1.27

1

$p=.2605$ 
For the methods moderator variable "Minimum hours tutored for inclusion in analysis," class 0 represents evaluations which required less than 15 hours of SES to be included in the analysis and class 1 represents evaluations which required more than 15 hours of SES to be included in the analysis. The effect size of the group requiring less than 15 hours was $d_{+0}=.013$ which was slightly lower than the overall mean of $d_{+}=.017$ and was also slightly lower than the effect size of the group requiring more than 15 hours of SES, $d_{+1}=.018$. Table 51 illustrates the $Q_{w}, Q_{w 1}, Q_{w 2,}$ and $Q_{b}$ values along with $p$ values for each of the within and between class fit statistics.

Table 51

$Q_{w}, Q_{w l}, Q_{w 0}, Q_{b}$, and $p$ values for Minimum Hours for Inclusion in Analysis - Reading

Minimum Hours for inclusion Fit Statistic Degrees of

in analysis $\quad\left(X^{2}\right.$ value $) \quad$ Freedom $\quad p$ Value

$Q_{w}$ - Overall within-variable $\quad 465.07$

227

$p<.0001$

$Q_{w l}$ - More than 15 hours

283.58

206

$p=.0003$

$Q_{w 0}$ - Less than 15 hours

181.49

21

$p<.0001$

$Q_{b}-$ Between Class

1.35

1

$p=.2460$ 
Because the within-class $p$ value for the evaluations including only students who received 15 or more hours of SES was statistically significant, $p<.0001$, subclassification and reanalysis were performed for those providers in this class. A frequency count of this class revealed that for minimum hours for inclusion $=18$ there was an $n$ of 130 , and for minimum hours for inclusion $=30$, there was an $n$ of 73 . Two new variables were created, one comparing effect sizes from evaluations which only included students receiving 18 or more hours of SES as compared to all other effect sizes and one comparing effect sizes from evaluations which only included students receiving 30 or more hours of SES as compared to all other students.

In the reading analysis comparing the 18 -hour group to all others, the effect size of the 18-hour group was $d_{+1}=.0007$ and the effect size of the comparison group was $d_{+0}$ $=.018$, revealing substantial differences in the effect sizes, though the between-group fit statistic of $Q_{b}=.1183$ did not reveal a statistically significant difference. Similarly, the analysis comparing the 30 -hour group to all others revealed an effect size for the 30 -hour group of $d_{+1}=.019$ and an effect size for the comparison group of $d_{+0}=.012$, with a between-class fit statistic of $Q_{b}=.1715$, indicating non significant differences between classes.

File Drawer Problem

Using Orwin's (1983) fail safe $n$ approach, the results revealed that for a criterion effect size of $.01,40,099$ reading effect sizes of 0.00 would be needed, or 2,864 evaluations. 


\section{CHAPTER V}

\section{DISCUSSION, RECOMMENDATIONS, \& CONCLUSION}

Research Question One: What are the mean provider effect size estimates in mathematics and reading?

The mean weighted effect size estimate in mathematics was calculated using data from 28 evaluations across 12 states or local school districts. A total of 400 effects were included in the math analysis, which revealed a mean weighted math effect size of 043 . The test for statistical significance revealed lower and upper confidence levels of .0353 .0499 , respectively, at the $95 \%$ level. This result indicates that the overall mean math effect of .043 was statistically significant despite being quite small.

For the reading analysis, 27 evaluations across 11 states or local school districts were included. Overall, the 401 reading effect sizes included revealed a mean weighted reading effect size of .017 . The test for statistical significance at the $95 \%$ level revealed lower and upper confidence levels of .0092 and .0238 , respectively, which indicates that the overall mean reading effect, though small, was also statistically significant.

Generally, effect sizes of .20 would be considered small, effect sizes of .50 would be considered moderate, and effect sizes of .80 would be considered large (Cohen, Manion, \& Morrison, 2000). However, in the context of educational research, a much lower and perhaps more concentrated scale is appropriate (Hill, Bloom, Black, \& Lipsey, 2008). Even in such a context, the effect size estimates revealed in this analysis are very small, particularly the reading outcome. The math results do align, though, with what some educational researchers believe may ultimately be all that can be expected from 3040 hours of SES tutoring over the duration of a school year: during the Supplemental 
Educational Services symposium at the 2009 annual meeting of the American Educational Research Association, experts stated that effect sizes of .05 to .15 may realistically be the result of SES (S. Ross, K. Wong, personal communication, April, 2009).

To appropriately interpret these effect sizes, they should be placed in the context and compared with the outcomes of other reform efforts. Meta-analyses of tutoring programs over the last quarter century have revealed much higher effects of tutoring on student achievement. For example, a meta-analysis of tutoring programs conducted by Cohen et al. (1982) revealed effect sizes of .29 for reading and .60 for math. A metaanalysis of volunteer tutoring programs conducted by Ritter et al. (2009) found a similar overall effect size for reading, .26 , and a .27 overall effect size for math tutoring. An examination of out-of-school-time instructional efforts conducted by Lauer et al. (2006) found a .07 overall effect size for reading and a .16 overall effect size for math programs, both of which are much lower than Cohen et al.'s (1982) and Ritter et al.'s (2009) findings but still substantially higher than what was found here.

When compared with other school reform efforts, the results of the analyses here are again found to be lacking. A meta-analysis of comprehensive school reform (CSR) efforts revealed an overall effect size of .15 (Borman, Hewes, Overman, \& Brown, 2003); according to Hill et al. (2008), this would substantiate a moderate to large program effect. The authors of that study concluded that CSR was positively impacting achievement on a school-wide basis and that effects were larger the longer the programs were in place (Borman et al., 2003). The results of the analyses conducted here imply that this is not the case with SES. Finally, a meta-analysis of all Title I programs from Title I's inception 
(1965) until 1994 revealed an overall effect of .11, which can be interpreted as a moderate effect (Hill et al., 2008) and is still much higher than the effect sizes of the SES program found here.

Though the effect sizes are very small, further analyses indicate that these estimated effect sizes can be interpreted with confidence of accuracy. For example, an examination of the confidence intervals for both subject areas revealed that neither set of intervals contained the value of zero, indicating that the null hypothesis (that the overall mean effect is equal to zero) can be rejected (Hedges \& Olkin, 1985). Furthermore, the fail-safe $n$ produced during the file-drawer problem analysis revealed that, to reflect even lower effect size levels of .01 for either math or reading, over 2,800 evaluations with nil results for either subject area would be necessary. Thus, each of the 50 states in the U.S. would need to have over 50 evaluations each; when considering this information, coupled with the fact that the SES program itself is only 7 years old, the effect sizes estimate results can be interpreted as being trustworthy (Long, 2001).

Research Question Two: How do provider effects vary as a function of provider characteristics for the mathematics and reading analyses?

For the math analysis, the results for the homogeneity of effects, where $p<.0001$, indicate that the math effect sizes were not homogeneous across studies. Similarly, results from the reading analysis revealed that the homogeneity of effects were also significant, $p<.0001$, revealing that reading effect sizes were not homogeneous across studies. These results further indicate that variances in the effects across studies may be attributable to the moderator variable (Hedges \& Olkin, 1985). As the analysis revealed very different results for the math and reading analyses by moderator variables, the results will be 
discussed within the context of the subject area, with the exception of the "Local District Provider" variable, for which results were comparable for the subject areas. This variable will be discussed first, followed by a discussion of providers moderator variables (research question two) for each subject area, then a discussion of methods moderator variables (research question three) by subject area.

\section{Local District Providers}

For both the math and reading analyses, local district providers, when compared to non-public or commercial providers, had a higher mean class effect size $\left(d_{+m l}=.094\right.$, $\left.d_{+r l}=.024\right)$ than the overall mean effect size of each subject area $\left(d_{++m}=.043, d_{++r}=\right.$ $.017)$ and than their non-public counterparts $\left(d_{+m 0}=.027, d_{+r 0}=.014\right)$. Figure 3 illustrates the differences among the three effect sizes for each subject area. These results suggest that local district providers may have a more substantial impact on student achievement. 


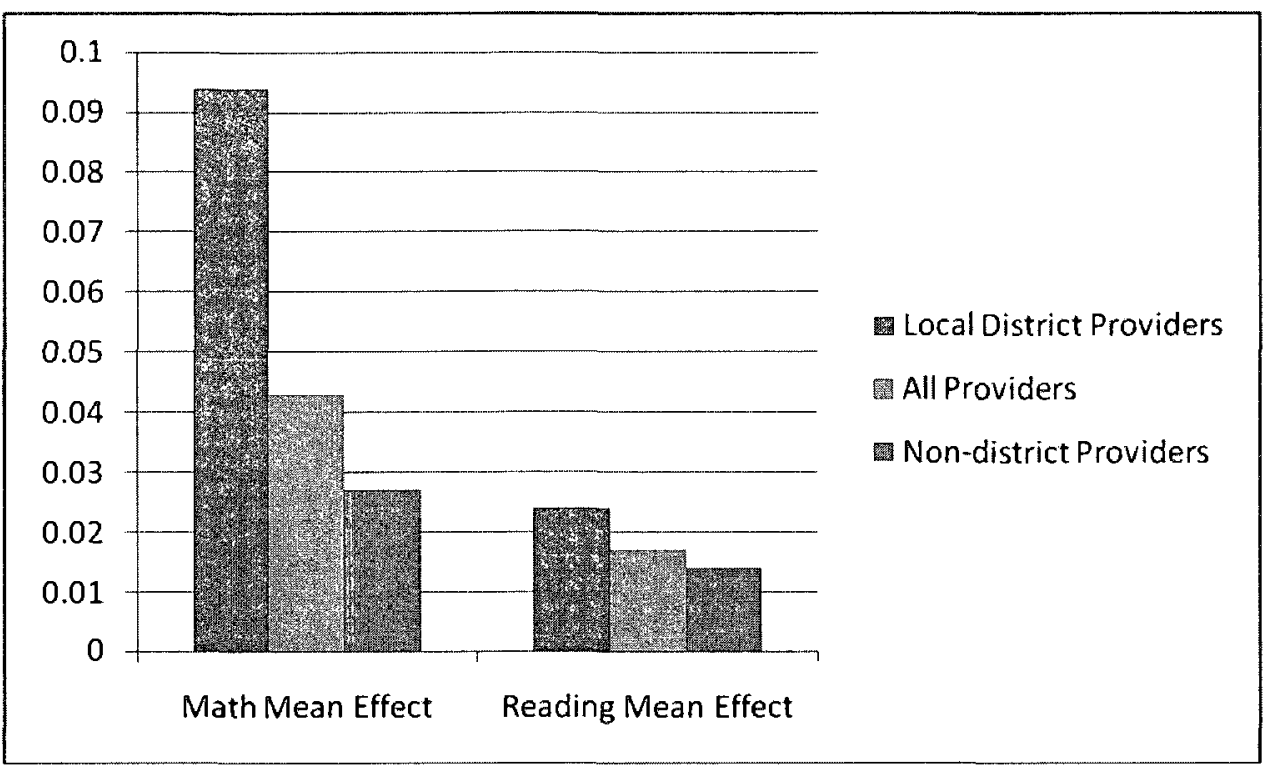

Figure 3. Mean Effect Sizes By Subject Area for Local District Providers as Compared to Overall Mean Effect Sizes and Non-District Providers

An argument could logically be made that local district providers share a combination of those characteristics which results which were found here to be influential in positively impacting student achievement. These characteristics include using tutors who hold at least a four-year degree, using a prescribed curriculum, offering tutoring in both subject areas, offering services to ELL and SPED students, and being a non-profit provider - all characteristics held by each district provider included in this analysis. A review of the literature on tutoring also indicates several of these same traits as being essential for a successful tutoring program (Cohen et al., 1982; Fashola, 1998; Topping, 2000; Wasik, 1998). These results also support the prediction of one SES researcher that SES programs, under the Obama administration, may move to a district-based provider system rather than the current program which uses mostly commercial providers (S. Ross, personal communication, April, 2009). 


\section{Math Provider Moderator Variables}

Results from the math provider moderator variables analyses revealed significant between-class differences for numerous variables and moderate to substantial differences in effect sizes for variables which did not have statistically significant between-class differences. The moderator variables "Nationally or locally based providers" and "Profit or non-profit providers" both had between-class fit statistic values of $p<.0001$, indicating substantial differences in effect sizes between classes. However, the results also revealed that both of these variables had statistically significant within-class differences in effect size for the locally based provider class and the non-profit class. Subsequent analyses were conducted with the local district providers removed from each variable (local providers were classified as non-profit); the results revealed that the effect size for the locally based providers decreased, as did the effect size for the non-profit providers. These findings suggest that at least some of the variance in the effect sizes for locally based and non-profit providers was attributable to local district providers, further supporting the stronger effect sizes found in the "Local District Provider" analysis discussed above. Figure 4 illustrates the mean effect sizes for both analyses for these two moderator variables. 


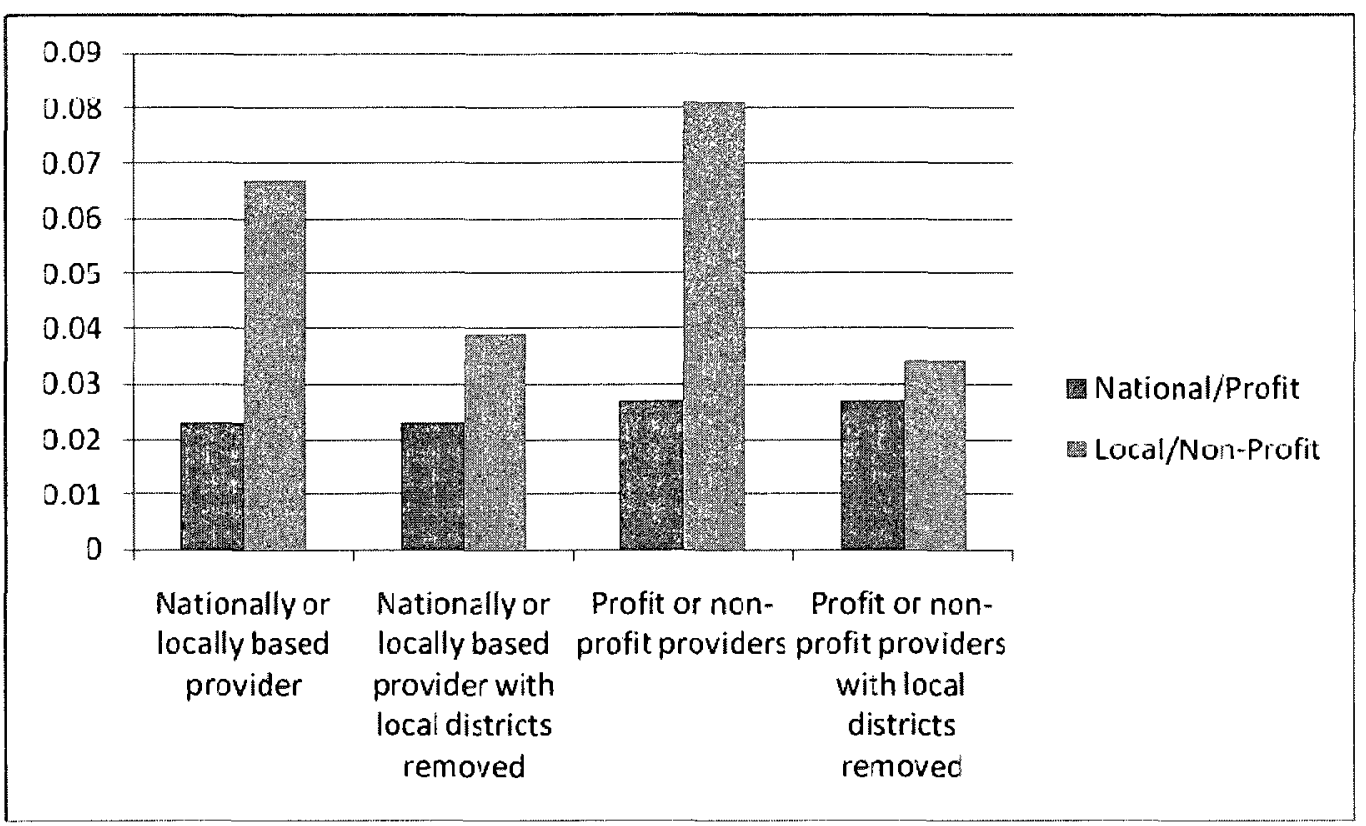

Figure 4. Mean Math Provider Moderator Variable Effect Sizes for Nationally or Locally Based Providers and Profit or Non-profit Providers

The math provider moderator variables "Provider staff qualifications," "Providers using a prescribed curriculum," and "Average cost per hour" all had between-class fit statistic values of $p<.0001$. The effect sizes were larger for providers whose tutors hold at least a four-year degree, providers using a prescribed curriculum, and providers whose cost per hour was less than $\$ 52$ (the mean cost per hour across providers) as illustrated in Figure 5. The effect sizes of these groups are also substantially larger than the overall mean math effect size of .043 . These results echo the literature which states that tutoring programs which employ qualified tutors (Fashola, 1998; Gordon, 2003) and which use quality instructional materials (Topping, 2000) are among those with the strongest potential for impacting student outcomes. 


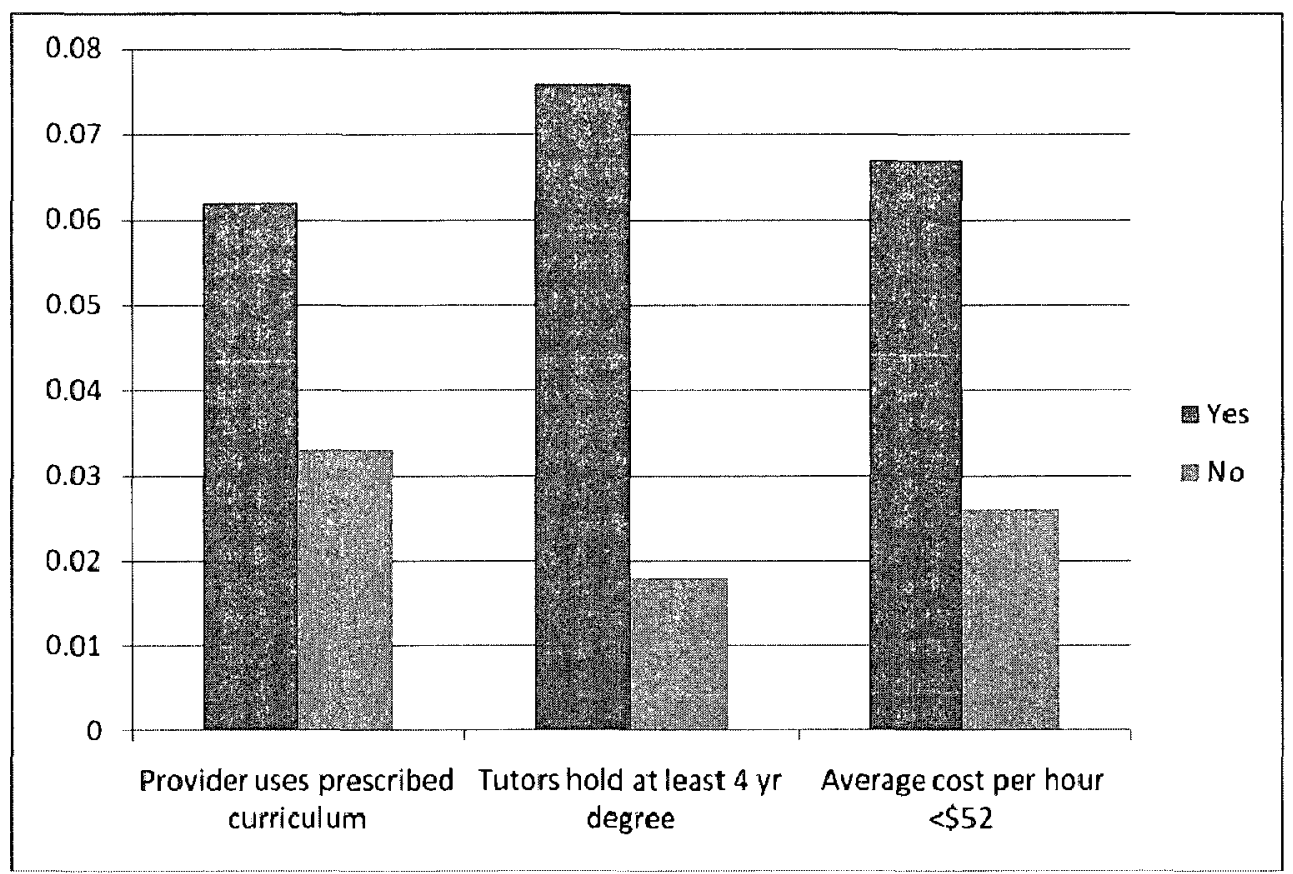

Figure 5. Mean Math Effect Sizes for Provider Moderator Variables with Statistically Significant Between-Class Differences

Other math provider moderator variables also had significant between-class fit statistic values; these variables, however, had only small to moderate differences in effect sizes between classes. The math provider variables "Providers offering ELL services," "Providers offering SPED services," "Providers offering initial training," and "Providers offering on-going training" each had between-class values of $p<.0001$. The results of the providers offering initial and on-going training support tutoring experts who feel that tutors should be provided clear, focused training before tutoring begins and that training should continue throughout the tutoring program to help tutors provide individualized instruction and to help tutors stay abreast of best practices (Fashola, 1998; Wasik, 1998; Topping, 2000). Effect sizes for each class for these four variables are reported in Figure 6. 


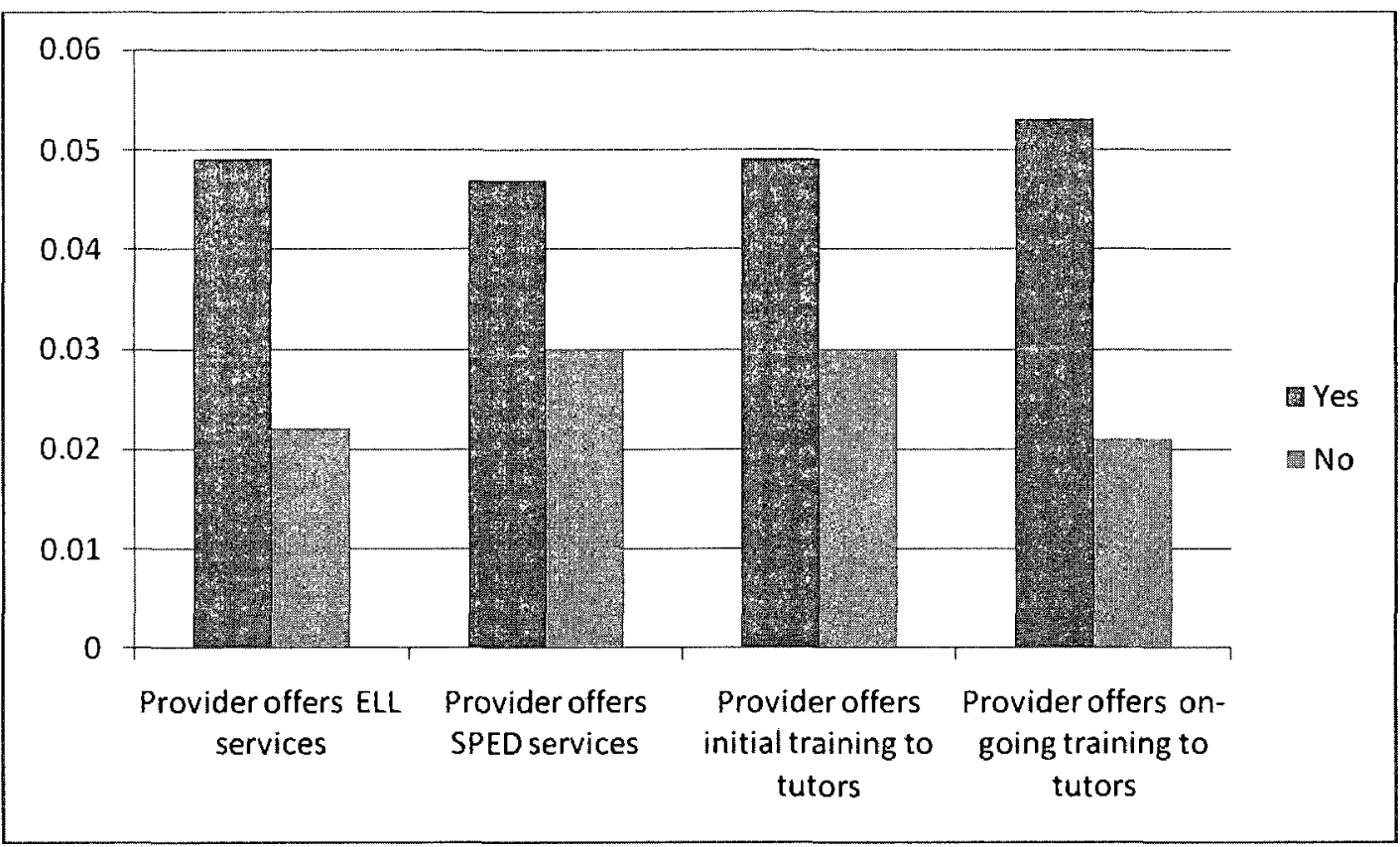

Figure 6. Mean Math Effect Sizes for Provider Moderator Variables with Small to Moderate Between-Class Differences

Other math provider moderator variables had between-class differences in effect size, though the differences were not statistically significant: the "Providers offering both math and reading tutoring" variable revealed a much stronger effect size for providers which offered both subject tutoring over those who offered only math tutoring. Additionally, results from the analysis of the "Providers offering 1:1 tutoring" revealed that the non 1:1 group had a higher effect size than the 1:1 group; a review of the literature, however, did indicate that small-group tutoring (1 instructor to 2-4 students) can be an effective strategy for math tutoring, while $1: 1$ tutoring is strongly recommended by experts for reading tutoring (Juel, 1996; Lauer et al., 2006). Effect sizes for these two variables are illustrated in Figure 7. 


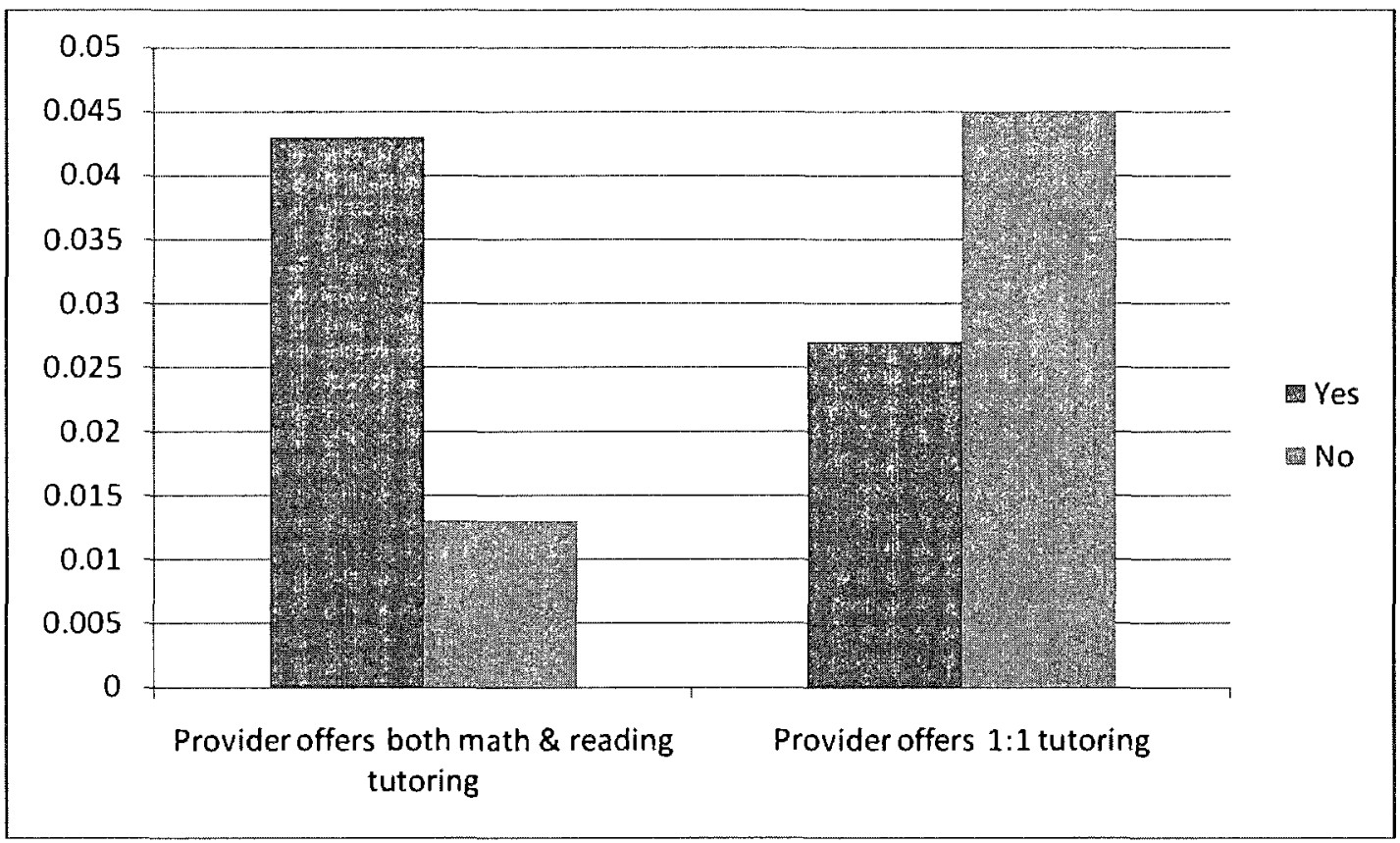

Figure 7. Mean Math Effect Sizes for Provider Moderator Variables without Significant Between-Class Differences

Results for the remaining math moderator variables "Online or face-to-face providers," "Newly established or pre-existing providers," and "Providers currently approved to offer services" revealed negligible differences between and within classes which neither support nor negate the literature.

\section{Reading Provider Moderator Variables}

Results from the reading provider moderator variables analyses revealed few differences within and/or between classes. This is contributed primarily to the small overall mean reading effect of .017 . However, some significant differences, particularly between classes of variables, were found. The moderator variables "Providers offering ELL services," "Providers offering SPED services," "Providers offering math and reading tutoring," "Average cost per hour," and "Provider staff qualifications" all had 
statistically significant between-class $p$ values. An examination of the effect sizes within each of these variables indicates that, except for the "Providers offering ELL services" variable, between-class effect size differences were substantial, with those providers offering SPED services, those offering both math and reading tutoring, those providers whose average cost was below the mean cost per hour, and those whose providers hold at least a four-year degree showing larger effect sizes. Though the literature concerning tutors' level of expertise varies among experts, the difference in effect sizes between providers whose tutors hold at least a 4-year degree and those who use non-degreed tutors supports researchers such as Fashola (1998) and Sanderson (2003), who feel that only well-qualified tutors provide the best experience for tutees. Figure 8 illustrates the differences in effect sizes for these four variables. 


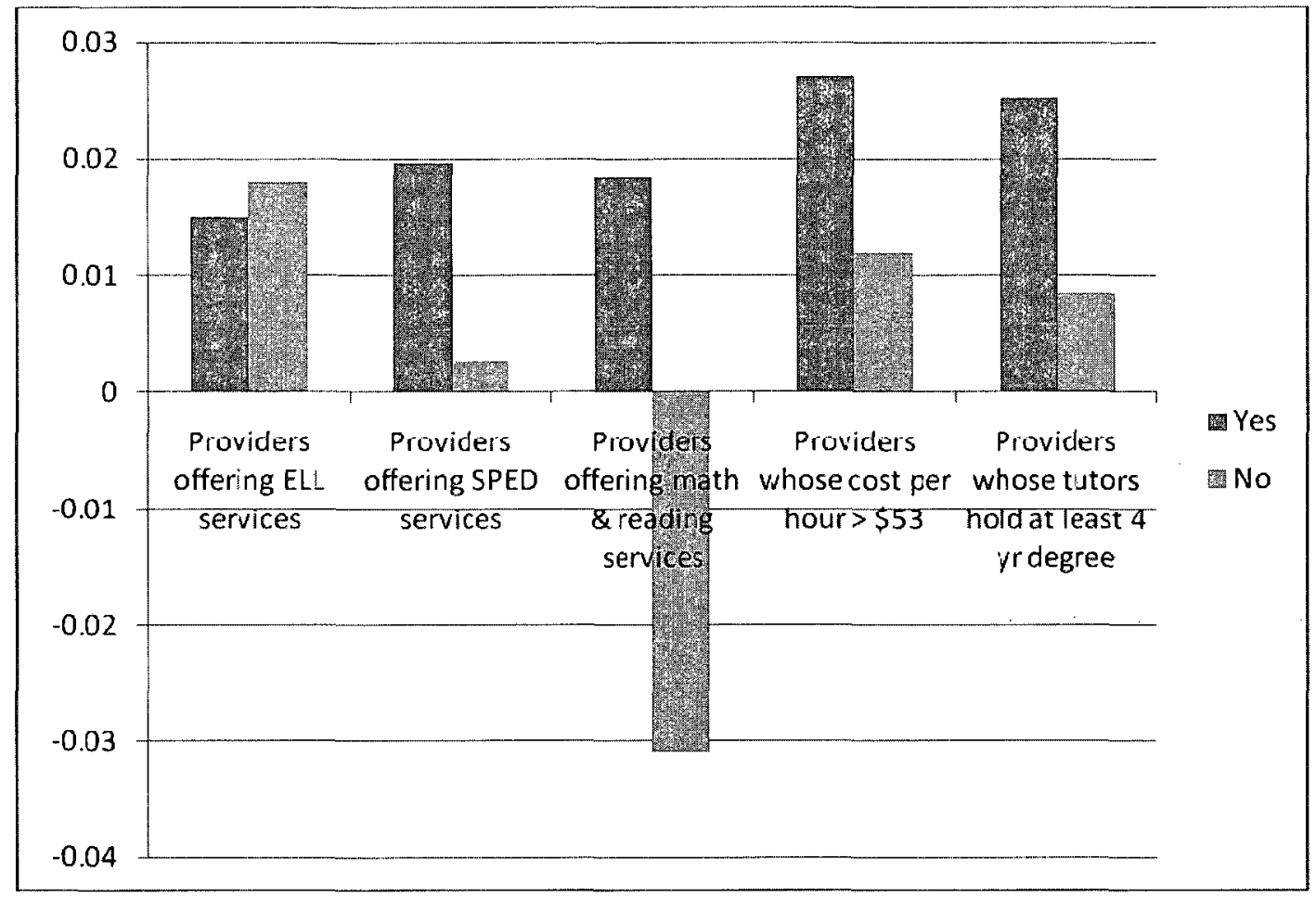

Figure 8. Mean Reading Effect Sizes for Provider Moderator Variables with Statistically Significant Between-Class Differences

Other reading provider moderator variables revealed moderate, though not statistically significant, differences in between-class effect sizes. Effect sizes were much higher for providers offering online services over face-to-face providers and for newly established providers over pre-existing agencies. It should be noted that local district providers and those providers for whom an establishment date was not available were classified as being newly established. Additionally, reading effect sizes were somewhat larger for providers offering one-to-one tutoring over those offering small- or largegroup tutoring, which is supported by the literature which states that one-to-one tutoring has had the strongest impact on the improvement of reading skills for tutees (Juel, 1996; 
Wasik, 1998; Lauer et al., 2006). Figure 9 highlights the differences in effect sizes between these reading provider moderator variables.

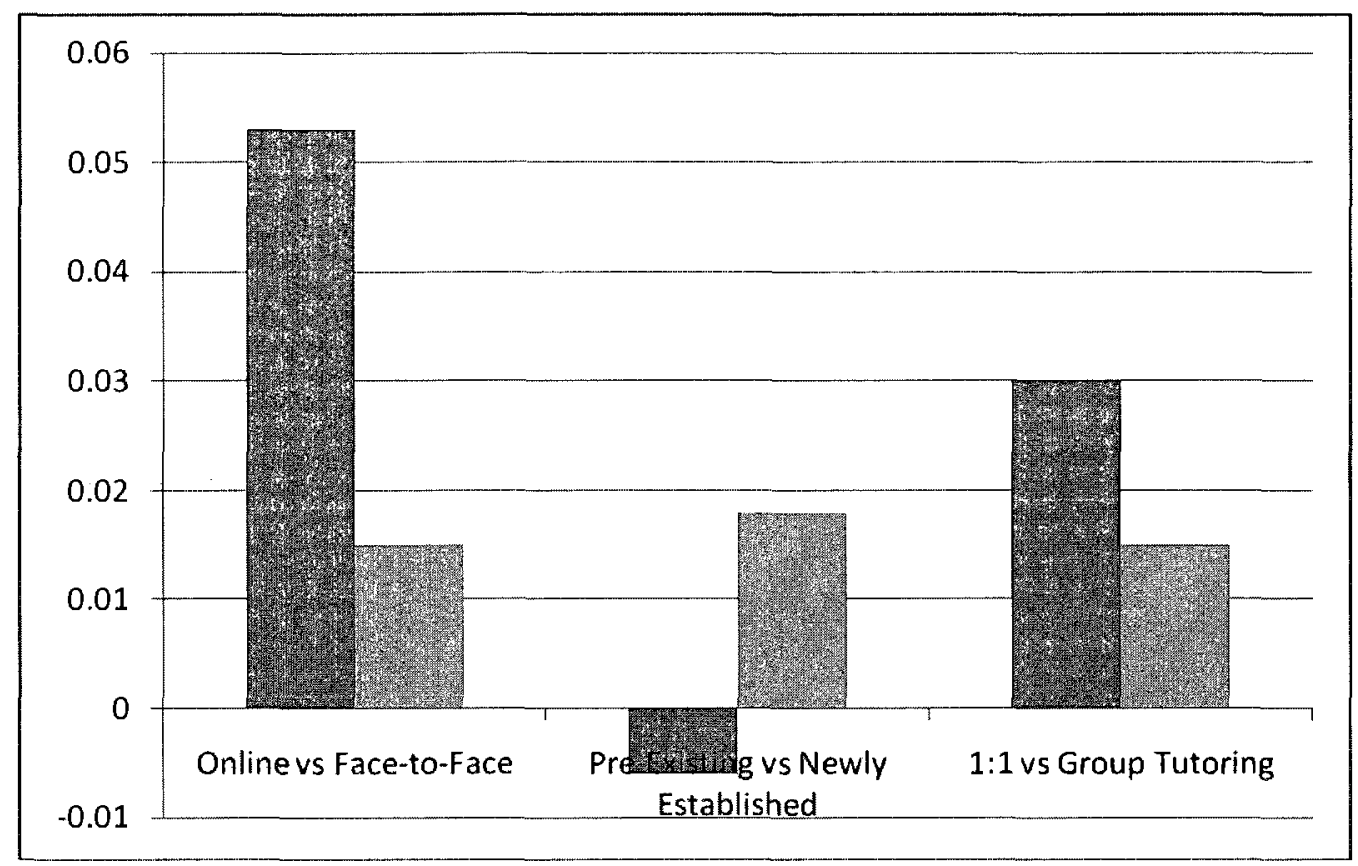

Figure 9. Mean Reading Effect Sizes for Provider Moderator Variables with Moderate Between-Class Differences

Between-class differences in the remaining reading provider moderator variables ("Nationally or locally based providers," Profit or non-profit providers," "Providers using prescribed curriculum," "Providers offering initial training," "Providers offering on-going training," and "Currently approved providers") were small or nil and neither supported nor refuted the literature on tutoring programs.

Research Question Three: How do provider effects vary as a function of the methodology used to estimate them?

The results for the analyses of math methods moderator variables indicated statistically significant between-class outcomes for the "Evaluations including ELL 
students," "Evaluations including SPED students," and "Minimum hours for inclusion" variables. Examination of the effect sizes for each class within these variables also revealed a substantial difference in effects between groups, with evaluations not including ELL students, evaluations including SPED students, and minimum hours for inclusion greater than 15 hours of SES having stronger effect sizes. The remaining two methods moderator variables did not have statistically significant between-class $p$ values, but there were moderate differences in the effect sizes of the classes within each variable. Figure 10 illustrates the differences for the five math methods moderator variables.

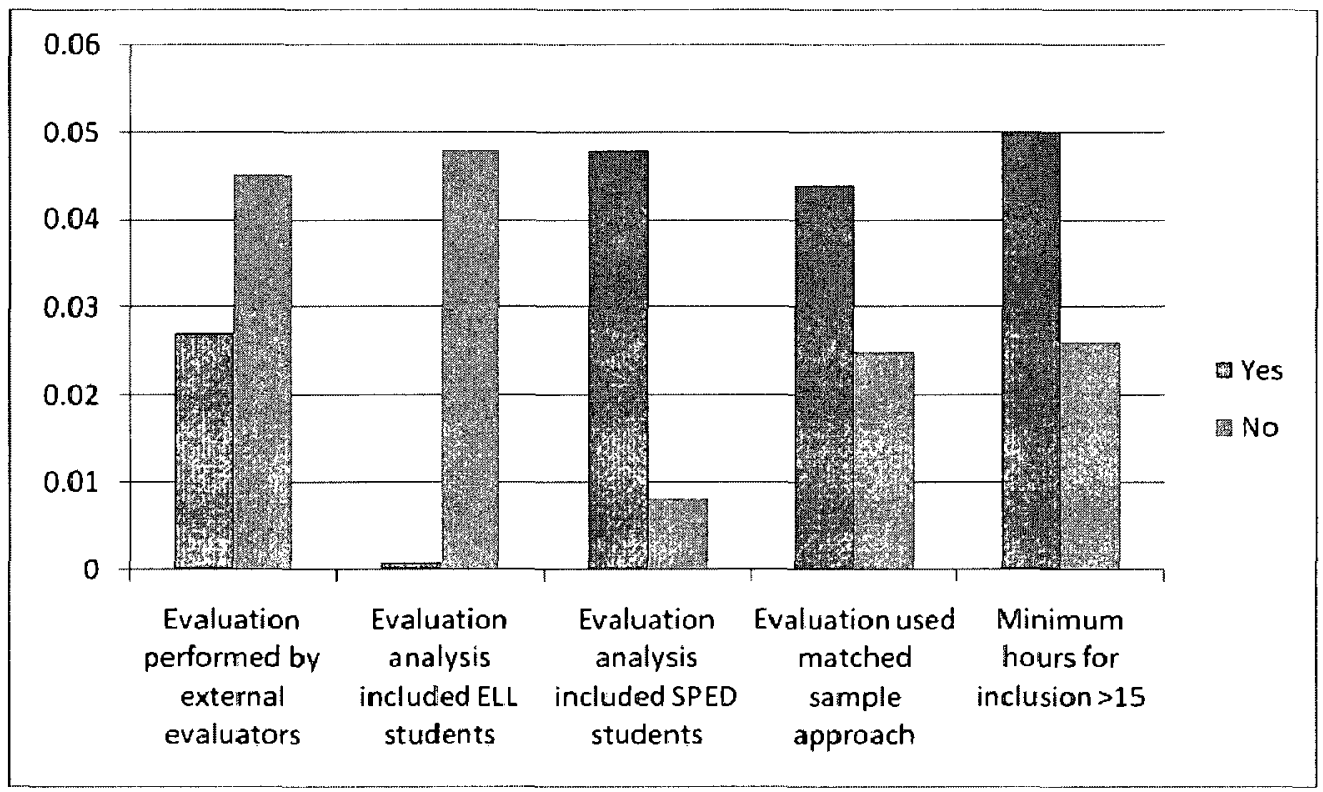

Figure 10. Mean Math Effect Sizes for Methods Moderator Variables

The analysis of reading methods moderator variables revealed that several of these variables had statistically significant between-class $p$ values, indicating a difference in effect sizes for each of the classes within variables. The "Evaluating agency type," "Evaluations which included ELL students," and "Evaluations which included SPED 
students" variables each revealed between-class fit statistics of $p<.0001$. The other two methods moderator variables did have a moderate difference in effect size between classes, though the between-class fit statistics for "Evaluations using matched pairs" and "Minimum hours for inclusion in analysis" were not statistically significant. For the "Evaluation used matched sample approach," the "no" group used a matched-pairs sampling approach and for the "Minimum hours in inclusion" variable, the "no" group required greater than 15 hours of SES for inclusion in the analysis. Figure 11 reports differences in effect sizes for the five reading methods moderator variables.

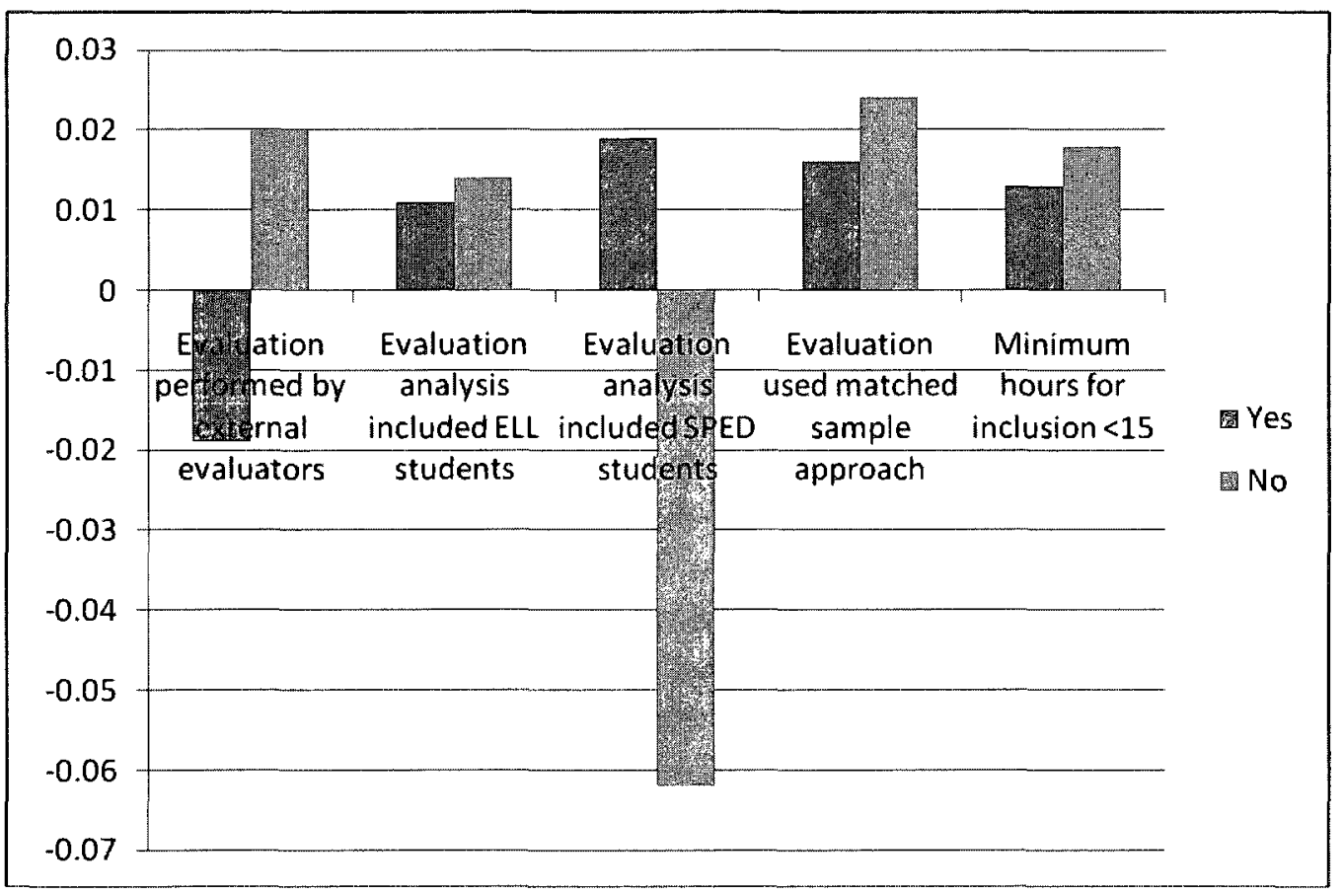

Figure 11. Mean Reading Effect Sizes for Methods Moderator Variables

These results should be interpreted with caution, however. There is not enough data in this analysis to support either negative or positive findings as being a more precise measure of student achievement for either subject area. For example, it is unclear if the 
lower effect size findings for the "External evaluator" and "ELL included" could be the result of more rigorous evaluation methods or other unmeasured variables. Further study is needed to more accurately define a model of effectiveness for conducting SES program evaluations to measure the program's impact on student achievement scores.

\section{Recommendations}

Based on the results of this meta-analysis, there are two recommendations for future study which could help present a broader view of the effectiveness of the SES program. First, using the v-known Hierarchical Linear Model (Bryk \& Raudenbush, 1992) would allow researchers to conduct a multi-level regression analysis. While this meta-analysis was thorough, it independently analyzed each moderator variable. The vknown HLM method would create a model for measuring effect sizes for a combination of moderator variables to create a more clearly defined description of the characteristics which have the strongest potential to positively impact student achievement.

Second, since the primary goal of NCLB (2001) is for students to reach levels of proficiency in core academic subjects, it would be interesting to focus evaluation methods on the movement of students between the established levels of proficiency. Some state and districts have done this (Potter \& Ross, 2005; Potter et al., 2007; Ross, Harmon, \& Wong, 2009), but the trend in evaluations seems to have moved from identifying changes in proficiency levels to measuring effect sizes. Certainly the latter is also important, but as states already measure proficiency levels, it seems that including this variable in evaluations would not involve an extraordinary effort and may reveal more optimistic results from the SES program by linking SES with students who successfully moved from below standard to a level of proficiency. 


\section{Conclusion}

The findings here suggest that the overall effect of SES on student achievement is quite small, particularly given the size and scope of the program. Considering the implications of the program to narrow or close the achievement gap by improving proficiency scores of historically underperforming populations, it is clear that SES program implementation and maintenance efforts should focus on those characteristics which have been shown here, and which support the literature, to have the strongest potential to create an ideal tutoring experience. Those characteristics include the use of local district providers; experienced (degreed), well-trained tutors; a national or prescribed curriculum; and, for reading instruction, one-to-one tutoring. Effect sizes estimates for both the math and reading analysis were higher than the estimated overall mean effect size for providers who exhibited these characteristics. Though the range of effect sizes for both math and reading reveals that some SES programs can be linked to improvements in student achievement, the results also indicate that there is still much work to be done before this program can be considered successful.

The findings from the methods moderator variables, however, aren't as straight forward. The results suggest that evaluations which excluded ELL students but included SPED students revealed higher effect sizes, but other methods indicated quite different results by subject area. In the math analysis, for example, the matched sample approach resulted in higher effect sizes but in the reading analysis, the matched pairs approach had a larger effect size. The minimum hours of SES received for inclusion moderator also varied by subject area. These findings suggest that further study is needed to more clearly identify the most precise evaluation method for SES programs; creating a rigorous 
evaluation model may help states and districts perform evaluations which do not result in accurate overall effects regardless of the direction (positive or negative) of the findings. Though the results here provide a one-dimensional view of provider and methods characteristics, the findings support two general conclusions. Ultimately, it appears that we can be cautiously optimistic of the potential for SES to positively impact student achievement, at least for math scores, under certain conditions. Yet, at the same time, very little of what has been done in the reading subject area would allow for a model of effectiveness to be formulated to meet the goals of the Title I and SES programs. As more state and district SES evaluations emerge, perhaps a clearer description of effective programs will materialize to drive the future of the SES program and to inform overall reform efforts. 


\section{References}

References marked with an asterisk indicate studies included in the meta-analysis.

*Allen, M. (2008). Assessing the effectiveness of Supplemental Educational Services in urban Florida school districts (Doctoral dissertation, Florida State University, 2008). (UMI No. 3322897)

Baker, J., Rieg, S., Clendaniel, T. (2006). An investigation of an after school math tutoring program: University tutors + elementary students $=$ a successful partnership. Education, 127(2), 287-293.

Barley, Z. \& Wegner, S. K. (2007). Access to Supplemental Educational Services in the Central Region states (Issues \& Answers Report, REL 2007-No. 007).

Washington, DC: U. S. Department of Education, Institute of Education Sciences, National Center for Education Evaluation and Regional Assistance, Regional Educational Laboratory Northwest.

Retrieved September 28, 2008 from http://ies.ed.gov/ncee/edlabs.

*Barnhart, M. (2009). The impact of participation in Supplemental Educational Services (SES) on student achievement: 2007-2008. Los Angeles, CA: Los Angeles Unified School District, Research and Planning, Pub. No. 2009-04.

Bathon, J. \& Spradlin, T. (2007). Outcomes of the School Choice and Supplemental Educational Services provisions of NCLB. Bloomington, IN: Center for Evaluation and Education Policy.

Bennett, A., Bridgall, B., Cauce, A.M., Everson, H., Gordon, E., Lee, C., et al. (2004). All students reaching the top: Strategies for closing the achievement gaps. A 
report of the National Study Group for the Affirmative Development of Academic Ability. Naperville, IL: Learning Point Associates.

Borman, G. \& D'Agostino, J. (1996). Title I and student achievement: A meta-analysis of federal evaluation results. Educational Evaluation and Policy Analysis, 18, 309326.

Borman, G., Hewes, G., Overman, L., \& Brown, S. (2003). Comprehensive School Reform and achievement: A meta-analysis. Review of Educational Research, 73, $125-230$.

Bryk, A. \& Raudenbush, S. (1992). Hierarchical linear models: Applications and data analysis. Newbury Park, CA: Sage Publications.

Burns, M., Senesac, B., \& Symington, T. (2004). The effectiveness of the HOSTS program in improving the reading achievement of children at-risk for reading failure. Reading Research and Instruction, 43(2), 87-104.

Center for Innovation and Improvement. (2008). State evaluation of SES providers. Retrieved February 12, 2009 from http://www.centerii.org/techassist/providers/. *Chicago Public Schools. (2007). SES Tutoring Programs: An evaluation of year 3 in the Chicago Public Schools. Chicago, IL: Office of Research, Evaluations, and Accountability \& Office of Extended Learning Opportunities, Author.

Cohen, L., Manion, L., \& Morrison, K. (2000). Research methods in education. London: Routledge Falmer.

Cohen, P., Kulik, J., \& Kulik, C. (1982). Educational outcomes of tutoring: A metaanalysis of findings. American Educational Research Journal, 19(2), 237-248.

Colasanti, M. (2007). Examples of state monitoring and evaluation of Supplemental 
Educational Service providers. Denver, CO: Education Commission of the States.

Darling, S. (2008). Family must be a part of the solution in closing the Achievement Gap. The Clearing House, 81(6), 245-246.

Evans, R. (2005). Reframing the Achievement Gap. Phi Delta Kappan, 86(8), 582-589.

Fashola, O. (1998). Building effective afterschool programs. Thousand Oaks, CA: Corwin Press.

*Ford, J., Harrison, L., Neergaard, L., Qian, H., Zoblotsky, T., McKay, D. et al. (2009). Supplemental Educational Services in the commonwealth of Virginia: 2007-2008. Memphis, TN: The University of Memphis, Center for Research in Educational Policy.

*Gallagher, B. \& Zoblotsky, T. (2009). Supplemental Educational Services in the state of North Carolina: 2006-2007 Student Achievement Analysis. Memphis, TN: The University of Memphis, Center for Research in Educational Policy.

*Gallagher, B. \& Zoblotsky, T. (2009). Supplemental Educational Services in the state of North Carolina: 2007-2008 Student Achievement Analysis. Memphis, TN: The University of Memphis, Center for Research in Educational Policy.

Glass, G., McGaw, B., \& Smith, M.L. (1981). Meta-analysis in social research. Newbury Park, CA: Sage Publications, Inc.

Gordon, E. (2003). Looking beyond the stereotypes: Ensuring the true potential of tutoring. Phi Delta Kappan, 84(6), 456-459.

Hedges, L. \& Olkin, I. (1985). Statistical methods for meta-analysis. San Diego, CA: Academic Press, Inc. 
Hill, C., Bloom, H., Black, A., \& Lipsey, M. (2008). Empirical benchmarks for interpreting effect sizes in research. Child Development Perspectives, 2(3), 172177.

*Inazu, J., Anderson, D., Holmes, J., Marker, N., Oda, E. A., Uyeno, R. et al. (2007). Evaluation of Supplemental Educational Services (SES) in Hawaii for school year 2005-2006. Manoa: University of Hawaii, Social Science Research Institute.

*Inazu, J., Anderson, D., Holmes, J., Marker, N., Oda, E. A., Uyeno, R. et al. (2008). Evaluation of Supplemental Educational Services (SES) in Hawaii for school year2 (2006-2007). Manoa: University of Hawaii, Social Science Research Institute.

*Jones, C. (2007). The 2007 Supplemental Educational Services program: Year 4 summative evaluation. Chicago, IL: Chicago Public Schools, Office of Extended Learning Opportunities.

*Jones, C. (2009). The 2008 Supplemental Educational Services program: Year 5 summative evaluation. Chicago, IL: Chicago Public Schools, Office of Extended Learning Opportunities.

Juel, C. (1996). What makes literacy tutoring effective? Reading Research Quarterly, 31(3), 268-289.

Lauer, P., Akiba, M., Wilkerson, S., Apthorp, H., Snow, D., \& Martin-Glenn, M. (2006). Out-of-school time programs: A meta-analysis of effects for at-risk students. Review of Educational Research, 76(2), 275-313.

Lietz, P. (2006). A meta-analysis of gender differences in reading achievement at the secondary school level. Studies in Educational Evaluation, 32, 317-344. 
Long, J. (2001). An introduction to and generalization of the "Fail-Safe N." New

Orleans, LA: Paper presented at the annual meeting of the Southwest Educational Research Association, February, 2001.

*Marquez, S. A. \& Kovacic, C. B. (2007). Supplemental Educational Services evaluation report 2006-2007. Santa Fe, NM: New Mexico Public Education Department.

Maryland State Department of Education. (2005). Maryland School Assessment (MSA) fact sheet. Retrieved March 31, 2009 from http://www.marylandpublicschools.org.

Maryland State Department of Education. (2007a). Maryland School Assessment - Math: Grades 3 through 8. Technical report: 2007 administration. Baltimore: Maryland State Department of Education.

Maryland State Department of Education. (2007b). Maryland School AssessmentReading: Grades 3 through 8. Technical report: 2007 administration. Baltimore: Maryland State Department of Education.

Maryland State Department of Education. (2008). School improvement in Maryland: Voluntary School Curriculum. Retrieved March 31, 2009 from http://www.mdk12.org/instruction/curriculum/index.html.

Mathis, W. (2005). Bridging the Achievement Gap: A bridge too far? Phi Delta Kappan, 86(8), $590-593$.

*McKay, D., Paek, J., Harrison, L., Qian, H., Zoblotsky, T., Ross, S. et al. (2008). Supplemental Educational Services in the state of Virginia: 2006-2007. Memphis, TN: The University of Memphis, Center for Research in Educational Policy.

Moss, M., Swartz, J., Obeidallah, D., Stewart, G., \& Greene, D. (2001). AmeriCorps tutoring 
outcomes study. Cambridge, MA: Abt Associates, Inc.

*Munoz, M. \& Ross, S. (2008). 2006-2007 Evaluation of Supplemental Educational Services in Kentucky: Student achievement analysis in Jefferson County Public Schools. Memphis, TN: The University of Memphis, Center for Research in Educational Policy.

*Munoz, M., Ross, S., \& Neergaard, L. (2009). Does Supplemental Educational Services raise student achievement? Test outcomes and consumer perceptions in a large urban district. Jefferson County, KY: Jefferson County Public Schools, Accountability, Research, and Planning Department.

National Center for Education Statistics. (2008). Trends in the achievement gaps in reading and mathematics. Washington, DC: Author. Retrieved March 12, 2009 from http://nces.ed.gov/programs/coe/2008/section2/indicator16/asp.

*Neergaard, L., Harrison, L., Ford, J., Paek, J., Ross, S. \& Mount, A. (2008). Supplemental Educational Services in the state of Tennessee: 2007-2008 Student Achievement Results. Memphis, TN: The University of Memphis, Center for Research in Educational Policy. No Child Left Behind Act. (2001). Pub. L. No. 107-110.

*Nunnery, J. (2008). Supplemental Educational Services in the state of Louisiana: 2006-2007 Student Achievement Results. Memphis, TN: The University of Memphis, Center for Research in Educational Policy.

*Nunnery, J. (2008). Supplemental Educational Services in the state of Louisiana: 2007-2008 Student Achievement Results. Memphis, TN: The University of Memphis, Center for Research in Educational Policy. 
Nunnery, J., Pribesh, S., \& Chappell, S. (2009). Issues in estimating Supplemental Educational Services provider effects: A review of state evaluations. San Diego, CA: Paper presented at the annual meeting of the American Educational Research Association, April, 2009.

Orwin, R. (1983). A fail-safe $N$ for effect size in meta-analysis. Journal of Educational Statistics, 8, $157-159$.

*Paek, J., McKay, D., Harrison, L., Ross, S., \& Fedde, F. (2008). Supplemental Educational Services in the state of Tennessee: 2006-2007 Student Achievement Analysis. Memphis, TN: The University of Memphis, Center for Research in Educational Policy.

*Paek, J., McKay, D., Harrison, L, Ross, S., Nunnery, J. \& Pribesh, S. (2008). Supplemental Educational Services in the State of Louisiana: 2005-2006. Memphis, TN: The University of Memphis, Center for Research in Educational Policy.

Peterson, P. (2005). Making up the rules as your play the game. Education Next, 5(4), 4348.

*Potter, A. \& Ross, S. (2005). A review of implementation of Supplemental Educational Services in Virginia and recommendations for future implementation. Memphis, TN: The University of Memphis, Center for Research in Educational Policy.

*Potter, A., Ross, S., Paek, J., McKay, D., Ashton, J., \& Sanders, W. (2007). Supplemental Educational Services in the state of Tennessee: 2005-2006 (2004-2005 Student Achievement Results). Memphis, TN: The University of Memphis, Center for Research in Educational Policy.

*Potter, A., Ross, S., Paek, J., McKay, D., \& Sanders, W. (2007). Supplemental Educational Services in the state of Tennessee: 2005-2006. Memphis, TN: The University of Memphis, Center for Research in Educational Policy. 
*Potter, A., Ross, S., Paek, J., Nunnery, J., \& Pribesh, S. (2005). Supplemental Educational Services in the state of Louisiana 2004-2005. Memphis, TN: The University of Memphis, Center for Research in Educational Policy.

*Pribesh, S. \& Nunnery, J. (2009). Study of Supplemental Educational Service Providers. Maryland: Student Achievement Analyses (2005-2006). Memphis, TN: The University of Memphis, Center for Research in Educational Policy.

*Pribesh, S. \& Nunnery, J. (2009). Study of Supplemental Educational Service Providers. Maryland: Student Achievement Analyses 2005-06 and 2006-07. Memphis, TN: The University of Memphis, Center for Research in Educational Policy.

Public Policy Associates, Inc. (2008). Evaluation of Supplemental Educational Services: Summary Report. Lansing, MI: Author.

*Rickles, J. \& Barnhart, M. (2007). The impact of Supplemental Educational Services participation on student achievement: 2005-2006. Los Angeles, CA: Los Angeles Unified School District, Program Evaluation and Research Branch, Planning, Assessment, and Research Division Pub. No. 352.

*Rickles, J., Barnhart, M., \& Gualpa, A. (2008). Supplemental Educational Services participation and impact on student achievement: The case of one urban district over five years. New York: Paper presented at the annual meeting of the American Educational Research Association, March, 2008.

*Rickles, J. \& White, J. (2006). The impact of Supplemental Educational Services participation on student achievement. Los Angeles, CA: Los Angeles Unified School District, Program Evaluation and Research Branch, Planning, Assessment, and Research Division Pub. No. 295. 
Ritter, G., Barnett, J., Denny, G., \& Albin, G. (2009). The effectiveness of volunteer tutoring programs for elementary and middle school students: A meta-analysis. Review of Educational Research, 79(1), 3-38.

Rosenthal, R. (1979). The "file drawer problem" and tolerance for null results. Psychological Bulletin, 86, 638-641.

Rosenthal, R. (2002). Correlations, contrasts, and conceptual clarity. Chicago, IL: Paper presented at the annual meeting of the American Psychological Association.

Rosenthal, R. \& DiMatteo, M. (2001). Meta-analysis: Recent developments in quantitative methods for literature reviews. Annual Review of Psychology, 52, 5982.

Rosenthal, R. \& Rubin, D. (2003). $r$ equivalent: A simple effect size indicator. Psychological Methods, 8(4), 492-496.

Ross, S. (2005). Evaluating Supplemental Educational Service providers: Suggested strategies for states. Memphis, TN: Center for Research in Educational Policy and Supplemental Educational Services Quality Center.

Ross, S., Harmon, J., \& Wong, K. (2009). Improving SES quality: State approval, monitoring, and evaluation of SES providers. Lincoln, IL: Center for Innovation and Improvement.

Saifer, S. \& Speth, T. (2007). Supplemental Educational Services and implementation challenges in the Northwest Region states (Issues \& Answers Report, REL 2007No. 006). Washington, DC: U. S. Department of Education, Institute of Education Sciences, National Center for Education Evaluation and Regional Assistance, 
Regional Educational Laboratory Northwest. Retrieved September 28, 3008 from http://ies.ed.gov/ncee/edlabs.

Salkind, N. (2006). Tests and measurements for people who (think they) hate tests and measurements. Thousand Oaks, CA: Sage Publications.

Sanderson, D. (2003). Setting up a successful after school tutorial program: One district's journey. Reading Improvement, 40(1), 13-20.

Sprinthall, R. (2007). Basic statistical analysis ( $8^{\text {th }}$ ed.). Pearson, Allyn, \& Bacon: Boston.

State Legislatures. (2008). Closing the Achievement Gap? State Legislatures, April 2008. Retrieved December 10, 2008 from http://www.ncsl.org/magazine/articles/2008/08SLApr08_Statestats.htm.

Stullich, S., Abrams, A., Eisner, E., \& Lee, E. (2009). Title I implementation - update on recent evaluation findings. Washington, DC: U. S. Department of Education, Office of Planning, Evaluation, \& Policy Department, Policy \& Program Studies Service.

Sunderman, G. L. \& Kim, J. (2004). Increasing bureaucracy or increasing opportunities? School district experience with Supplemental Educational Services. Cambridge, MA: The Civil Rights Project.

Topping, K. (2000). Tutoring. Brussels, Belgium: International Academy of Education.

U. S. Department of Education. (2005). Supplemental Educational Serviced nonregulatory guidance. Washington, DC: Author. Retrieved February 12, 2009 from http://www.ed.gov/policy/elsec/guid/suppsvcsguid.doc.

U. S. Department of Education. (2007a). National assessment of Title I final report. 
Summary of key findings. Washington, DC: Author.

U. S. Department of Education. (2007b). Status and trends in the education of racial and ethnic minorities. Washington, DC: National Center for Education Statistics (NCES).

U. S. Government Accountability Office. (2006). No Child Left Behind Act. Education actions needed to improve local implementation and state evaluation of Supplemental Educational Services (US GAO Publication No. GAO-06-758). Washington, DC.

Viadero, D. (2007). Evidence thin on student gains from NCLB tutoring. Education Week,26(41), 7.

Wasik. B. (1998). Using volunteers as reading tutors: Guidelines for successful practices. Reading Teacher, 51(7), 562-570.

*Zoblotsky, T. \& Gallagher, B. (2009). Supplemental Educational Services in the state of Kentucky: 2007-2008 Student Achievement Analyses. Memphis, TN: The University of Memphis, Center for Research in Educational Policy. 
Provider Characteristics Coding Scheme

\section{APPENDIX A}

\section{Identifying descriptor variables:}

\begin{tabular}{|c|c|}
\hline Provider name/code & \\
\hline $\begin{array}{c}\text { Type of provider } \\
\text { 1. National }\end{array}$ & \\
2. Local & \\
Type of services & \\
2. Face-to-face only & \\
3. Face-to-face and Internet & \\
\hline Year Agency was established (last 2-digits) & \\
\hline
\end{tabular}

Service descriptor variables:

Average cost per student

Location of service delivery

1. Student's school

2. Provider's place of business

3. Student's home

4. None-Internet

5. Community location (comm. Center, church)

Grade level(s) served

Provides services for ELL students?

0 . No

1. Yes

Provides services for SPED students?

0 . No

1. Yes

Subjects tutored

1. Math

2. English/language arts

3. Both

Student/Tutor Ratio

Uses prescribed curriculum?

0 . No

1. Uses proprietary curriculum

2. Uses national curriculum 
Qualification descriptor variables:

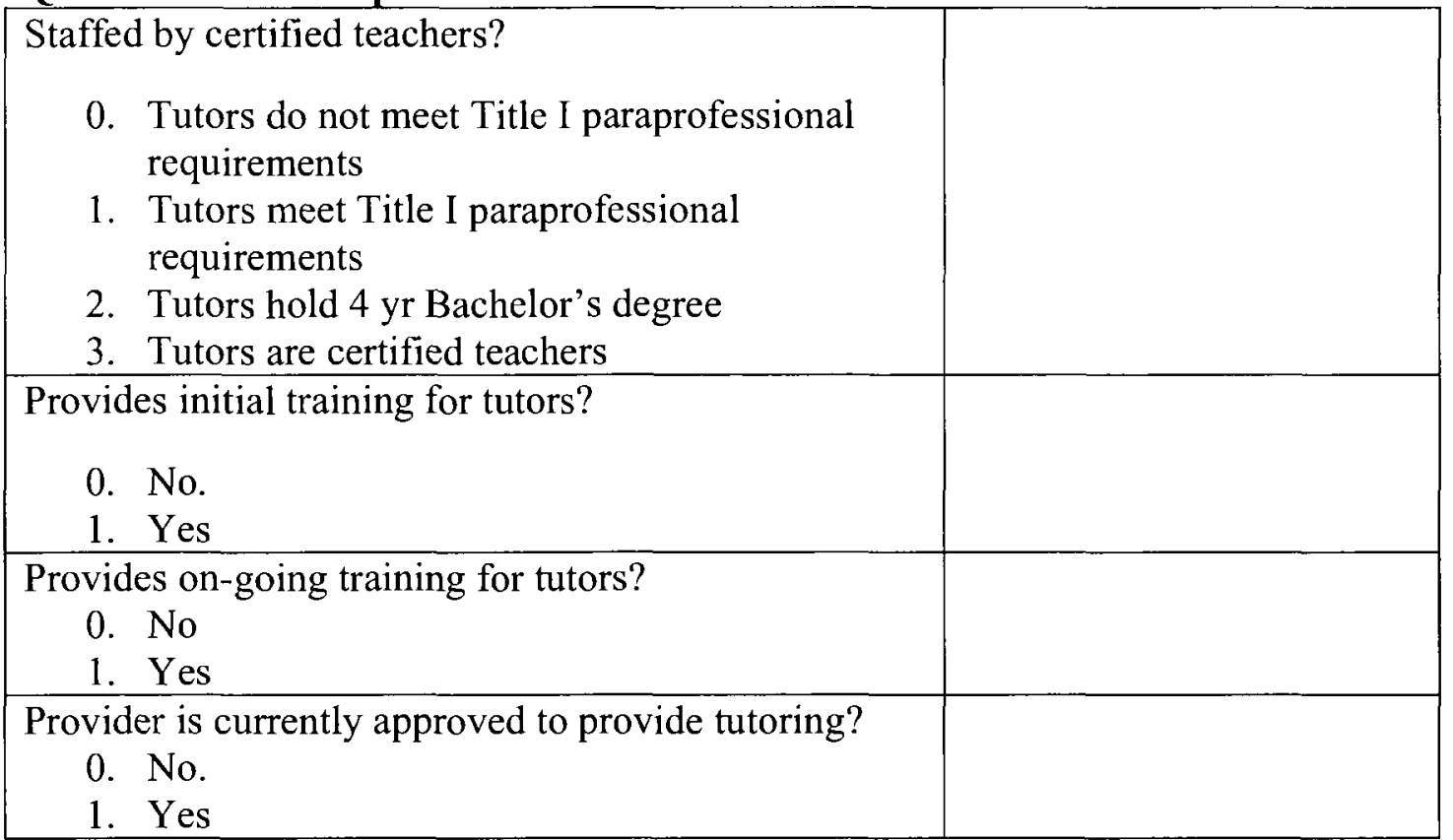




\section{APPENDIX B}

Methodological Data Coding Scheme

Study identifier variables:

\begin{tabular}{|c|c|}
\hline Study code & \\
\hline Year being evaluated & \\
\hline Authors & \\
1. External evaluator(s) & \\
2. State Department of Education & \\
3. Dissertation & \\
\hline
\end{tabular}

Sample descriptor variables:

\begin{tabular}{|l|l|}
\hline Number of students receiving services & \\
\hline Number of students included in analysis & \\
\hline Analysis includes LEP students? & \\
0. No & \\
1. Yes & \\
\hline Analysis includes SPED students? & \\
0. No & \\
1. Yes & \\
\hline
\end{tabular}

Design descriptor variables:

Type of research design/analysis method

1. Pre-post comparison using matched samples

2. Pre-post comparison using matched pairs

Minimum Hours Served for Inclusion in Analysis (provide number of hours) 


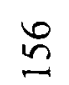

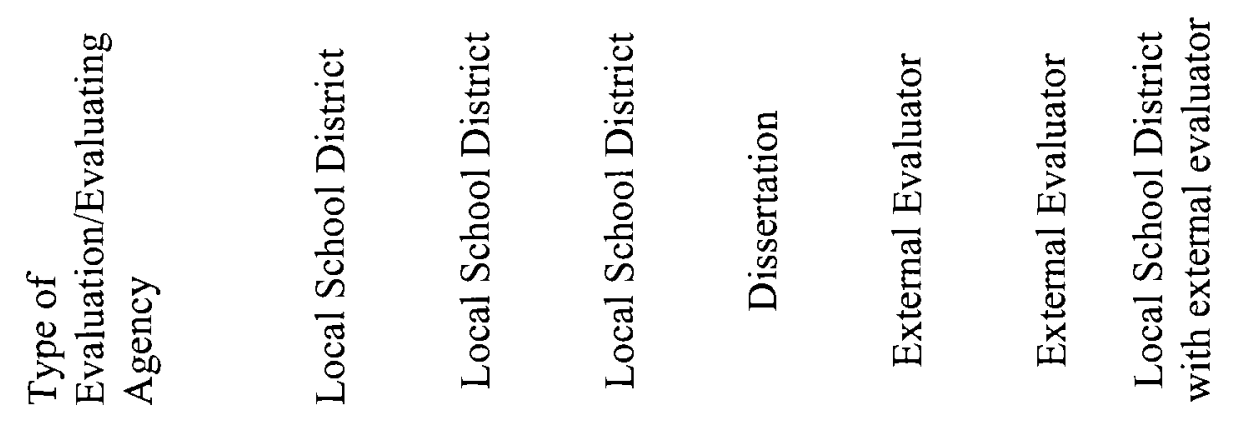

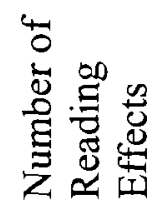

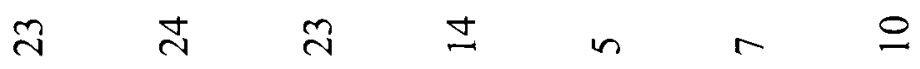

岁

$\bar{\sim} \stackrel{\sim}{\sim} \quad \sigma \quad \forall \quad b$
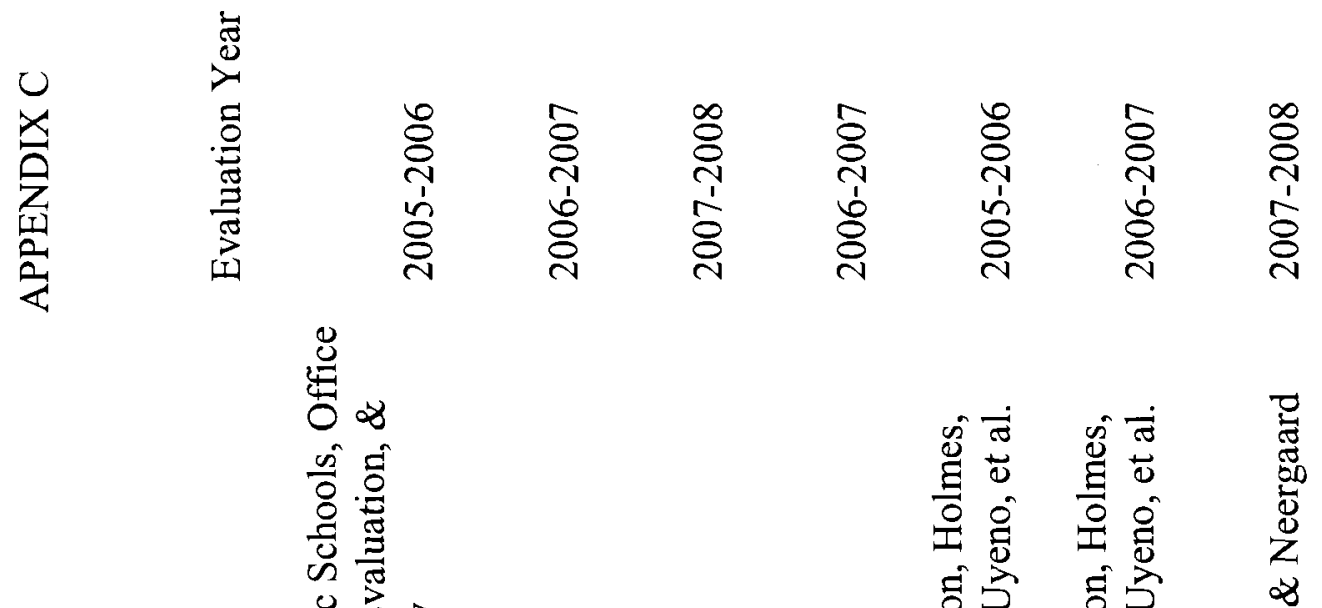

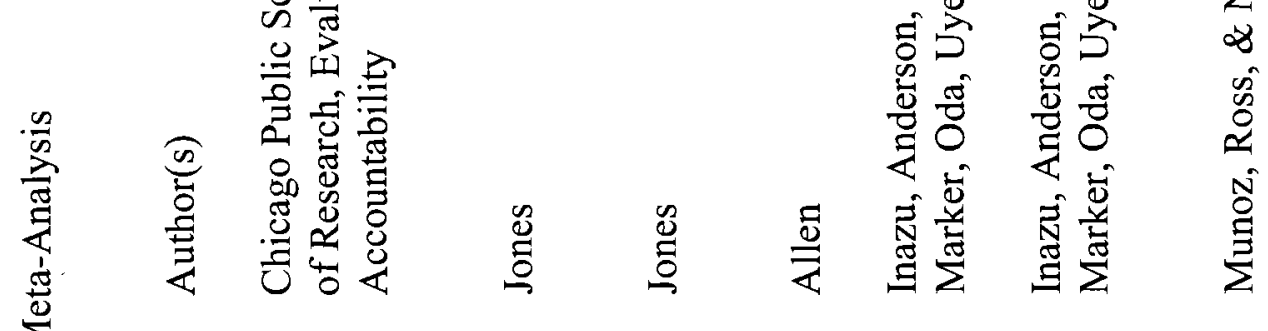

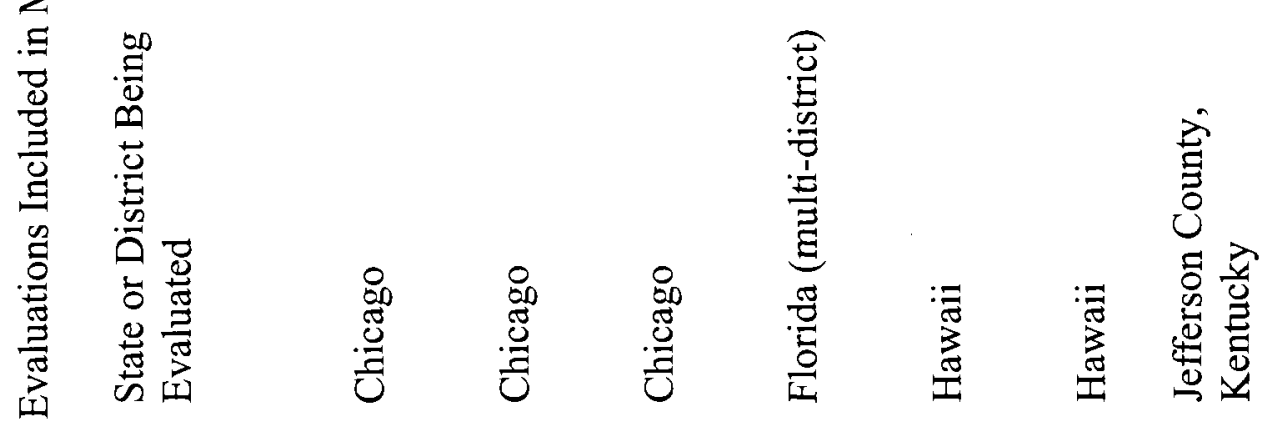


5
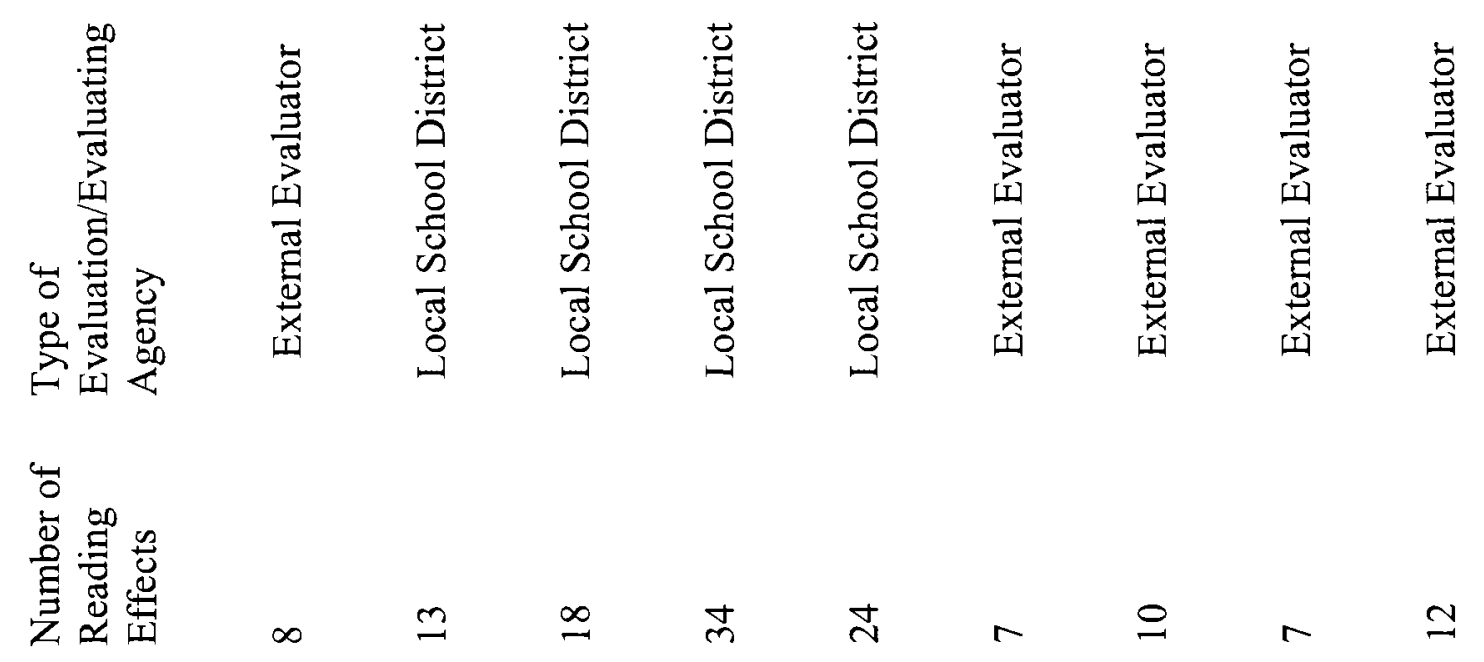

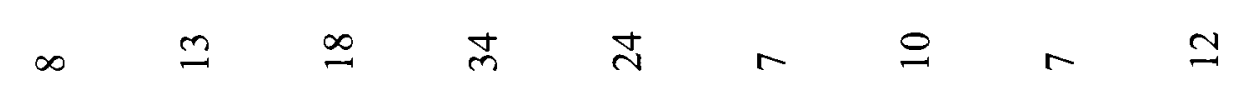

亮商商

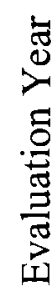

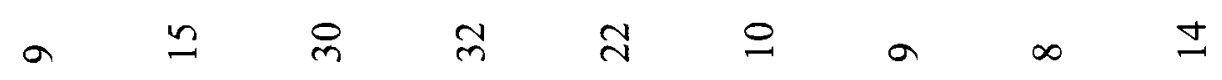

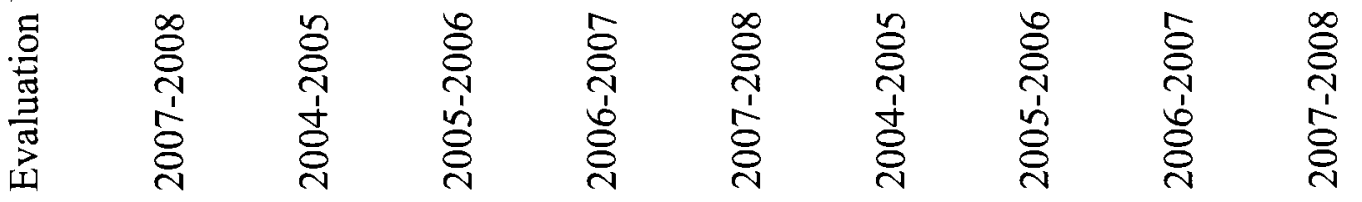
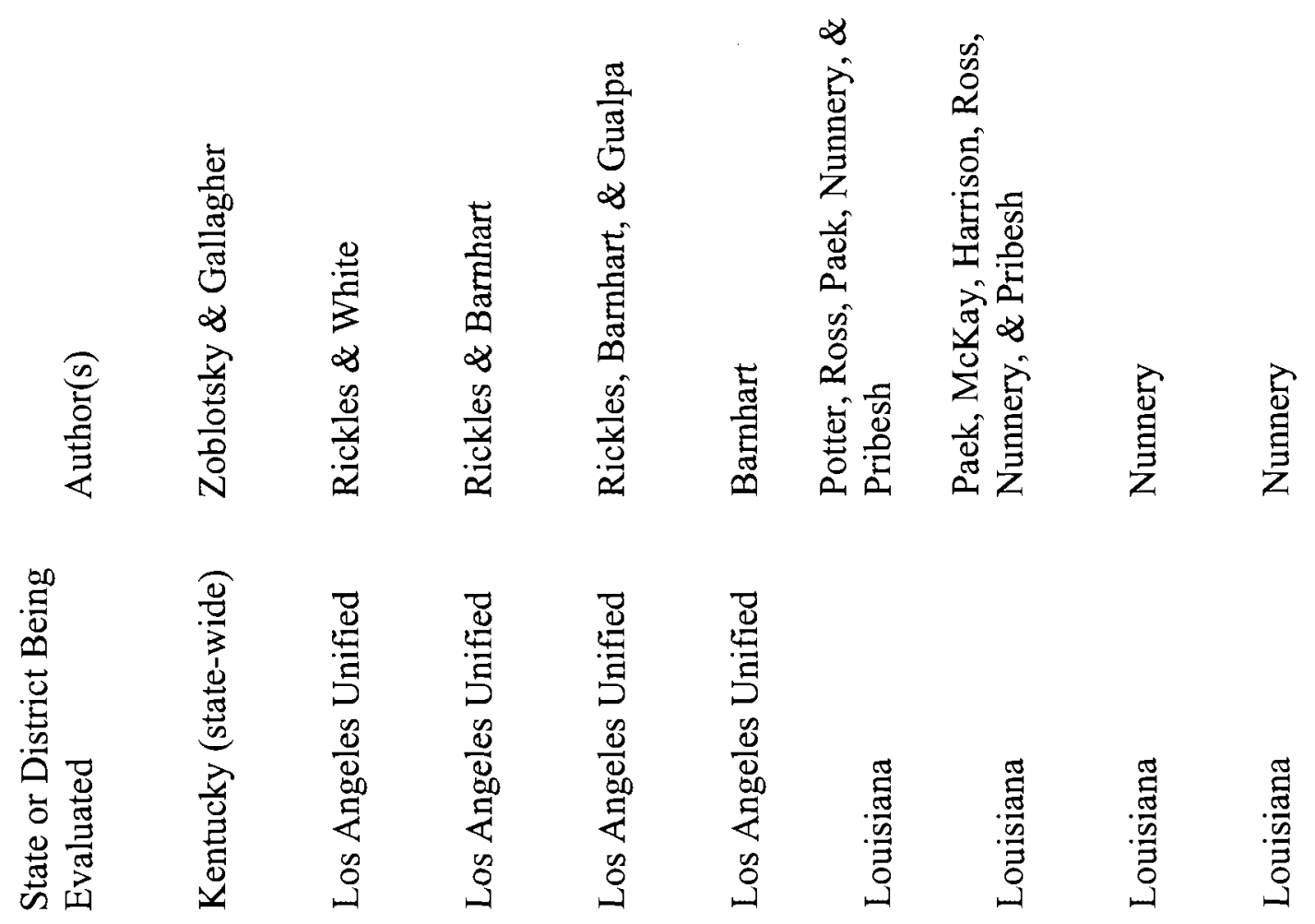
$\stackrel{\infty}{\stackrel{\infty}{\infty}}$

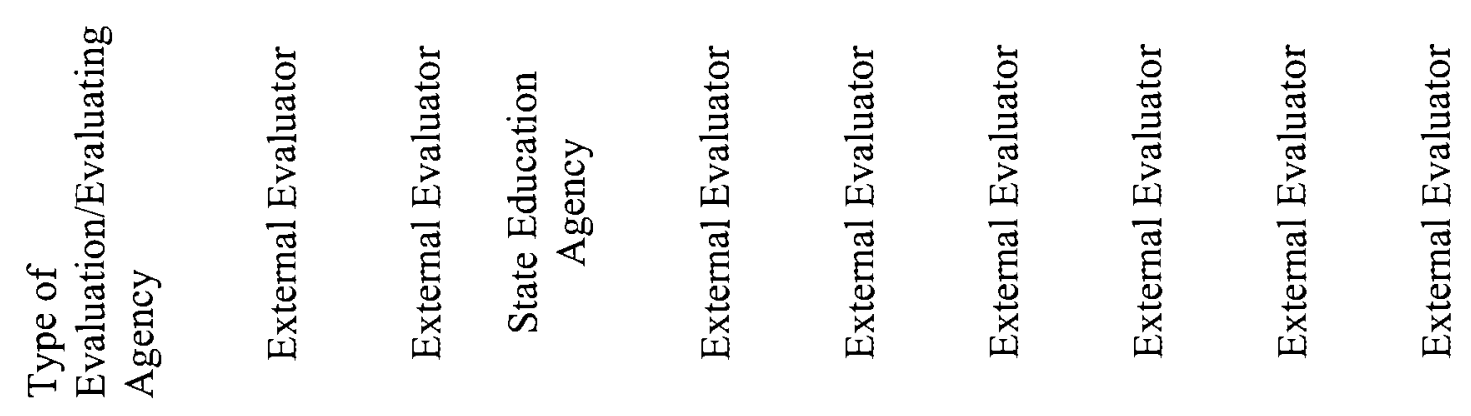

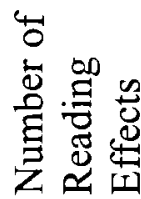

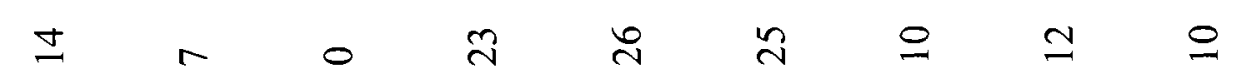

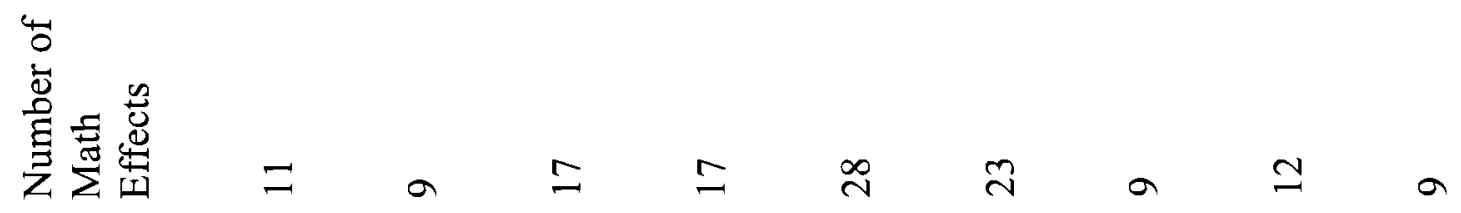

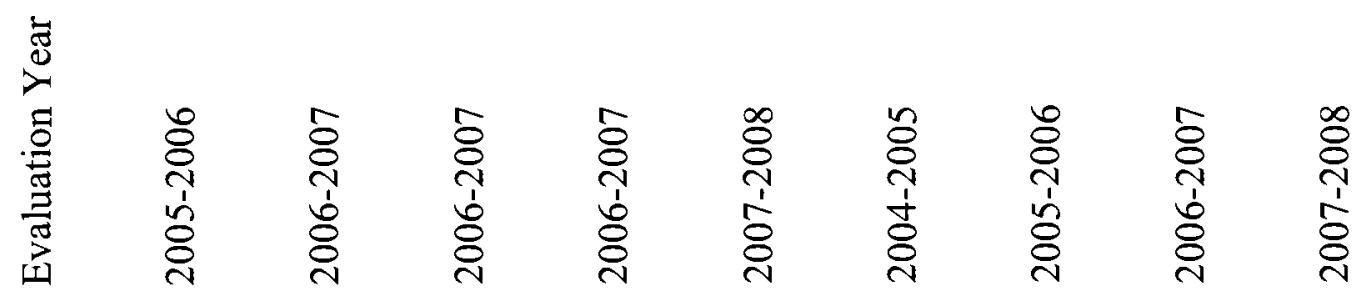

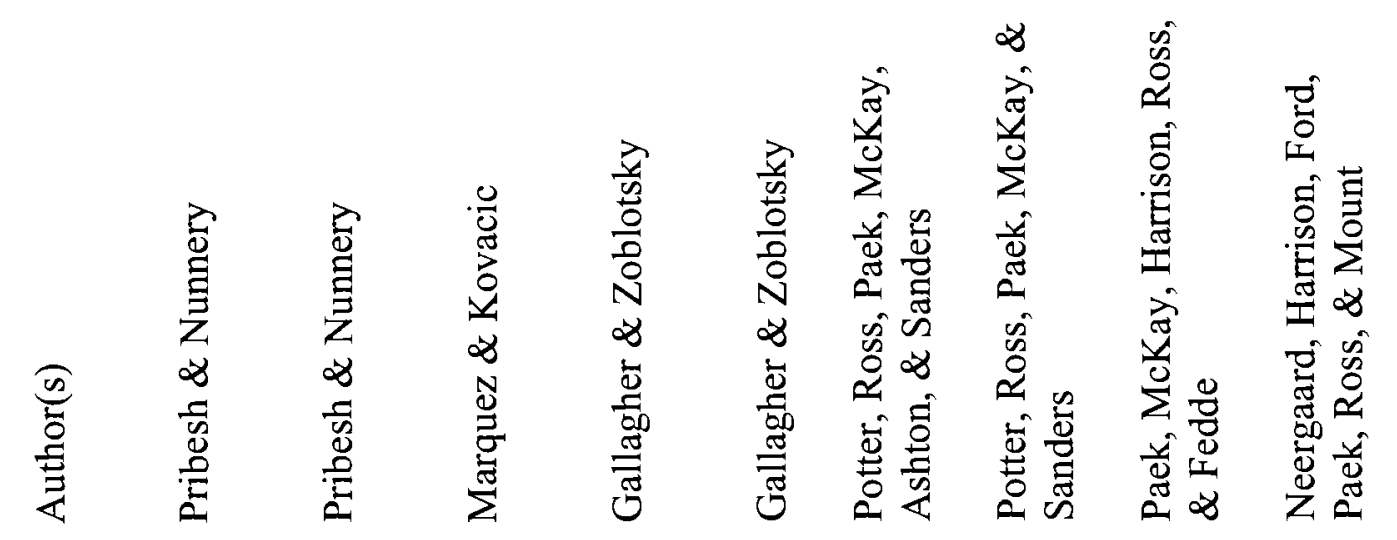

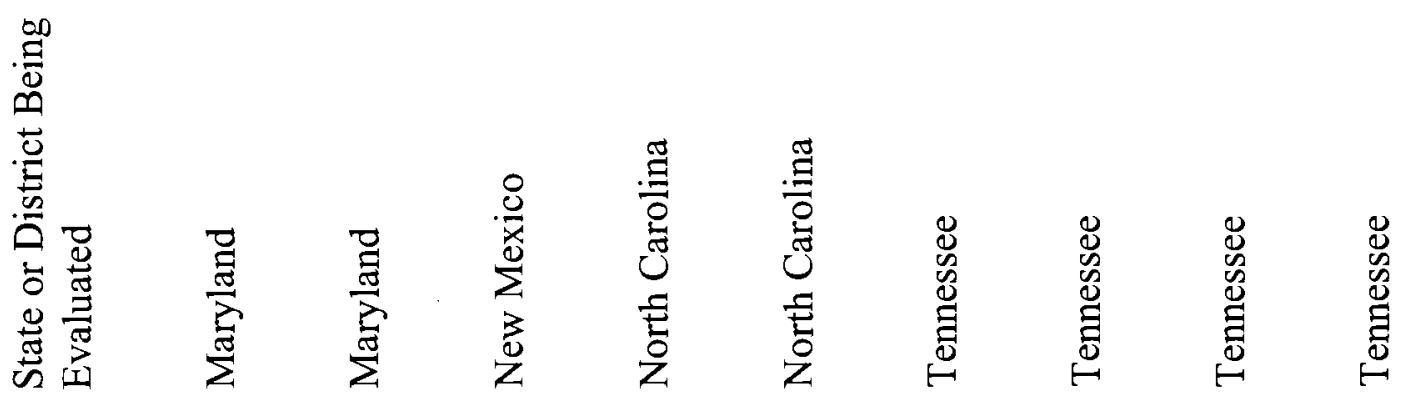




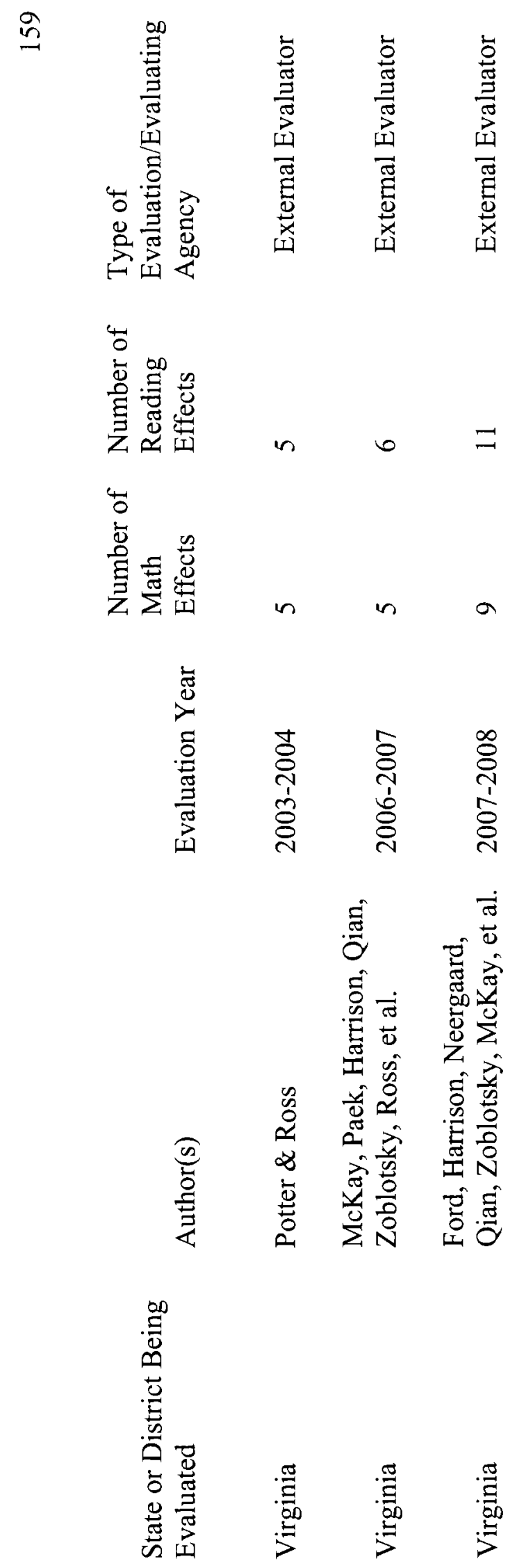




\section{APPENDIX D}

Math Effect Sizes Included in Analysis

\begin{tabular}{|c|c|c|c|c|}
\hline State or District & $\begin{array}{c}\text { Academic } \\
\text { Year }\end{array}$ & Provider Name & $n$ & $\begin{array}{l}\text { Effect } \\
\text { size (d) }\end{array}$ \\
\hline Chicago & 06 & A+ TUTORING SERVICE LTD & 440 & 0.01 \\
\hline Chicago & 06 & BRAIN HURRICANE, LLC & 118 & 0.02 \\
\hline Chicago & 06 & BRAINFUSE ONE-TO-ONE & 174 & -0.03 \\
\hline Chicago & 06 & BRAINFUSE ONE-TO-ONE & 266 & -0.07 \\
\hline Chicago & 06 & BRILLIANCE ACADEMY & 313 & -0.14 \\
\hline Chicago & 06 & CAMBRIDGE EDUCATIONAL SERVICES & 1362 & 0.04 \\
\hline Chicago & 06 & Catapult & 353 & 0.01 \\
\hline Chicago & 06 & Club Z! In-Home Tutoring & 391 & -0.12 \\
\hline Chicago & 06 & ED SOLUTIONS, INC. & 285 & 0.11 \\
\hline Chicago & 06 & Education Station & 2830 & -0.12 \\
\hline Chicago & 06 & EDUCATIONAL SPECIALTIES & 119 & -0.08 \\
\hline Chicago & 06 & NCLB TUTORS & 106 & -0.4 \\
\hline Chicago & 06 & Newton Learning & 7813 & -0.03 \\
\hline Chicago & 06 & ONE-TO-ONE LEARNING CENTER & 157 & -0.18 \\
\hline Chicago & 06 & Platform Learning & 1782 & -0.13 \\
\hline Chicago & 06 & Plato Learning & 113 & -0.1 \\
\hline Chicago & 06 & PROGRESSIVE LEARNING & 950 & -0.14 \\
\hline Chicago & 06 & SCHOOL SERVICE SYSTEMS & 569 & 0.03 \\
\hline Chicago & 06 & SCORE EDUCATIONAL CENTERS & 202 & 0.13 \\
\hline Chicago & 06 & The Princeton Review & 3996 & -0.05 \\
\hline Chicago & 06 & UNPARALLELED SOLUTIONS, INC. & 519 & 0.16 \\
\hline Chicago & 07 & A+ TUTORING SERVICE LTD & 925 & 0.25 \\
\hline Chicago & 07 & AIM HIGH - CPS & 14760 & 0.12 \\
\hline Chicago & 07 & Alternatives Unlimited & 84 & 0.16 \\
\hline Chicago & 07 & BRAIN HURRICANE, LLC & 372 & 0.09 \\
\hline Chicago & 07 & BRAINFUSE ONE-TO-ONE & 782 & 0.06 \\
\hline Chicago & 07 & BRILLIANCE ACADEMY & 1548 & 0.04 \\
\hline Chicago & 07 & CAMBRIDGE EDUCATIONAL SERVICES & 861 & 0.09 \\
\hline Chicago & 07 & Catapult & 1465 & 0.14 \\
\hline Chicago & 07 & CHAMPIONS & 1510 & 0.03 \\
\hline Chicago & 07 & CHESS ACADEMY & 177 & 0.14 \\
\hline Chicago & 07 & Club Z! In-Home Tutoring & 1959 & -0.04 \\
\hline Chicago & 07 & Education Station & 3293 & 0.02 \\
\hline Chicago & 07 & EDUCATIONAL SPECIALTIES & 265 & -0.08 \\
\hline Chicago & 07 & Huntington Learning & 495 & -0.02 \\
\hline Chicago & 07 & LITERACY FOR ALL & 126 & 0 \\
\hline Chicago & 07 & Newton Learning & 3966 & 0.04 \\
\hline
\end{tabular}




\begin{tabular}{|c|c|c|c|c|}
\hline Chicago & 07 & ONE-TO-ONE LEARNING CENTER & 256 & 0.17 \\
\hline Chicago & 07 & ORION'S MIND & 146 & -0.09 \\
\hline Chicago & 07 & Platform Learning & 1724 & 0.04 \\
\hline Chicago & 07 & PROGRESSIVE LEARNING & 1830 & 0.13 \\
\hline Chicago & 07 & SCHOOL SERVICE SYSTEMS & 748 & 0.14 \\
\hline Chicago & 07 & Socratic Learning & 1228 & 0.07 \\
\hline Chicago & 07 & SPECTRA SERVICES & 136 & 0.18 \\
\hline Chicago & 07 & The Princeton Review & 2952 & 0.11 \\
\hline Chicago & 07 & UNPARALLELED SOLUTIONS, INC. & 805 & 0.2 \\
\hline Chicago & 08 & A+ TUTORING SERVICE LTD & 97 & 0.01 \\
\hline Chicago & 08 & AIM HIGH - CPS & 9412 & 0.06 \\
\hline Chicago & 08 & BRAIN HURRICANE, LLC & 206 & 0.05 \\
\hline Chicago & 08 & BRAINFUSE ONE-TO-ONE & 165 & -0.01 \\
\hline Chicago & 08 & BRILLIANCE ACADEMY & 125 & 0.05 \\
\hline Chicago & 08 & CAMBRIDGE EDUCATIONAL SERVICES & 160 & 0.17 \\
\hline \multirow[t]{2}{*}{ Chicago } & 08 & Catapult & 421 & 0.08 \\
\hline & & CENTER OF HIGHER DEVELOPMENT & & \\
\hline Chicago & 08 & (ONSITE) & 48 & -0.05 \\
\hline Chicago & 08 & Club Z! In-Home Tutoring & 133 & -0.03 \\
\hline Chicago & 08 & CS\&amp;C, INC.- JULEX LEARNING & 59 & 0.2 \\
\hline Chicago & 08 & Education Station & 629 & -0.04 \\
\hline Chicago & 08 & EDUCATIONAL SPECIALTIES & 43 & 0.18 \\
\hline Chicago & 08 & Huntington Learning & 194 & 0.03 \\
\hline \multirow[t]{2}{*}{ Chicago } & 08 & LITERACY FOR ALL & 115 & 0 \\
\hline & & MAINSTREAM DEVELOPMENT ED & & \\
\hline Chicago & 08 & GROUP & 52 & 0.17 \\
\hline Chicago & 08 & Newton Learning & 3651 & 0.05 \\
\hline Chicago & 08 & ONE-TO-ONE LEARNING CENTER & 46 & 0.03 \\
\hline Chicago & 08 & ORION'S MIND & 884 & 0.05 \\
\hline Chicago & 08 & Platform Learning & 429 & -0.12 \\
\hline Chicago & 08 & PROGRESSIVE LEARNING & 1956 & 0.09 \\
\hline Chicago & 08 & SCHOOL SERVICE SYSTEMS & 735 & 0.18 \\
\hline Chicago & 08 & SES OF ILLINOIS & 228 & 0.35 \\
\hline Chicago & 08 & The Princeton Review & 2082 & 0.04 \\
\hline Chicago & 08 & UNPARALLELED SOLUTIONS, INC. & 866 & 0.15 \\
\hline Florida & 07 & Rocket Learning & 60 & -0.133 \\
\hline Florida & 07 & Academy of Success & 104 & 0.323 \\
\hline Florida & 07 & Advanced Learning & 88 & -0.441 \\
\hline Florida & 07 & A+ Tutor $U$ & 113 & -0.201 \\
\hline Florida & 07 & Club Z! & 55 & -0.437 \\
\hline Florida & 07 & AlphaBest & 268 & -0.1 \\
\hline rida & 07 & Studentnest & 163 & -0.423 \\
\hline
\end{tabular}




\begin{tabular}{|c|c|c|c|c|}
\hline Florida & 07 & ACES & 70 & 0.114 \\
\hline Florida & 07 & PCTA & 55 & -0.186 \\
\hline Hawaii & 06 & College Connections & 13 & 0.2178 \\
\hline Hawaii & 06 & Community Schools for Adults & 2 & -0.3401 \\
\hline Hawaii & 06 & It's all about Kids & 103 & 0.0006 \\
\hline Hawaii & 06 & Learning Hale & 2 & 0.9525 \\
\hline Hawaii & 07 & College Connections & 109 & 0.0697 \\
\hline Hawaii & 07 & Community Schools for Adults & 10 & 0.1864 \\
\hline Hawaii & 07 & Hui Malama & 8 & -0.4691 \\
\hline Hawaii & 07 & It's all about Kids & 431 & -0.0364 \\
\hline Hawaii & 07 & Kumon & 37 & -0.1092 \\
\hline Hawaii & 07 & Learning Hale & 4 & -0.2558 \\
\hline $\begin{array}{l}\text { Jefferson County, } \\
\text { KY }\end{array}$ & 08 & A Better Grade Tutoring & 128 & 0.11 \\
\hline $\begin{array}{l}\text { Jefferson County, } \\
\text { KY }\end{array}$ & 08 & A Plus Tutoring & 328 & 0.07 \\
\hline $\begin{array}{l}\text { Jefferson County, } \\
\text { KY }\end{array}$ & 08 & A to $\mathrm{Z}$ In-home Tutoring & 190 & 0.01 \\
\hline $\begin{array}{l}\text { Jefferson County, } \\
\text { KY }\end{array}$ & 08 & Catapult & 416 & 0.18 \\
\hline $\begin{array}{l}\text { Jefferson County, } \\
\text { KY }\end{array}$ & 08 & Club Z! In-Home Tutoring & 280 & 0.09 \\
\hline $\begin{array}{l}\text { Jefferson County, } \\
\text { KY }\end{array}$ & 08 & $\begin{array}{l}\text { Porter Education and Communications, } \\
\text { Inc }\end{array}$ & 64 & 0.17 \\
\hline $\begin{array}{l}\text { Jefferson County, } \\
\text { KY }\end{array}$ & 08 & The Salvation Army & 104 & 0.07 \\
\hline $\begin{array}{l}\text { Jefferson County, } \\
\text { KY }\end{array}$ & 08 & Yes! All Students Can Learn & 64 & 0.08 \\
\hline Kentucky & 08 & A Better Grade Tutoring & 22 & -0.01 \\
\hline Kentucky & 08 & A Plus Tutoring & 52 & -0.17 \\
\hline Kentucky & 08 & A to $\mathrm{Z}$ In-home Tutoring & 38 & 0.05 \\
\hline Kentucky & 08 & Catapult & 78 & 0.13 \\
\hline Kentucky & 08 & Club Z! In-Home Tutoring & 39 & -0.14 \\
\hline Kentucky & 08 & Graham Consulting Group & 15 & -0.01 \\
\hline Kentucky & 08 & $\begin{array}{l}\text { Porter Education and Communications, } \\
\text { Inc }\end{array}$ & 16 & -0.43 \\
\hline Kentucky & 08 & The Salvation Army & 17 & 0.16 \\
\hline Kentucky & 08 & Yes! All Students Can Learn & 15 & 0.19 \\
\hline Los Angeles & 05 & A+ Educational Centers & 1040 & 0.06 \\
\hline Los Angeles & 05 & ABC-Learn, Inc & 128 & -0.08 \\
\hline Los Angeles & 05 & Best/Tutors of the Inland Empire & 185 & 0.03 \\
\hline Los Angeles & 05 & Boys \&amp; Girls Clubs of America & 40 & -0.01 \\
\hline Los Angeles & 05 & BRAINFUSE ONE-TO-ONE & 67 & -0.03 \\
\hline
\end{tabular}




\begin{tabular}{|c|c|c|c|c|}
\hline Los Angeles & 05 & Club Z! In-Home Tutoring & 184 & 0 \\
\hline Los Angeles & 05 & Education Station & 215 & 0.26 \\
\hline Los Angeles & 05 & Educational and Tutorial & 37 & 0.3 \\
\hline Los Angeles & 05 & Los Angeles USD & 2976 & 0.05 \\
\hline Los Angeles & 05 & MATH Ability & 154 & 0.05 \\
\hline Los Angeles & 05 & Newton Learning & 78 & 0.275 \\
\hline Los Angeles & 05 & Professional Tutors of America & 476 & 0.11 \\
\hline Los Angeles & 05 & Say YES to Life & 517 & -0.05 \\
\hline Los Angeles & 05 & SCORE! Learning, Inc & 151 & 0.15 \\
\hline Los Angeles & 05 & Smart Kids Tutoring \&amp; Learning & 164 & 0.2 \\
\hline Los Angeles & 06 & A+ Educational Centers & 1968 & 0.02 \\
\hline Los Angeles & 06 & ABC-Learn, Inc & 106 & -0.01 \\
\hline Los Angeles & 06 & Academic Advantage/Tutors Club & 422 & 0.09 \\
\hline Los Angeles & 06 & Ace Tutoring Services & 495 & 0.07 \\
\hline Los Angeles & 06 & African American Unity Center & 49 & 0.02 \\
\hline Los Angeles & 06 & Basic Education Services & 311 & 0.015 \\
\hline Los Angeles & 06 & Boys \&amp; Girls Clubs of America & 50 & 0.06 \\
\hline Los Angeles & 06 & BRAINFUSE ONE-TO-ONE & 127 & 0.07 \\
\hline Los Angeles & 06 & Bresee Foundation & 31 & -0.13 \\
\hline Los Angeles & 06 & Carney Education Services & 157 & -0.025 \\
\hline Los Angeles & 06 & Club Z! In-Home Tutoring & 371 & -0.03 \\
\hline Los Angeles & 06 & Community College Foundation & 363 & 0.06 \\
\hline Los Angeles & 06 & Dreambuilders & 97 & -0.09 \\
\hline Los Angeles & 06 & Education 2020 & 35 & 0.02 \\
\hline Los Angeles & 06 & Education Station & 1143 & 0.05 \\
\hline Los Angeles & 06 & Educational Support & 50 & -0.075 \\
\hline Los Angeles & 06 & Educators Plus & 108 & 0.03 \\
\hline Los Angeles & 06 & Genesis 8 & 44 & 0.02 \\
\hline Los Angeles & 06 & Huntington Learning & 37 & -0.01 \\
\hline Los Angeles & 06 & Kumon & 91 & 0.03 \\
\hline Los Angeles & 06 & Learning Fun Center & 111 & -0.025 \\
\hline Los Angeles & 06 & Mathnasium & 77 & 0.02 \\
\hline Los Angeles & 06 & Newton Learning & 288 & 0.02 \\
\hline Los Angeles & 06 & The Princeton Review & 35 & 0.04 \\
\hline Los Angeles & 06 & Professional Tutors of America & 533 & 0.05 \\
\hline Los Angeles & 06 & Say YES to Life & 641 & -0.04 \\
\hline Los Angeles & 06 & SCORE! Learning, Inc & 155 & 0.015 \\
\hline Los Angeles & 06 & Socratic Learning & 112 & 0.065 \\
\hline Los Angeles & 06 & Total Education Solutions & 55 & 0.02 \\
\hline Los Angeles & 06 & Youth Policy Institute & 66 & 0.07 \\
\hline Los Angeles & 07 & A+ Educational Centers & 1450 & 0.015 \\
\hline Los Angeles & 07 & ABC-Learn, Inc & 179 & 0.015 \\
\hline
\end{tabular}




\begin{tabular}{|c|c|c|c|c|}
\hline Los Angeles & 07 & Academic Advantage/Tutors Club & 1045 & 0.065 \\
\hline Los Angeles & 07 & Ace Tutoring Services & 694 & 0.03 \\
\hline Los Angeles & 07 & African American Unity Center & 35 & 0.12 \\
\hline Los Angeles & 07 & Arithmetic Solutions & 116 & 0.06 \\
\hline Los Angeles & 07 & Best/Tutors of the Inland Empire & 375 & 0.02 \\
\hline Los Angeles & 07 & BRAINFUSE ONE-TO-ONE & 103 & -0.04 \\
\hline Los Angeles & 07 & Bresee Foundation & 35 & 0.09 \\
\hline Los Angeles & 07 & Carney Education Services & 379 & 0.02 \\
\hline Los Angeles & 07 & Catapult & 1484 & 0.015 \\
\hline Los Angeles & 07 & Century/LIFT & 56 & 0.2 \\
\hline Los Angeles & 07 & Club Z! In-Home Tutoring & 334 & 0.09 \\
\hline Los Angeles & 07 & Community College Foundation & 313 & 0.045 \\
\hline Los Angeles & 07 & Daekyo America & 155 & 0.045 \\
\hline Los Angeles & 07 & Dreambuilders & 177 & 0.06 \\
\hline Los Angeles & 07 & Educators Plus & 122 & -0.02 \\
\hline Los Angeles & 07 & Genesis 8 & 54 & -0.03 \\
\hline Los Angeles & 07 & Gwen Bolden & 42 & -0.01 \\
\hline Los Angeles & 07 & Kumon & 149 & 0.04 \\
\hline Los Angeles & 07 & Learning Fun Center & 145 & -0.015 \\
\hline Los Angeles & 07 & Mathnasium & 81 & -0.06 \\
\hline Los Angeles & 07 & Positive Visions & 46 & -0.01 \\
\hline Los Angeles & 07 & Professional Tutors of America & 737 & 0.065 \\
\hline Los Angeles & 07 & Project Impact & 38 & 0.05 \\
\hline Los Angeles & 07 & Say YES to Life & 506 & -0.005 \\
\hline Los Angeles & 07 & SCORE! Learning, Inc & 191 & 0.045 \\
\hline Los Angeles & 07 & Studentnest.com & 91 & 0.06 \\
\hline Los Angeles & 07 & Teach Learning Academy & 37 & -0.01 \\
\hline Los Angeles & 07 & Total Education Solutions & 86 & -0.09 \\
\hline Los Angeles & 07 & WE CAN Foundation & 125 & 0.11 \\
\hline Los Angeles & 07 & Youth Policy Institute & 184 & 0.06 \\
\hline Los Angeles & 08 & A+Educational Centers & 1407 & 0.03 \\
\hline Los Angeles & 08 & ABC-Learn, Inc & 244 & 0.06 \\
\hline Los Angeles & 08 & Academic Advantage/Tutors Club & 1341 & 0.07 \\
\hline Los Angeles & 08 & Ace Tutoring Services & 774 & 0.1 \\
\hline Los Angeles & 08 & Alternatives Unlimited & 102 & 0.08 \\
\hline Los Angeles & 08 & Arithmetic Solutions & 235 & -0.015 \\
\hline Los Angeles & 08 & Best/Tutors of the Inland Empire & 345 & 0.015 \\
\hline Los Angeles & 08 & BRAINFUSE ONE-TO-ONE & 118 & 0.09 \\
\hline Los Angeles & 08 & Carney Education Services & 517 & 0.02 \\
\hline Los Angeles & 08 & Catapult & 1026 & 0.02 \\
\hline Los Angeles & 08 & Club Z! In-Home Tutoring & 364 & 0.04 \\
\hline Los Angeles & 08 & Community College Foundation & 505 & 0.055 \\
\hline Los Angeles & 08 & Daekyo America & 400 & 0.07 \\
\hline
\end{tabular}




\begin{tabular}{|c|c|c|c|c|}
\hline Los Angeles & 08 & Dreambuilders & 149 & 0.01 \\
\hline Los Angeles & 08 & Kumon & 188 & -0.115 \\
\hline Los Angeles & 08 & Professional Tutors of America & 489 & -0.01 \\
\hline Los Angeles & 08 & Project Impact & 79 & -0.02 \\
\hline Los Angeles & 08 & Say YES to Life & 424 & 0.01 \\
\hline Los Angeles & 08 & Teach Learning Academy & 96 & 0.01 \\
\hline Los Angeles & 08 & Total Education Solutions & 100 & -0.035 \\
\hline Los Angeles & 08 & WE CAN Foundation & 244 & -0.03 \\
\hline Los Angeles & 08 & Youth Policy Institute & 263 & 0.04 \\
\hline Louisiana & 05 & Asian Youth Services & 7 & 0.21 \\
\hline Louisiana & 05 & Dryades YMCA & 242 & 0.32 \\
\hline Louisiana & 05 & Education Station & 75 & 0.22 \\
\hline Louisiana & 05 & Louisiana Learning Circle & 88 & 0.25 \\
\hline Louisiana & 05 & Master Mind Tutoring & 6 & 0.18 \\
\hline Louisiana & 05 & New Orleans Parish School System & 124 & 0.12 \\
\hline Louisiana & 05 & The Princeton Review & 51 & 0.26 \\
\hline Louisiana & 05 & Socratic Learning & 27 & 0.18 \\
\hline Louisiana & 05 & $\begin{array}{l}\text { Sylvan Learning Centers of Baton } \\
\text { Rouge \&amp; Gonzales }\end{array}$ & 4 & 0.44 \\
\hline Louisiana & 05 & Urban League of Greater New Orleans & 228 & 0.1 \\
\hline Louisiana & 06 & A to $Z$ In-home Tutoring & 26 & 0.21 \\
\hline Louisiana & 06 & Education Station & 3 & 0.09 \\
\hline Louisiana & 06 & Fully Devoted Developer of Children & 108 & 0.16 \\
\hline Louisiana & 06 & Gaining Academic Progress & 8 & 0.42 \\
\hline Louisiana & 06 & Louisiana Learning Circle & 171 & -0.05 \\
\hline Louisiana & 06 & NAACP Achievement Academy & 80 & 0.27 \\
\hline Louisiana & 06 & Newton Learning & 60 & 0.09 \\
\hline Louisiana & 06 & Sylvan Learning Centers & 7 & 0.49 \\
\hline Louisiana & 06 & The Princeton Review & 71 & 0.1 \\
\hline Louisiana & 07 & A to $\mathrm{Z}$ In-Home Tutoring & 62 & 0.02 \\
\hline Louisiana & 07 & Back 2 Basics & 22 & -0.09 \\
\hline Louisiana & 07 & Club Z! In-Home Tutoring & 57 & 0.04 \\
\hline Louisiana & 07 & Fully Devoted Developer of Children & 729 & 0.02 \\
\hline Louisiana & 07 & Gaining Academic Progress & 59 & 0.09 \\
\hline Louisiana & 07 & Louisiana Learning Circle & 318 & 0.01 \\
\hline & & Sylvan Learning Centers of Baton & & \\
\hline Louisiana & 07 & Rouge/Gonzales & 49 & 0.03 \\
\hline Louisiana & 07 & The Achievement Academy & 489 & 0.04 \\
\hline Louisiana & 08 & A to $\mathrm{Z}$ In-Home Tutoring & 59 & 0.09 \\
\hline Louisiana & 08 & All About Education & 26 & -0.09 \\
\hline
\end{tabular}




\begin{tabular}{|c|c|c|c|c|}
\hline Louisiana & 08 & Catapult & 24 & -0.04 \\
\hline Louisiana & 08 & CFNLA Bright Futures & 64 & -0.02 \\
\hline Louisiana & 08 & Club Z! In-Home Tutoring & 67 & 0.03 \\
\hline Louisiana & 08 & Fully Devoted Developer of Children & 243 & 0.05 \\
\hline Louisiana & 08 & Gaining Academic Progress & 22 & 0.15 \\
\hline Louisiana & 08 & Louisiana Learning Circle & 109 & 0.06 \\
\hline \multirow[t]{2}{*}{ Louisiana } & 08 & Sci-Port Discovery Center & 12 & -0.17 \\
\hline & & $\begin{array}{l}\text { Strengthening Our Students - } \\
\text { Academically (SOSA) - Monroe City }\end{array}$ & & \\
\hline Louisiana & 08 & Schools & 40 & -0.18 \\
\hline Louisiana & 08 & Sylvan Learning Center of Baton Rouge & 36 & 0.17 \\
\hline Louisiana & 08 & The Achievement Academy & 196 & 0.12 \\
\hline Louisiana & 08 & Training Connections & 215 & -0.01 \\
\hline Louisiana & 08 & Volunteers of America North Lousiana & 27 & 0.54 \\
\hline Maryland & 06 & ABC Educate Me & 53 & 0.07 \\
\hline Maryland & 06 & Baltimore Curriculum Project & 30 & 0.19 \\
\hline \multirow[t]{2}{*}{ Maryland } & 06 & $\begin{array}{l}\text { BELL (Building Educated Leaders for } \\
\text { Life) }\end{array}$ & 51 & -0.02 \\
\hline & & Edison Schools dba Newton Learning & & \\
\hline Maryland & 06 & Division & $\begin{array}{r}80 \\
295\end{array}$ & $\begin{array}{r}-0.01 \\
0.09\end{array}$ \\
\hline Maryland & $\begin{array}{l}06 \\
06\end{array}$ & GapBuster Learning Center & $\begin{array}{r}295 \\
27\end{array}$ & -0.13 \\
\hline \multirow[t]{2}{*}{ Maryland } & 06 & Huntington Learning & 18 & 0.38 \\
\hline & & IEP (Innovative Educational Programs) & & \\
\hline Maryland & 06 & LLC & 66 & -0.07 \\
\hline \multirow[t]{2}{*}{ Maryland } & 06 & Mrs. Dowd's Teaching Services & 63 & 0.06 \\
\hline & 06 & $\begin{array}{l}\text { Porter Education and Communications, } \\
\text { Inc }\end{array}$ & 73 & 0.18 \\
\hline Maryland & 06 & The Princeton Review & 52 & 0.33 \\
\hline \multirow[t]{2}{*}{ Maryland } & 07 & Baltimore Curriculum Project & 23 & -0.1 \\
\hline & 07 & $\begin{array}{l}\text { BELL (Building Educated Leaders for } \\
\text { Life) }\end{array}$ & 63 & 0.25 \\
\hline Maryland & & Edison Schools dba Newton Learning & & \\
\hline Maryland & 07 & Division & 80 & 0.15 \\
\hline Maryland & 07 & Education Station & 317 & 0.04 \\
\hline Maryland & 07 & GapBuster Learning Center & 10 & 0.06 \\
\hline \multirow[t]{2}{*}{ Maryland } & 07 & Huntington Learning & 13 & -0.02 \\
\hline & & IEP (Innovative Educational Programs) & & \\
\hline Maryland & 07 & LLC & 60 & -0.12 \\
\hline Maryland & 07 & Mrs. Dowd's Teaching Services & 129 & 0.01 \\
\hline
\end{tabular}




$\begin{array}{ll}\text { Maryland } & 07 \\ \text { New Mexico } & 07 \\ \text { New Mexico } & 07 \\ \text { New Mexico } & 07 \\ \text { New Mexico } & 07 \\ \text { New Mexico } & 07 \\ \text { New Mexico } & 07 \\ \text { New Mexico } & 07 \\ \text { New Mexico } & 07 \\ \text { New Mexico } & 07 \\ \text { New Mexico } & 07 \\ \text { New Mexico } & 07 \\ \text { New Mexico } & 07 \\ \text { New Mexico } & 07 \\ \text { New Mexico } & 07 \\ \text { New Mexico } & 07 \\ \text { New Mexico } & 07 \\ \text { New Mexico } & 07 \\ \text { North Carolina } & 07\end{array}$

North Carolina $\quad 07$

North Carolina $\quad 07$

North Carolina 07

North Carolina $\quad 07$

North Carolina $\quad 07$

North Carolina $\quad 07$

North Carolina $\quad 07$

North Carolina $\quad 07$

North Carolina 07

North Carolina $\quad 07$

North Carolina

07

07

07

07

07

07

07

07

07

07

07

07

07

07

07

07

07

07

07

07

07

07

07

07

07

07

07

07

07

North Carolina

North Carolina

07

North Carolina

07

North Carolina

07

North Carolina

Porter Education and Communications,

Inc

A to $Z$ In-home Tutoring

Adelante Educational

Advantage Educational

Apex Educational

ATF Teacher Tutoring

Catapult

Club Z! In-Home Tutoring

Club Z! In-Home Tutoring

CompatibleLand Inc

Education Station

eProgress Academy

LaPromesa A+ Tutoring

Northern New Mexico

One Room School House

Rio Grande Educational

Sylvan-Farmington (SuccessSylvan)

Youth Development Inc

Academics by Venture

Achieve Success/University Instructors

Brainworks Learning Center

Brame Institute

Bright Futures Learning Center

Club Z! In-Home Tutoring

Community Education Durham Public

Schools

Huntington Learning

Mastermind Prep

North Carolina Central University

Southridge Learning Center

Sylvan Ace It (Bladen, Brunswick,

Columbus, Lumberton, Robeson)

Sylvan Ace It (Greenville, Washington,
38

$81-0.2805$

$29-0.0966$

$583-0.0414$

251

787

134

115

104

188

135

577

403

148

Kinston, Jacksonville, New Bern)

Sylvan Learning Center Charlotte

University

Sylvan Learning Center Columbus

Sylvan Learning Center Elizabeth City

Sylvan Learning Center Robeson
18

55

38

58

75

86

10

16

16

16

21

33

63

71

10

61

$-0.14$

80

$-0.09$

$-0.333$

$-0.0942$

0.2502

$-0.0445$

0.0281

$-0.0792$

$-0.0324$

0.1021

0.0543

0.0345

$-0.1408$

$-0.0301$

$-0.0558$

0.1367

$-0.18$

$-0.13$

$-0.38$

$-0.07$

0.69

0.06

$-0.3$

$-0.22$

0.34

$-0.31$

0.39

$32 \quad-0.08$

$14 \quad 0.43$

$22 \quad-0.73$

$16 \quad 0.39$ 


$\begin{array}{ll}\text { North Carolina } & 08 \\ \text { North Carolina } & 08 \\ \text { North Carolina } & 08 \\ \text { North Carolina } & 08 \\ \text { North Carolina } & 08 \\ \text { North Carolina } & 08 \\ \text { North Carolina } & 08 \\ \text { North Carolina } & 08 \\ & \\ \text { North Carolina } & 08 \\ & \\ \text { North Carolina } & 08 \\ \text { North Carolina } & 08 \\ \text { North Carolina } & 08 \\ \text { North Carolina } & 08 \\ \text { North Carolina } & 08 \\ \text { North Carolina } & 08 \\ \text { North Carolina } & 08 \\ \text { North Carolina } & 08\end{array}$

North Carolina

North Carolina

08

North Carolina $\quad 08$

North Carolina $\quad 08$

North Carolina $\quad 08$

North Carolina $\quad 08$

North Carolina $\quad 08$

North Carolina 08

North Carolina $\quad 08$

North Carolina $\quad 08$

North Carolina 08

Tennessee 05

Tennessee 05

Tennessee 05

Tennessee 05

Tennessee 05

Tennessee
Academics by Venture

$\begin{array}{rr}77 & -0.06 \\ 458 & -0.03\end{array}$

Academics Plus

Achieve Success/University Instructors

179

Brainworks Learning Center

Brame Institute

Bright Futures Learning Center

Capitol Education Support

Carter Reddy and Associates

Communities in Schools: Brunswick

County

Community Technology Learning

Center

Cool Kids Learn, Inc.

East Carolina Educational Center

I Can Kids, Inc.

Mastermind Prep

Measurement Inc.

North Carolina Central University

S \&amp; L Consultants

Sylvan Ace It (Greenville, Washington,

Kinston, Jacksonville, New Bern)

Sylvan Ace It (Henderson and Roanoke Rapids)

Sylvan Learning Center Charlotte

University

Sylvan Learning Center Clinton

Sylvan Learning Center Elizabeth City

Sylvan Learning Center Hickory

Sylvan Learning Center Lumberton

Sylvan Learning Center Mt. Airy

Sylvan Learning Center Whiteville

TCAL Center for Accelerated Learning

TRAC Enrichment Center, Inc.

$A$ to $Z$ In-home Tutoring

A's \& B's

Back on Track

Boys \&amp; Girls Clubs of America

Club Z! In-Home Tutoring

Education Station
123

77

$53-0.09$

$279 \quad 0.08$

$57-0.05$

$69 \quad-0.09$

$16 \quad-0.04$

$22-1.01$

$22 \quad 0.01$

$13 \quad 0.06$

$47-0.02$

$241-0.06$

$18-0.13$

$121 \quad 0.22$

$39 \quad 0.09$

$\begin{array}{ll}39 & 0.36\end{array}$

$66 \quad 0.14$

$25 \quad 0.39$

$94 \quad 0.01$

$19-0.41$

$22-0.08$

$36 \quad 0.21$

$15 \quad 0.06$

$31-0.23$

$\begin{array}{ll}79 & -0.07\end{array}$

$72 \quad-0.09$

$\begin{array}{ll}9 & -0.29\end{array}$

$18-0.11$

$190-0.02$
$15 \quad 0.19$ 


\begin{tabular}{|c|c|c|c|c|}
\hline Tennessee & 05 & Failure Free Reading & 11 & -0.36 \\
\hline Tennessee & 05 & Fannie Battle & 7 & 0.53 \\
\hline Tennessee & 05 & Honors Learning & 24 & -0.09 \\
\hline Tennessee & 05 & If I Had a Hammer & 35 & -0.26 \\
\hline Tennessee & 05 & Innovative Ideas & 106 & 0.04 \\
\hline Tennessee & 05 & Kumon & 9 & 0 \\
\hline Tennessee & 05 & Learning Zone & 3 & 0.39 \\
\hline Tennessee & 05 & Martha O Bryan & 14 & 0.41 \\
\hline Tennessee & 05 & Newton Learning & 118 & 0.07 \\
\hline Tennessee & 05 & Plato Learning & 18 & 0.08 \\
\hline Tennessee & 05 & $\begin{array}{l}\text { Porter Education and Communications, } \\
\text { Inc }\end{array}$ & 1 & -0.05 \\
\hline Tennessee & 05 & Project HELP & 51 & 0.23 \\
\hline Tennessee & 05 & SkyLearn Digital Systems & 9 & 0.34 \\
\hline Tennessee & 05 & Sylvan Learning & 2 & -0.49 \\
\hline Tennessee & 05 & The Princeton Review & 24 & -0.13 \\
\hline Tennessee & 05 & The Street Academy/Urban League & 135 & 0.05 \\
\hline Tennessee & 05 & $X-C E L$ & 20 & 0.13 \\
\hline Tennessee & 06 & A to $\mathrm{Z}$ In-home Tutoring & 52 & 0.07 \\
\hline Tennessee & 06 & Club Z! In-Home Tutoring & 15 & 0.19 \\
\hline Tennessee & 06 & Education Station & 46 & -0.48 \\
\hline Tennessee & 06 & Honors Learning & 20 & -0.52 \\
\hline Tennessee & 06 & If I Had a Hammer & 102 & 0.01 \\
\hline Tennessee & 06 & Innovative Ideas & 83 & -0.14 \\
\hline Tennessee & 06 & Newton Learning & 70 & 0.07 \\
\hline Tennessee & 06 & Plato Learning & 20 & 0.02 \\
\hline Tennessee & 06 & The Street Academy/Urban League & 102 & 0.12 \\
\hline Tennessee & 07 & A to $\mathrm{Z}$ In-home Tutoring & 97 & 0.07 \\
\hline Tennessee & 07 & $A^{\prime} s \&$ B's & 25 & 0.04 \\
\hline Tennessee & 07 & Bright Sky Learning & 39 & -0.11 \\
\hline Tennessee & 07 & Club Z! In-Home Tutoring & 38 & -0.13 \\
\hline Tennessee & 07 & Cool Kids Learn, Inc. & 19 & -0.42 \\
\hline Tennessee & 07 & Education Station & 203 & 0.05 \\
\hline Tennessee & 07 & Innovative Ideas & 165 & 0.09 \\
\hline Tennessee & 07 & Kastle Instruction & 103 & -0.03 \\
\hline Tennessee & 07 & Learning Zone & 25 & 0.12 \\
\hline Tennessee & 07 & Memphis City Schools' Project Achieve & 92 & -0.14 \\
\hline Tennessee & 07 & Success Educational Services & 45 & 0.42 \\
\hline Tennessee & 07 & The Street Academy/Urban League & 73 & 0.08 \\
\hline Tennessee & 08 & A to $\mathrm{Z}$ In-Home Tutoring & 27 & -0.57 \\
\hline Tennessee & 08 & AlphaBest & 24 & -0.48 \\
\hline Tennessee & 08 & Bright Sky Learning & 45 & -0.16 \\
\hline
\end{tabular}




\begin{tabular}{|c|c|c|c|c|}
\hline Tennessee & 08 & Cool Kids Learn, Inc. & 19 & -0.28 \\
\hline Tennessee & 08 & Education Station & 12 & -0.37 \\
\hline Tennessee & 08 & Kastle Instruction & 21 & -0.64 \\
\hline Tennessee & 08 & Knowledge Points of Middle TN & 32 & 0.04 \\
\hline Tennessee & 08 & Success Educational Services & 26 & -0.67 \\
\hline Tennessee & 08 & The Street Academy/Urban League & 42 & -0.27 \\
\hline Virginia & 04 & Achieve Success/University Instructors & 152 & 0.17 \\
\hline Virginia & 04 & Destiny Achievers & 7 & -0.09 \\
\hline Virginia & 04 & EdSolutions & 20 & -0.23 \\
\hline Virginia & 04 & Huntington Learning & 2 & 0.78 \\
\hline Virginia & 04 & Lightspan/Plato & 34 & 0.61 \\
\hline & & . & & \\
\hline Virginia & 07 & Achieve Success/University Instructors & 69 & 0.16 \\
\hline Virginia & 07 & Club Z! In-Home Tutoring & 19 & 0.11 \\
\hline Virginia & 07 & Huntington Learning & 17 & 0.23 \\
\hline Virginia & 07 & NonPublic Educational Services Inc & 13 & 0.5 \\
\hline Virginia & 07 & $\begin{array}{l}\text { Porter Education and Communications, } \\
\text { Inc }\end{array}$ & 11 & 0.5 \\
\hline Virginia & 08 & A+ Markem & 17 & 0.53 \\
\hline Virginia & 08 & Achieve Success/University Instructors & 80 & 0.2 \\
\hline Virginia & 08 & Club Z! In-Home Tutoring & 28 & 0.06 \\
\hline Virginia & 08 & Compass Learning & 38 & -0.24 \\
\hline Virginia & 08 & Education Online & 11 & -0.12 \\
\hline Virginia & 08 & Huntington Learning & 31 & 0.18 \\
\hline Virginia & 08 & NonPublic Educational Services, Inc & 24 & -0.13 \\
\hline Virginia & 08 & $\begin{array}{l}\text { Porter Education and Communications, } \\
\text { Inc }\end{array}$ & 24 & -0.09 \\
\hline Virginia & 08 & T-squared Tutors, LLC & 11 & -0.01 \\
\hline
\end{tabular}


APPENDIX E

Reading Effect Sizes Included in Analysis

\begin{tabular}{|c|c|c|c|c|}
\hline State or District & $\begin{array}{c}\text { Academic } \\
\text { Year }\end{array}$ & Provider Name & $n$ & $\begin{array}{c}\text { Effect } \\
\text { Size (d) }\end{array}$ \\
\hline Chicago & 06 & A+ TUTORING SERVICE LTD & 440 & -0.15 \\
\hline Chicago & 06 & BRAIN HURRICANE, LLC & 118 & 0.04 \\
\hline Chicago & 06 & BRAINFUSE ONE-TO-ONE & 174 & 0.07 \\
\hline Chicago & 06 & BRAINFUSE ONE-TO-ONE & 266 & -0.16 \\
\hline Chicago & 06 & BRILLIANCE ACADEMY & 313 & -0.06 \\
\hline Chicago & 06 & CAMBRIDGE EDUCATIONAL SERVICES & 1362 & 0.01 \\
\hline Chicago & 06 & Catapult & 353 & 0.04 \\
\hline Chicago & 06 & Club Z! In-Home Tutoring & 391 & -0.1 \\
\hline Chicago & 06 & CS\&amp;C, INC.- JULEX LEARNING & 482 & -0.16 \\
\hline Chicago & 06 & ED SOLUTIONS, INC. & 285 & 0.25 \\
\hline Chicago & 06 & Education Station & 2830 & -0.06 \\
\hline Chicago & 06 & EDUCATIONAL SPECIALTIES & 119 & 0.22 \\
\hline Chicago & 06 & Failure Free Reading & 130 & -0.35 \\
\hline Chicago & 06 & NCLB TUTORS & 106 & -0.06 \\
\hline Chicago & 06 & Newton Learning & 7813 & -0.03 \\
\hline Chicago & 06 & ONE-TO-ONE LEARNING CENTER & 157 & 0 \\
\hline Chicago & 06 & Platform Learning & 1782 & -0.01 \\
\hline Chicago & 06 & Plato Learning & 113 & -0.07 \\
\hline Chicago & 06 & PROGRESSIVE LEARNING & 950 & -0.03 \\
\hline Chicago & 06 & SCHOOL SERVICE SYSTEMS & 569 & 0.11 \\
\hline Chicago & 06 & SCORE EDUCATIONAL CENTERS & 202 & 0.07 \\
\hline Chicago & 06 & The Princeton Review & 3996 & 0.02 \\
\hline Chicago & 06 & UNPARALLELED SOLUTIONS, INC. & 519 & 0.1 \\
\hline Chicago & 07 & A+ TUTORING SERVICE LTD & 925 & 0.16 \\
\hline Chicago & 07 & AIM HIGH - CPS & 14760 & 0.02 \\
\hline Chicago & 07 & Alternatives Unlimited & 84 & -0.07 \\
\hline Chicago & 07 & BRAIN HURRICANE, LLC & 372 & 0.04 \\
\hline Chicago & 07 & BRAINFUSE ONE-TO-ONE & 782 & 0.07 \\
\hline Chicago & 07 & BRILLIANCE ACADEMY & 1548 & -0.03 \\
\hline Chicago & 07 & CAMBRIDGE EDUCATIONAL SERVICES & 861 & 0.06 \\
\hline Chicago & 07 & Catapult & 1465 & 0.14 \\
\hline Chicago & 07 & CHAMPIONS & 1510 & 0 \\
\hline Chicago & 07 & Club Z! In-Home Tutoring & 1959 & 0.03 \\
\hline Chicago & 07 & CS\&amp;C, INC.- JULEX LEARNING & 327 & 0.2 \\
\hline Chicago & 07 & Education Station & 3293 & 0.02 \\
\hline
\end{tabular}




\begin{tabular}{|c|c|c|c|c|}
\hline Chicago & 07 & EDUCATIONAL SPECIALTIES & 265 & 0.02 \\
\hline Chicago & 07 & Failure Free Reading & 405 & -0.16 \\
\hline Chicago & 07 & Huntington Learning & 495 & 0.17 \\
\hline Chicago & 07 & LITERACY FOR ALL & 126 & -0.03 \\
\hline Chicago & 07 & Newton Learning & 3966 & 0 \\
\hline Chicago & 07 & ONE-TO-ONE LEARNING CENTER & 256 & 0.2 \\
\hline Chicago & 07 & ORION'S MIND & 146 & -0.03 \\
\hline Chicago & 07 & Platform Learning & 1724 & -0.03 \\
\hline Chicago & 07 & PROGRESSIVE LEARNING & 1830 & 0.05 \\
\hline Chicago & 07 & SCHOOL SERVICE SYSTEMS & 748 & -0.04 \\
\hline Chicago & 07 & Socratic Learning & 1228 & 0.11 \\
\hline Chicago & 07 & The Princeton Review & 2952 & 0.03 \\
\hline Chicago & 07 & UNPARALLELED SOLUTIONS, INC. & 805 & 0.12 \\
\hline Chicago & 08 & A+ TUTORING SERVICE LTD & 97 & -0.15 \\
\hline Chicago & 08 & AIM HIGH - CPS & 9412 & 0.04 \\
\hline Chicago & 08 & BRAIN HURRICANE, LLC & 204 & -0.03 \\
\hline Chicago & 08 & BRAINFUSE ONE-TO-ONE & 167 & 0.02 \\
\hline Chicago & 08 & BRILLIANCE ACADEMY & 125 & -0.12 \\
\hline Chicago & 08 & CAMBRIDGE EDUCATIONAL SERVICES & 159 & 0.13 \\
\hline Chicago & 08 & Catapult & 423 & 0.02 \\
\hline & & CENTER OF HIGHER DEVELOPMENT & & \\
\hline Chicago & 08 & (ONSITE) & 48 & 0.08 \\
\hline Chicago & 08 & Club Z! In-Home Tutoring & 133 & -0.09 \\
\hline Chicago & 08 & CS\&amp;C, INC.- JULEX LEARNING & 60 & -0.45 \\
\hline Chicago & 08 & Education Station & 633 & 0 \\
\hline Chicago & 08 & EDUCATIONAL SPECIALTIES & 44 & 0.2 \\
\hline Chicago & 08 & Failure Free Reading & 53 & -0.21 \\
\hline Chicago & 08 & Huntington Learning & 195 & -0.02 \\
\hline \multirow[t]{2}{*}{ Chicago } & 08 & LITERACY FOR ALL & 115 & 0.17 \\
\hline & & MAINSTREAM DEVELOPMENT ED & & \\
\hline Chicago & 08 & GROUP & 52 & -0.13 \\
\hline Chicago & 08 & Newton Learning & 3651 & 0.04 \\
\hline Chicago & 08 & ONE-TO-ONE LEARNING CENTER & 46 & -0.17 \\
\hline Chicago & 08 & ORION'S MIND & 888 & -0.02 \\
\hline Chicago & 08 & Platform Learning & 429 & -0.12 \\
\hline Chicago & 08 & PROGRESSIVE LEARNING & 1956 & 0.07 \\
\hline Chicago & 08 & SCHOOL SERVICE SYSTEMS & 736 & 0.03 \\
\hline Chicago & 08 & SES OF ILLINOIS & 229 & 0.11 \\
\hline Chicago & 08 & The Princeton Review & 2082 & 0.04 \\
\hline Chicago & 08 & UNPARALLELED SOLUTIONS, INC. & 866 & 0.04 \\
\hline Florida & 07 & "A" Wise Choice & 45 & -0.059 \\
\hline Florida & 07 & A+ Tutor U & 371 & 0.039 \\
\hline
\end{tabular}




\begin{tabular}{|c|c|c|c|c|}
\hline Florida & 07 & Academy of Success & 113 & 0.091 \\
\hline Florida & 07 & ACES & 57 & 0.181 \\
\hline Florida & 07 & Achievia & 43 & 0.056 \\
\hline Florida & 07 & Advanced Learning & 97 & -0.385 \\
\hline Florida & 07 & AlphaBest & 268 & 0.248 \\
\hline Florida & 07 & Club Z! & 34 & -0.398 \\
\hline Florida & 07 & Cool Kids Learn & 208 & 0.301 \\
\hline Florida & 07 & Education Station & 1254 & 0.02 \\
\hline Florida & 07 & Huntington Learning & 158 & -0.16 \\
\hline Florida & 07 & Huxtable Education & 59 & -0.083 \\
\hline Florida & 07 & PCTA & 55 & -0.178 \\
\hline Florida & 07 & Rocket Learning & 816 & -0.027 \\
\hline Hawaii & 06 & College Connections & 9 & -0.9016 \\
\hline Hawaii & 06 & Community Schools for Adults & 9 & -0.7762 \\
\hline Hawaii & 06 & Education Therapy & 7 & 0.5502 \\
\hline Hawaii & 06 & It's all about Kids & 45 & -0.2975 \\
\hline Hawaii & 06 & Learning Hale & 7 & -0.0146 \\
\hline Hawaii & 07 & College Connections & 85 & -0.4467 \\
\hline Hawaii & 07 & Community Schools for Adults & 15 & -0.5113 \\
\hline Hawaii & 07 & Education Therapy & 11 & -0.883 \\
\hline Hawaii & 07 & Hui Malama & 2 & -0.251 \\
\hline Hawaii & 07 & It's all about Kids & 238 & -0.5127 \\
\hline Hawaii & 07 & Kumon & 15 & -0.2953 \\
\hline Hawaii & 07 & Learning Hale & 23 & -0.1523 \\
\hline $\begin{array}{l}\text { Jefferson } \\
\text { County, KY }\end{array}$ & 08 & A Better Grade Tutoring & 136 & 0.2 \\
\hline $\begin{array}{l}\text { Jefferson } \\
\text { County, KY }\end{array}$ & 08 & A Plus Tutoring & 310 & 0.13 \\
\hline $\begin{array}{l}\text { Jefferson } \\
\text { County, KY }\end{array}$ & 08 & A to $\mathrm{Z}$ In-home Tutoring & 208 & 0.15 \\
\hline $\begin{array}{l}\text { Jefferson } \\
\text { County, KY }\end{array}$ & 08 & Catapult & 270 & 0.12 \\
\hline $\begin{array}{l}\text { Jefferson } \\
\text { County, KY }\end{array}$ & 08 & Club Z! In-Home Tutoring & 314 & 0.11 \\
\hline $\begin{array}{l}\text { Jefferson } \\
\text { County, KY }\end{array}$ & 08 & Huntington Learning & 250 & 0.13 \\
\hline $\begin{array}{l}\text { Jefferson } \\
\text { County, KY }\end{array}$ & 08 & $\begin{array}{l}\text { Porter Education and Communications, } \\
\text { Inc }\end{array}$ & 70 & 0.2 \\
\hline $\begin{array}{l}\text { Jefferson } \\
\text { County, KY }\end{array}$ & 08 & SOAR & 196 & 0.17 \\
\hline $\begin{array}{l}\text { Jefferson } \\
\text { County, KY }\end{array}$ & 08 & The Salvation Army & 104 & 0.14 \\
\hline
\end{tabular}


Jefferson

County, KY

08

Kentucky

Kentucky

Kentucky

Kentucky

Kentucky

Kentucky

Kentucky

Kentucky

Los Angeles

Los Angeles

Los Angeles

Los Angeles

Los Angeles

Los Angeles

Los Angeles

Los Angeles

Los Angeles

Los Angeles

Los Angeles

Los Angeles

Los Angeles

Los Angeles

Los Angeles

Los Angeles

Los Angeles

Los Angeles

Los Angeles

Los Angeles

Los Angeles

Los Angeles

Los Angeles

Los Angeles

Los Angeles

Los Angeles

Los Angeles

Los Angeles

Los Angeles

Los Angeles

Los Angeles
08

08

08

08

05

05

05

05

05

05

05

05

05

05

05

05

05

06

06

06

06

06

06

06

06

06

06

06

06

06

06

06

06

06

06
Yes! All Students Can Learn

A Better Grade Tutoring

A Plus Tutoring

A to $Z$ In-home Tutoring

Club Z! In-Home Tutoring

Porter Education and Communications,

Inc

Radcliff Reading Clinic

The Salvation Army

Yes! All Students Can Learn

A+ Educational Centers

ABC-Learn, Inc

Best/Tutors of the Inland Empire

Club Z! In-Home Tutoring

Education Station

Educational and Tutorial

Huntington Learning

Los Angeles USD

Newton Learning

Professional Tutors of America

Say YES to Life

SCORE! Learning, Inc

Smart Kids Tutoring \&amp; Learning

At Educational Centers

ABC-Learn, Inc

Academic Advantage/Tutors Club

Ace Tutoring Services

America's Tutors

Basic Education Services

Boys \&amp; Girls Clubs of America

BRAINFUSE ONE-TO-ONE

Carney Education Services

Club Z! In-Home Tutoring

Community College Foundation

Dreambuilders

Education 2020

Education Station

Educational and Tutorial

Educational Support

Educators Plus

Huntington Learning

$\begin{array}{rr}76 & 0.13 \\ 22 & -0.14 \\ 45 & -0.09 \\ 37 & -0.1 \\ 41 & -0.07\end{array}$

$\begin{array}{ll}18 & -0.07\end{array}$

$11-0.33$

$17 \quad 0.1$

$15-0.06$

$774 \quad 0.075$

$254 \quad 0.035$

$116 \quad 0.06$

$129-0.097$

$124 \quad 0.075$

$52-0.045$

$102 \quad 0.075$

$5073 \quad 0.01$

$59-0.075$

$306 \quad 0.05$

$64 \quad 0.04$

$127-0.02$

$97 \quad 0.03$

$1138 \quad 0.01$

$342 \quad 0.04$

$418 \quad 0.11$

$464 \quad 0.06$

$50 \quad-0.035$

$278 \quad 0$

$76 \quad 0.1$

$63-0.06$

$111 \quad 0.12$

$233 \quad 0.01$

$397 \quad 0.07$

$65-0.05$

$33 \quad 0.065$

$536 \quad 0.025$

$71-0.05$

$41-0.04$

$71 \quad 0.05$

$134 \quad 0.035$ 


\begin{tabular}{|c|c|c|c|c|}
\hline Los Angeles & 06 & Kumon & 38 & -0.14 \\
\hline Los Angeles & 06 & Learning Fun Center & 223 & -0.035 \\
\hline Los Angeles & 06 & Newton Learning & 294 & 0.045 \\
\hline Los Angeles & 06 & Platform Learning & 77 & -0.09 \\
\hline Los Angeles & 06 & Professional Tutors of America & 501 & 0.06 \\
\hline Los Angeles & 06 & Say YES to Life & 319 & -0.11 \\
\hline Los Angeles & 06 & SCORE! Learning, Inc & 114 & 0.065 \\
\hline Los Angeles & 06 & Total Education Solutions & 76 & -0.05 \\
\hline Los Angeles & 06 & Urok & 68 & -0.1 \\
\hline Los Angeles & 06 & Youth Policy Institute & 150 & -0.04 \\
\hline Los Angeles & 07 & A+ Educational Centers & 1489 & -0.018 \\
\hline Los Angeles & 07 & ABC Phonetic Reading School & 82 & 0.05 \\
\hline Los Angeles & 07 & ABC-Learn, Inc & 163 & 0.03 \\
\hline Los Angeles & 07 & Academic Advantage/Tutors Club & 1289 & 0.035 \\
\hline Los Angeles & 07 & Academic Tutoring Service & 37 & -0.13 \\
\hline Los Angeles & 07 & Ace Tutoring Services & 783 & 0.03 \\
\hline Los Angeles & 07 & America's Tutors & 34 & -0.12 \\
\hline Los Angeles & 07 & Best/Tutors of the Inland Empire & 301 & 0.065 \\
\hline Los Angeles & 07 & BRAINFUSE ONE-TO-ONE & 38 & -0.005 \\
\hline Los Angeles & 07 & Bright Futures Learning Center & 32 & -0.16 \\
\hline Los Angeles & 07 & Carney Education Services & 333 & 0.01 \\
\hline Los Angeles & 07 & Catapult & 1213 & 0.015 \\
\hline Los Angeles & 07 & Century/LIFT & 31 & -0.01 \\
\hline Los Angeles & 07 & Club Z! In-Home Tutoring & 262 & -0.02 \\
\hline Los Angeles & 07 & Community College Foundation & 389 & 0.02 \\
\hline Los Angeles & 07 & Dreambuilders & 164 & 0.01 \\
\hline Los Angeles & 07 & Educational and Tutorial & 64 & 0.04 \\
\hline Los Angeles & 07 & Educators Plus & 120 & 0.005 \\
\hline Los Angeles & 07 & Genesis 8 & 38 & -0.1 \\
\hline Los Angeles & 07 & Gwen Bolden & 40 & -0.14 \\
\hline Los Angeles & 07 & Huntington Learning & 78 & 0.075 \\
\hline Los Angeles & 07 & Kumon & 36 & 0.02 \\
\hline Los Angeles & 07 & Learning Fun Center & 183 & 0.02 \\
\hline Los Angeles & 07 & Positive Visions & 32 & 0.01 \\
\hline Los Angeles & 07 & Professional Tutors of America & 732 & 0.06 \\
\hline Los Angeles & 07 & Project Impact & 41 & -0.04 \\
\hline Los Angeles & 07 & Say YES to Life & 250 & -0.04 \\
\hline Los Angeles & 07 & SCORE! Learning, Inc & 183 & 0.03 \\
\hline Los Angeles & 07 & SkyLearn Digital Systems & 45 & 0.065 \\
\hline Los Angeles & 07 & Teach Learning Academy & 45 & -0.095 \\
\hline Los Angeles & 07 & Total Education Solutions & 107 & 0.013 \\
\hline Los Angeles & 07 & Urok & 134 & -0.03 \\
\hline Los Angeles & 07 & WE CAN Foundation & 87 & -0.03 \\
\hline
\end{tabular}




\begin{tabular}{|c|c|c|c|c|}
\hline Los Angeles & 07 & Youth Policy Institute & 293 & -0.015 \\
\hline Los Angeles & 08 & A+ Educational Centers & 1443 & 0.035 \\
\hline Los Angeles & 08 & ABC-Learn, Inc & 331 & 0.03 \\
\hline Los Angeles & 08 & Academic Advantage/Tutors Club & 1579 & 0.03 \\
\hline Los Angeles & 08 & Academic Tutoring Service & 114 & 0.065 \\
\hline Los Angeles & 08 & Ace Tutoring Services & 878 & 0.04 \\
\hline Los Angeles & 08 & Alternatives Unlimited & 197 & 0.03 \\
\hline Los Angeles & 08 & Best/Tutors of the Inland Empire & 374 & 0.075 \\
\hline Los Angeles & 08 & Carney Education Services & 564 & 0.005 \\
\hline Los Angeles & 08 & Catapult & 1163 & 0.07 \\
\hline Los Angeles & 08 & Club Z! In-Home Tutoring & 348 & -0.01 \\
\hline Los Angeles & 08 & Community College Foundation & 598 & 0.03 \\
\hline Los Angeles & 08 & Daekyo America & 277 & 0.03 \\
\hline Los Angeles & 08 & Dreambuilders & 154 & 0.07 \\
\hline Los Angeles & 08 & Genesis 8 & 67 & 0.035 \\
\hline Los Angeles & 08 & Huntington Learning & 57 & 0.14 \\
\hline Los Angeles & 08 & Kumon & 81 & -0.02 \\
\hline Los Angeles & 08 & Professional Tutors of America & 529 & 0.08 \\
\hline Los Angeles & 08 & Project Impact & 64 & 0.015 \\
\hline Los Angeles & 08 & Say YES to Life & 281 & -0.11 \\
\hline Los Angeles & 08 & Teach Learning Academy & 144 & 0.13 \\
\hline Los Angeles & 08 & Total Education Solutions & 159 & 0.07 \\
\hline Los Angeles & 08 & Urok & 206 & 0.065 \\
\hline Los Angeles & 08 & WE CAN Foundation & 242 & 0.045 \\
\hline Los Angeles & 08 & Youth Policy Institute & 333 & 0.04 \\
\hline Louisiana & 05 & Catholic Charities & 34 & 0.21 \\
\hline Louisiana & 05 & Education Station & 580 & 0.04 \\
\hline Louisiana & 05 & Failure Free Reading & 65 & -0.24 \\
\hline Louisiana & 05 & Louisiana Learning Circle & 25 & 0.13 \\
\hline & & Sylvan Learning Centers of Baton & & \\
\hline Louisiana & 05 & Rouge \&amp; Gonzales & 4 & -0.2 \\
\hline Louisiana & 05 & Training Connections & 33 & 0.06 \\
\hline Louisiana & 05 & Yes We Can! & 36 & 0.29 \\
\hline Louisiana & 06 & Club Z! In-Home Tutoring & 31 & -0.61 \\
\hline Louisiana & 06 & Education Station & 92 & 0.05 \\
\hline Louisiana & 06 & Failure Free Reading & 64 & -0.13 \\
\hline Louisiana & 06 & Fully Devoted Developer of Children & 276 & 0.17 \\
\hline Louisiana & 06 & Gaining Academic Progress & 6 & 0.63 \\
\hline Louisiana & 06 & NAACP Achievement Academy & 81 & 0.32 \\
\hline Louisiana & 06 & Newton Learning & 22 & -0.03 \\
\hline Louisiana & 06 & Sylvan Learning Centers & 7 & -0.21 \\
\hline Louisiana & 06 & The Princeton Review & 64 & 0.03 \\
\hline
\end{tabular}




\begin{tabular}{|c|c|c|c|c|}
\hline Louisiana & 06 & Training Connections & 102 & 0.07 \\
\hline Louisiana & 07 & Club Z! In-Home Tutoring & 79 & -0.01 \\
\hline Louisiana & 07 & Education Station & 35 & 0.08 \\
\hline Louisiana & 07 & Failure Free Reading & 83 & -0.01 \\
\hline Louisiana & 07 & Fully Devoted Developer of Children & 161 & 0.07 \\
\hline \multirow[t]{2}{*}{ Louisiana } & 07 & St. Paul Community Outreach & 32 & 0.1 \\
\hline & & Sylvan Learning Centers of Baton & & \\
\hline Louisiana & 07 & Rouge/Gonzales & 52 & 0.12 \\
\hline Louisiana & 07 & Training Connections & 185 & 0.06 \\
\hline Louisiana & 08 & A to $Z$ In-Home Tutoring & 61 & 0.03 \\
\hline Louisiana & 08 & All About Education & 26 & -0.17 \\
\hline Louisiana & 08 & CFNLA Bright Futures & 64 & 0.14 \\
\hline Louisiana & 08 & Club Z! In-Home Tutoring & 67 & -0.05 \\
\hline Louisiana & 08 & Fully Devoted Developer of Children & 161 & 0 \\
\hline Louisiana & 08 & MTS Tutorial Services & 84 & 0.05 \\
\hline \multirow[t]{2}{*}{ Louisiana } & 08 & St. Paul Community Outreach & 34 & 0.06 \\
\hline & & $\begin{array}{l}\text { Strengthening Our Students - } \\
\text { Academically (SOSA) - Monroe City }\end{array}$ & & \\
\hline Louisiana & 08 & Schools & 40 & 0.22 \\
\hline Louisiana & 08 & Sylvan Learning Center of Baton Rouge & 25 & 0.09 \\
\hline Louisiana & 08 & The Achievement Academy & 200 & -0.01 \\
\hline Louisiana & 08 & Training Connections & 215 & 0.05 \\
\hline Louisiana & 08 & Volunteers of America North Lousiana & 27 & 0.1 \\
\hline Maryland & 06 & ABC Educate Me & 51 & 0.03 \\
\hline \multirow[t]{2}{*}{ Maryland } & 06 & Baltimore Curriculum Project & 33 & -0.05 \\
\hline & 06 & $\begin{array}{l}\text { BELL (Building Educated Leaders for } \\
\text { Life) }\end{array}$ & 51 & -0.07 \\
\hline Maryland & & Edison Schools dba Newton Learning & & \\
\hline Maryland & 06 & Division & 81 & 0.2 \\
\hline Maryland & 06 & Education Station & 246 & 0.07 \\
\hline Maryland & 06 & GapBuster Learning Center & 27 & -0.29 \\
\hline \multirow[t]{2}{*}{ Maryland } & 06 & Huntington Learning & 22 & -0.2 \\
\hline & & IEP (Innovative Educational Programs) & & \\
\hline \multirow[t]{2}{*}{ Maryland } & 06 & LLC & 79 & -0.14 \\
\hline & 06 & $\begin{array}{l}\text { Johns Hopkins - East Baltimore Mental } \\
\text { Health Partnership }\end{array}$ & 25 & 0.24 \\
\hline Maryland & 06 & Mrs. Dowd's Teaching Services & 63 & 0 \\
\hline Maryland & 06 & Plato Learning & 13 & 0.15 \\
\hline
\end{tabular}


Maryland $\quad 06$

Maryland $\quad 06$

Maryland 06

Maryland

Maryland

Maryland

Maryland

Maryland

Maryland

Maryland

North Carolina

North Carolina

North Carolina

North Carolina

North Carolina

North Carolina

North Carolina

North Carolina

North Carolina

North Carolina

North Carolina

North Carolina

North Carolina

North Carolina

North Carolina

North Carolina

North Carolina

North Carolina

North Carolina

North Carolina
07

07

07

07

07

06

07

07

07

07

07

07

07

07

07

07

07

07

07

07

Porter Education and Communications,

Inc

The Princeton Review

YMCA of Central Maryland

Baltimore Curriculum Project

BELL (Building Educated Leaders for

Life)

Edison Schools dba Newton Learning

Division

Education Station

IEP (Innovative Educational Programs)

LLC

Mrs. Dowd's Teaching Services

Porter Education and Communications, Inc

Academics by Venture

Academics Plus

Achieve Success/University Instructors

Brame Institute

Bright Futures Learning Center

Club Z! In-Home Tutoring

Community Education Durham Public

Schools

21

Education Station

Failure Free Reading

Huntington Learning

Mastermind Prep

North Carolina Central University

Prime Time for Kids

Southridge Learning Center

Sylvan Ace It (Bladen, Brunswick,

Columbus, Lumberton, Robeson)

Sylvan Ace It (Greenville, Washington, Kinston, Jacksonville, New Bern)

Sylvan Ace It (Harnett, Wayne, Wilson)

100

Sylvan Ace It (Henderson and Roanoke Rapids)

Sylvan Ace It (Wake)

39

$-0.02$

0.05

0.05

0.42

$-0.05$

0.05

0.33

$-0.04$

0.16

$-0.09$

$-0.06$

$-0.15$

0.13

$-0.24$

$-0.25$

0.13

$-0.28$

0.04

$-0.2$

0.22

0.12

$-0.07$

$-0.36$

0

Sylvan Learning Center Charlotte

University
97

0.16 
$\begin{array}{ll}\text { North Carolina } & 07 \\ \text { North Carolina } & 07 \\ \text { North Carolina } & 07 \\ \text { North Carolina } & 08 \\ \text { North Carolina } & 08 \\ & \\ \text { North Carolina } & 08 \\ \text { North Carolina } & 08 \\ \text { North Carolina } & 08 \\ \text { North Carolina } & 08 \\ \text { North Carolina } & 08 \\ \text { North Carolina } & 08 \\ \text { North Carolina } & 08 \\ \text { North Carolina } & 08 \\ \text { North Carolina } & 08 \\ \text { North Carolina } & 08 \\ \text { North Carolina } & 08 \\ \text { North Carolina } & 08 \\ \text { North Carolina } & 08\end{array}$

North Carolina

08

North Carolina $\quad 08$

North Carolina $\quad 08$

North Carolina 08

North Carolina $\quad 08$

North Carolina $\quad 08$

North Carolina $\quad 08$

North Carolina $\quad 08$

North Carolina $\quad 08$

North Carolina $\quad 08$

North Carolina $\quad 08$

Tennessee 05

Tennessee 05

Tennessee 05

Tennessee 05

Tennessee

08
08
08

08
08
05
05
05
05
05

8

08

08

8

08

08

08

08

08

08

08

08

08

08

08

08

8

08

08

08

Sylvan Learning Center Columbus

Sylvan Learning Center Elizabeth City

Sylvan Learning Center Robeson

0.76

Academics by Venture

Academics Plus

$-0.09$

Achieve Success/University Instructors

$-0.15$

Brainworks Learning Center

0.03

Brame Institute

$-0.06$

Bright Futures Learning Center

$-0.12$

Capitol Education Support

$-0.26$

Carter Reddy and Associates

0.1

Cool Kids Learn, Inc.

0.09

Education Station

$-0.14$

Failure Free Reading

$-0.28$

It's Simply English

$-0.34$

Mastermind Prep

$-0.24$

Measurement Inc.

North Carolina Central University

0.07

$-0.12$

Sylvan Ace It (Greenville, Washington, Kinston, Jacksonville, New Bern)

Sylvan Ace It (Henderson and Roanoke

Rapids)

47

Sylvan Learning Center Charlotte

University

125

0.11

Sylvan Learning Center Clinton

Sylvan Learning Center Elizabeth City

Sylvan Learning Center Hickory

Sylvan Learning Center Lumberton

0.05

Sylvan Learning Center Mt. Airy

$-0.12$

Sylvan Learning Center Whiteville

TCAL Center for Accelerated Learning

TRAC Enrichment Center, Inc.

$-0.21$

$A$ to $Z$ In-home Tutoring

11

$-0.09$

A's \& B's

0.44

Back on Track

0.08

Bethlehem Literacy

0.16

Boys \&amp; Girls Clubs of America 


\begin{tabular}{|c|c|c|c|c|}
\hline Tennessee & 05 & Club Z! In-Home Tutoring & 15 & -0.01 \\
\hline Tennessee & 05 & Education Station & 220 & -0.11 \\
\hline Tennessee & 05 & Failure Free Reading & 55 & -0.27 \\
\hline Tennessee & 05 & Fannie Battle & 7 & 0.35 \\
\hline Tennessee & 05 & Honors Learning & 24 & -0.06 \\
\hline Tennessee & 05 & If I Had a Hammer & 4 & 0.22 \\
\hline Tennessee & 05 & Innovative Ideas & 58 & 0.13 \\
\hline Tennessee & 05 & Kumon & 9 & -0.93 \\
\hline Tennessee & 05 & Learning Zone & 2 & 1.14 \\
\hline Tennessee & 05 & Martha O Bryan & 14 & 0.17 \\
\hline Tennessee & 05 & Newton Learning & 46 & 0 \\
\hline Tennessee & 05 & PENCIL & 21 & 0.25 \\
\hline Tennessee & 05 & Plato Learning & 16 & -0.14 \\
\hline Tennessee & 05 & $\begin{array}{l}\text { Porter Education and Communications, } \\
\text { Inc }\end{array}$ & 1 & 0.29 \\
\hline Tennessee & 05 & Project HELP & 50 & 0.16 \\
\hline Tennessee & 05 & SkyLearn Digital Systems & 9 & 0.26 \\
\hline Tennessee & 05 & Sylvan Learning & 2 & -0.58 \\
\hline Tennessee & 05 & The Princeton Review & 4 & -0.48 \\
\hline Tennessee & 05 & The Street Academy/Urban League & 135 & 0.03 \\
\hline Tennessee & 05 & $X-C E L$ & 7 & 0.34 \\
\hline Tennessee & 06 & A to $Z$ In-home Tutoring & 40 & 0.29 \\
\hline Tennessee & 06 & Club Z! In-Home Tutoring & 21 & -0.04 \\
\hline Tennessee & 06 & Education Station & 16 & -0.03 \\
\hline Tennessee & 06 & Honors Learning & 18 & 0.11 \\
\hline Tennessee & 06 & If I Had a Hammer & 50 & 0.08 \\
\hline Tennessee & 06 & Innovative Ideas & 80 & 0.23 \\
\hline Tennessee & 06 & Newton Learning & 76 & -0.09 \\
\hline Tennessee & 06 & Plato Learning & 20 & -1.01 \\
\hline Tennessee & 06 & The Street Academy/Urban League & 104 & -0.02 \\
\hline Tennessee & 06 & $X$-CEL & 19 & 0.47 \\
\hline Tennessee & 07 & A to $\mathrm{Z}$ In-home Tutoring & 67 & 0.18 \\
\hline Tennessee & 07 & Bethlehem Literacy & 14 & -0.15 \\
\hline Tennessee & 07 & Bright Sky Learning & 46 & -0.18 \\
\hline Tennessee & 07 & Club Z! In-Home Tutoring & 35 & 0.02 \\
\hline Tennessee & 07 & Cool Kids Learn, Inc. & 10 & -0.57 \\
\hline Tennessee & 07 & Education Station & 249 & -0.23 \\
\hline Tennessee & 07 & Innovative Ideas & 124 & 0.09 \\
\hline Tennessee & 07 & Kastle Instruction & 77 & -0.22 \\
\hline Tennessee & 07 & Learning Zone & 13 & -0.02 \\
\hline
\end{tabular}




\begin{tabular}{|c|c|c|c|c|}
\hline Tennessee & 07 & Memphis City Schools' Project Achieve & 80 & -0.13 \\
\hline Tennessee & 07 & Success Educational Services & 35 & 0.19 \\
\hline Tennessee & 07 & The Street Academy/Urban League & 69 & -0.22 \\
\hline Tennessee & 08 & A to $\mathrm{Z}$ In-Home Tutoring & 33 & 0.07 \\
\hline Tennessee & 08 & AlphaBest & 24 & 0.1 \\
\hline Tennessee & 08 & Bright Sky Learning & 53 & -0.28 \\
\hline Tennessee & 08 & Cool Kids Learn, Inc. & 20 & 0.06 \\
\hline Tennessee & 08 & Education Station & 14 & -0.23 \\
\hline Tennessee & 08 & Kastle Instruction & 23 & 0.08 \\
\hline \multirow[t]{2}{*}{ Tennessee } & 08 & Knowledge Points of Middle TN & 92 & 0.22 \\
\hline & & $\begin{array}{l}\text { Project Achieve - Intervention } \\
\text { Assistance for Students (previously }\end{array}$ & & \\
\hline Tennessee & 08 & Memphis City Schools' Project Achieve) & 12 & -0.03 \\
\hline Tennessee & 08 & Success Educational Services & 22 & -0.62 \\
\hline Tennessee & 08 & The Street Academy/Urban League & 42 & -0.24 \\
\hline Virginia & 04 & Achieve Success/University Instructors & 163 & -0.27 \\
\hline Virginia & 04 & Destiny Achievers & 7 & -0.16 \\
\hline Virginia & 04 & EdSolutions & 22 & -0.59 \\
\hline Virginia & 04 & Failure Free Reading & 16 & -0.61 \\
\hline Virginia & 04 & Lightspan/Plato & 36 & 0.31 \\
\hline Virginia & 07 & Achieve Success/University Instructors & 45 & 0.32 \\
\hline Virginia & 07 & Bright Futures Learning Center & 58 & 0.25 \\
\hline Virginia & 07 & Club Z! In-Home Tutoring & 47 & 0.04 \\
\hline Virginia & 07 & Huntington Learning & 30 & 0.04 \\
\hline Virginia & 07 & NonPublic Educational Services Inc & 15 & 0.14 \\
\hline Virginia & 07 & $\begin{array}{l}\text { Porter Education and Communications, } \\
\text { Inc }\end{array}$ & 22 & 0.24 \\
\hline Virginia & 08 & A+ Markem & 28 & -0.19 \\
\hline Virginia & 08 & Academics Plus & 11 & 0.2 \\
\hline Virginia & 08 & Achieve Success/University Instructors & 43 & -0.05 \\
\hline & & Aligned Intervention Educational & & \\
\hline Virginia & 08 & Services & 16 & -0.46 \\
\hline Virginia & 08 & Bright Futures Learning Center & 35 & -0.13 \\
\hline Virginia & 08 & Club Z! In-Home Tutoring & 26 & -0.15 \\
\hline Virginia & 08 & Extended Learning Opportunities & 16 & 0.2 \\
\hline
\end{tabular}


Virginia

Virginia

Virginia

Virginia
08

08

08

08
Huntington Learning

NonPublic Educational Services, Inc

Porter Education and Communications,

Inc

TutorFind
80

0.07

17

0.12

18

$-0.43$

13

$-0.23$ 


\author{
APPENDIX F \\ Curriculum Vita \\ Shanan L. Chappell \\ Old Dominion University $\cdot$ Darden College of Education \\ 145 Education Bldg. $•$ Norfolk, Virginia 23529 \\ schappel@odu.edu
}

EDUCATION

OLD DOMINION UNIVERSITY

Norfolk, VA

Ph.D. candidate

Education Curriculum and Instruction

REGENT UNIVERSITY

Master of Education Degree, December 2002

Virginia Beach, VA

VIRGINIA WESLEYAN COLLEGE

Bachelor of Arts Degree in Communications, May 1991

Norfolk, VA

\title{
EXPERIENCE
}

OLD DOMINION UNIVERSITY RESEARCH FOUNDATION, 2008 Norfolk, VA

Research Assistant

- Research assistant, grant for the Center for Research in Educational Policy (CREP)

- Research assistant, grant for the U.S. Department of Defense's Troops to Teachers program

- Evaluation of providers of Supplemental Education Services (SES) for public schools

- Writing, manuscripts and technical reports

COLLEGE OF THE ALBEMARLE, 2008

Elizabeth City, NC

Adjunct Professor

- Instructor, Basic PC Literacy Skills course

- Instructor, Introductory \& Advanced Spreadsheets courses

- Teach face-to-face and distance courses

OLD DOMINION UNIVERSITY, 2006-2008

Norfolk, VA

Graduate/Research Assistant, Education Curriculum and Instruction

- Instructor, master's level education research and assessment course

- Instructional support, undergraduate methods courses (math, science, social studies)

- Teaching assistant, undergraduate educational foundations courses

- Research, literature and grants

- Writing, grants and manuscripts 
CORNERSTONE CHRISTIAN SCHOOL, 2006-2007

Chesapeake, VA

Technology Specialist and Computer Resource Instructor

- Maintained hardware and software support for all school systems

- Taught weekly computer class for grades 1 through 7

CORNERSTONE CHRISTIAN SCHOOL, 2002-2006

Chesapeake, VA

Teacher

- Taught $4^{\text {th }}$ grade in a self-contained classroom

- Taught weekly computer class for grades 1 through 6

\section{PRESENTATIONS}

Chappell, S., Nunnery, J., Pribesh, S., \& Hager, J. (2009). Supplemental Educational Services (SES) provider effects on student achievement: A meta-analysis. Paper to be presented at the American Educational Research Association's (AERA) annual conference, Denver, CO, April, 2010.

Chappell, S. \& Pribesh, S. (2009). Evaluation of the Integrating Technology for Inquiry (NTeQ) model. Poster to be presented at the American Educational Research Association's (AERA) annual conference, Denver, CO, April, 2010.

Nunnery, J., Pribesh, S., \& Chappell, S. Issues in estimating Supplemental Educational Services provider effects: A review of state evaluations. Paper presented at the American Educational Research Association's (AERA) annual conference, San Diego, CA, April, 2009.

Stonier, F., Chappell, S., \& McKinney, S. Incorporating best practices in mathematics methods courses: A comparison of teletechnet and traditional classrooms. Paper presented at the Association for the Advancement of Computing in Education's (AACE) E-Learn 2008 annual conference, Las Vegas, NV, November 2008.

Chappell, S. "Integrating technology for inquiry" training, Professional Development Workshop Creator, Presenter, and Instructor, Currituck County School System, July, 2008.

Chappell, S. Successful use of the Hands-on Equation model for teaching algebra at the elementary level. Guest lecturer, Old Dominion University, August 2008.

Chappell, S. Using the Van Hiele model for teaching geometry at the elementary level. Guest lecturer, Old Dominion University, August 2008.

Chappell, S. Incorporating technology into an elementary social studies classroom. Guest lecturer, Old Dominion University, September 2007. 
Chappell, S., DePew, K., \& Allen, D. Evaluation of the Wikitext Instructional Process at Old Dominion University. Presented at the International Society of Technology in Education's (ISTE) annual National Educational Computing Conference (NECC), Atlanta, GA, June 2007.

Pribesh, S. \& Chappell, S. Young Audiences of Virginia, Inc. Program Evaluation. Poster Presented at the 2007 Research Expo, Old Dominion University, Norfolk, VA, April 2007.

O'Shea, P. \& Chappell, S. Issues confronted while designing a student-developed online textbook. Presented at the Society for Technology and Teacher Education (SITE) annual conference, San Antonio, TX, March 2007.

Allen, D., Baker, P., Chappell, S., Konstantopoulou, D., Xiao, Y. Darden Research Brown-bag Presentation Series: A student written wiki-text for a foundations in education course. Presented at Old Dominion University's Darden College of Education, Norfolk, VA, January 2007.

Dickerson, D., Overbaugh, R., Warham, E., Horne, P., Hotchkiss, R., \& Chappell, S. The tablet computer and science methods courses: Explorations and possibilities. Paper presented at the Association for Science Teacher Education conference, Clearwater Beach, FL, January 2007.

\section{PUBLICATIONS}

Nunnery, J., Chappell, S., \& Ross, S. (2009). It's Time to Take a Hard Look at Supplemental Educational Services-A Sneak Peek at a Comprehensive Metaanalysis. (under review)

McKinney, S., Chappell, S., Berry, R., \& Hickman, B. (2009). An examination of the instructional practices of mathematics teachers in urban schools. Preventing School Failure, 53(4), 278-284.

Pribesh, S., Chappell, S., \& Nunnery, J. (2009). Little Rock School District preschool evaluation. Memphis, TN: University of Memphis.

\section{FELLOWSHIPS \& AWARDS}

- University Fellowship, Old Dominion University, December 2006 - tuition \& stipend for spring 2007

- Young Artists of Virginia, Inc., Norfolk, Virginia, October 2006 - Program Evaluation Fellowship.

\section{MEMBERSHIPS \& ORGANIZATIONS}

- Member - Association for the Advancement of Computers in Education (AACE)

- Member - American Educational Research Association (AERA) 